\title{
EXPERIMENTAL ELECTRON DENSITY DETERMINATION OF UNCONVENTIONALLY BONDED BORON
}

\author{
Dissertation zur Erlangung des \\ mathematisch-naturwissenschaftlichen Doktorgrades \\ der Georg-August-Universität Göttingen
}

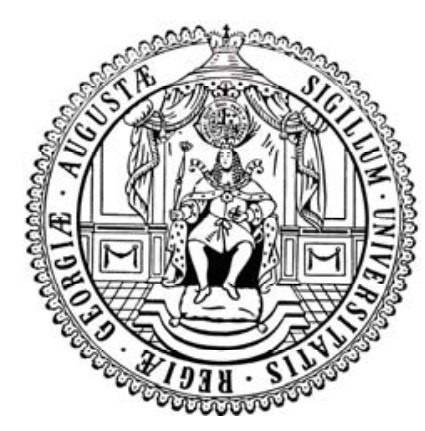

vorgelegt von

Ulrike Flierler aus Eichstätt

Göttingen 2009 

D7

Referent:

Korreferent:

Datum der mündlichen Prüfung:

Prüfer Anorganische Chemie:

Prüfer Analytische Chemie:

Prüfer Kristallographie:

Erweiterte Prüfungskommission:
Prof. Dr. D. Stalke

Prof. Dr. G. Eckold
Prof. Dr. D. Stalke

Prof. Dr. U. Klingebiel

Prof. Dr. H. Sowa
Prof. Dr. Dr. h.c. L. F. Tietze

Prof. Dr. Dr. h.c. mult. H. W. Roesky 

"Die Naturwissenschaft unterscheidet sich von anderen Formen der Dichtung durch ihre Wahrheitsanmabung." 



\section{DANKSAGUNG}

Die vorliegende Arbeit wurde in der Zeit von April 2006 bis März 2009 im Arbeitskreis von Herrn Prof. Dr. Dietmar Stalke am Institut für Anorganische Chemie der Universität Göttingen angefertigt. An dieser Stelle soll all jenen Dank ausgesprochen werden, die zum Gelingen dieser Arbeit beigetragen haben.

Als erstes möchte ich Herrn Prof. Dr. Dietmar Stalke, der mir als „Nur-“ Lehrämtlerin die Möglichkeit (und vor allem ein interessantes Thema) zur Promotion gab, für das in mich gesetzte Vertrauen danken. Sowohl die mir gewährten wissenschaftlichen Freiheiten, als auch die stete Diskussionsbereitschaft und das angenehme Arbeitsklima habe ich sehr geschätzt.

Allen ehemaligen und aktuellen Mitgliedern des Arbeitskreises danke ich für das gute Team-Work, die stete Hilfs- und Diskussionsbereitschaft und vor allem für die gute Stimmung. Dass wir jetzt so viele geworden sind, hat auch den bestechenden Vorteil, dass sich immer jemand zum Kaffee-Trinken, Pizza-Bestellen, Kochen, Kuchenbacken oder für ein Feierabendbier findet.

Ein ganz spezieller Dank gebührt außerdem...

... Herrn Dr. Dirk Leusser, meinem Meister, für die Einweisung sowohl in die Elektronendichtestudien als auch in alles andere was es über das Leben an sich, die Politik und vor allem Südamerika zu wissen gibt.

... Herrn Dipl.-Chem. Holger Ott, meinem Leidensgenossen auf dem Gebiet der experimentellen Dichte und während der gemeinsamen Aufschreibezeit für seine Freundschaft und dafür, dass wir uns immer über alles Chemische und vor allem über alles Nicht-Chemische unterhalten konnten.

... Frau Dipl.-Chem. Ina Objartel für ihr immer offenes Ohr und ihre aufmunternden Worte sowie die guten - nein, perfekten-Frauenabende mit Sekt und/oder Frauenfilmen. Ohne ihre Hilfe bei der Seminar- und Klausurbetreuung wäre ich wohl am Ende nie zum Zusammenschreiben gekommen.

... Herrn Dr. Stephan Deuerlein für seine Anwerbung in den AK und seine Hilfe bei... eigentlich allem, wo man Hilfe gebrauchen konnte.

... meinen geduldigen Korrektoren Ina, Stephan, Dirk und Egon, die mich vor so mancher Blamage bewahrt haben (oder hat schon mal jemand etwas von donnernden Wechselwirkungen gehört?!).

... Frau Heike Tappe, der Mama des Arbeitskreises, für das mir gewährte Asyl während der Zeit des Zusammenschreibens, die vielfältigen Hilfestellungen („Ich mach das mal schnell...") und die aufmunternden Worte, dann, wenn ich sie am nötigsten hatte. 
... den Würzburger Veteranen, allen voran Herrn Dr. Stephan Deuerlein, Herrn Dipl.Chem Holger Ott, Herrn Dipl.-Chem. Thomas Schulz und Herrn Dr. Gerald Schwab für die grandiose Zeit in Würzburg und die nicht ganz so schlechte Zeit im außerbayerischen Exil (Psst... so übel wars doch eigentlich gar nicht, aber das schriftlich zugeben...?!).

... unseren Computeradmins Herrn Dr. Stephan Deuerlein, Herrn Dipl.-Chem. Daniel Kratzert und Herrn Felix Engelhard für die Sicherstellung der Funktionsfähigkeit meines wichtigsten Arbeitsgerätes und die Bereitschaft, meine Fragen („Wie ging das noch mal mit dem Screen?“) immer und immer wieder zu beantworten.

... Herrn Dipl.-Chem. Christian Kling für die professionellen „Werbefotos" des Montiertisches sowie zahlreiche Tipps und Hilfestellungen bei der Bildbearbeitung.

... Herrn Dr. Michael Burzler, ebenso wie Herrn Prof. Dr. Holger Braunschweig und Herrn Prof. Dr. Gerhard Erker für die Bereitstellung der Kristalle und Herrn Dr. Julian Henn und Herrn Prof. Dr. Stefan Grimme für die Durchführung der quantenchemischen Rechnungen.

... allen Mitarbeitern der Werkstätten, besonders Herrn Hans-Joachim Heymel und Herrn Bernd Wichmann, die meine wirren Pläne für den Montiertisch professionell in die Tat umgesetzt haben.

... Herrn Dipl.-Chem. Markus Granitzka für seinen Musikgeschmack und dafür, dass Pöbeln mit inm am meisten Spass macht, dicht gefolgt von Herrn Dipl.-Chem. Daniel Stern, dessen unerschöpfliches Repertoire an dummen Sprüchen vor 10 Uhr kaum zu ertragen wäre, würde man nicht schon immer sehnsüchtig darauf warten.

... Herrn Dr. Gerald Schwab für die Grundsteinlegung zur musikalischen Untermalung unserer AK-Feiern ebenso wie Herrn Dipl.-Chem. Nils Finkelmeier, Herrn Jakob Hey und Herrn Dipl.-Chem. Conny „Dachs“ Weichbrodt für würdige Fortsetzung dieser Tradition. Jetzt müsst ihr nur noch das Lebkuchen-Lied lernen!

... Herrn Dipl.-Inf. (FH) Egon Fernolend für so manch kleines Tool und die Hilfe bei der Erstellung meiner eigenen Progrämmchen, die mir viel unnütze und langweilige Kopiererei und Sucherei erspart haben. Viel wichtiger aber waren sein Zuspruch und sein Vertrauen in mich, nicht nur während der Zeit des Zusammenschreibens.

... allen, denen ebenfalls ein Wort des Dankes gebührt und die ich ich hier lediglich vergessen habe.

Nicht zuletzt möchte ich meiner Familie für ihren immerwährenden Rückhalt danken. Da ich so etwas immer schwer in Worte fassen kann, klaue ich einfach bei jemandem, der's kann:

„Zwei Dinge sollen Kinder von ihren Eltern bekommen: Wurzeln und Flügel.“

(GOETHE)

Danke dafür! 


\section{CONTENTS}

1 FROM X-RAY DIFFRACTION EXPERIMENTS TO EXPERIMENTAL ELECTRON DENSITY STUDIES

2 EXPERIMENTAL ELECTRON DENSITY STUDIES - THE BASICS ..............................13

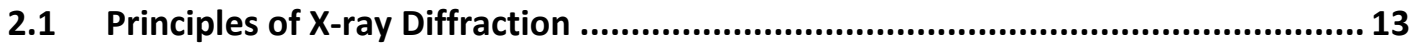

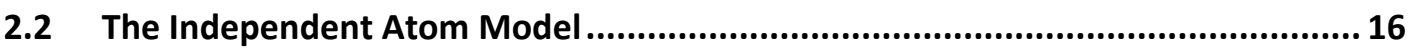

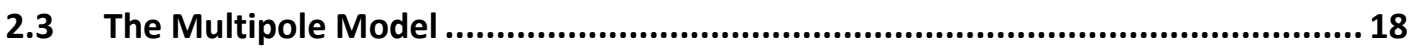

2.4 Quality Criteria of the Refinements.................................................................... 20

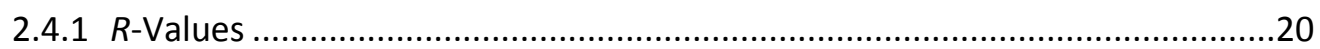

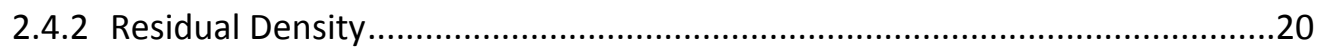

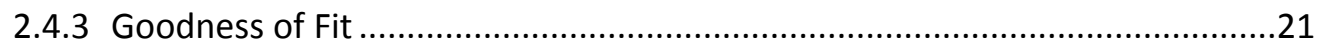

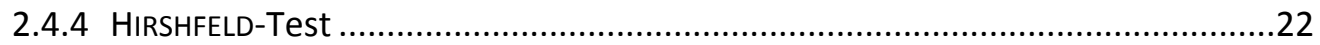

2.5 Functions and Moments Derived from Electron Density Distributions................. 23

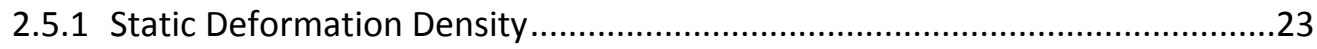

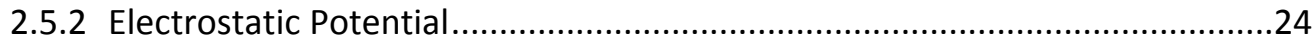

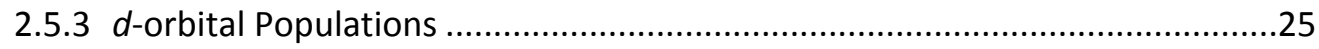

2.6 The Quantum Theory of Atoms in Molecules .................................................... 26

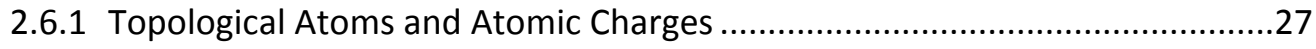

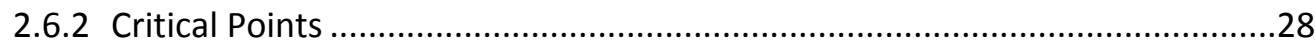

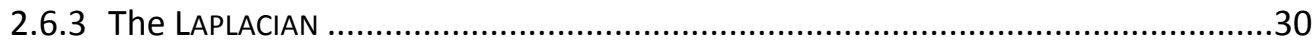

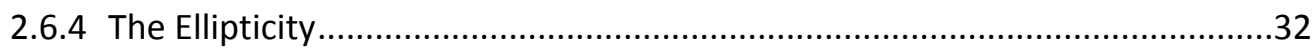

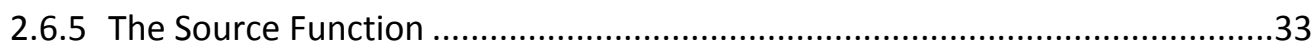

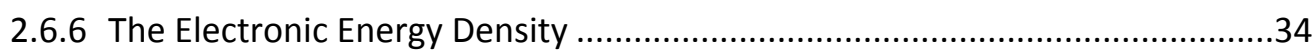


3.1 Crystal Application, Data Collection and Data Reduction .................................. 35

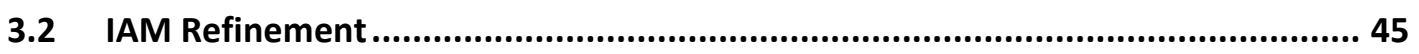

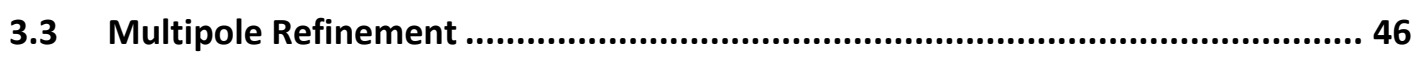

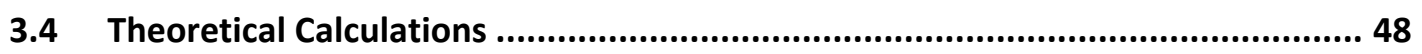

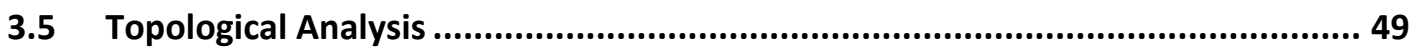

4 ELECTRON DENSITY STUDIES ON LEWIS ACIDIC ORGANOBORON COMPLEXES ...51

4.1 Chemistry and Applications of LEWIS Acidic Organoboron Complexes................ 51

4.2 Comparative Electron Density Study on $\left[\left(\mathrm{C}_{6} \mathrm{~F}_{5}\right)_{2} \mathrm{~B}\left(\mathrm{NC}_{4} \mathrm{H}_{4}\right)\right](1)$ and

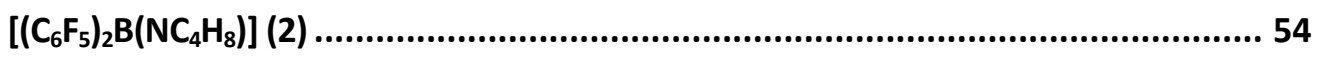

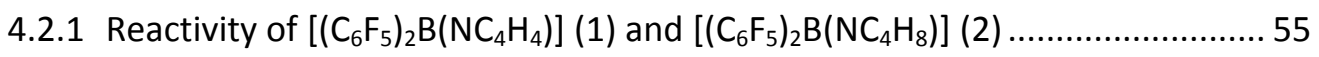

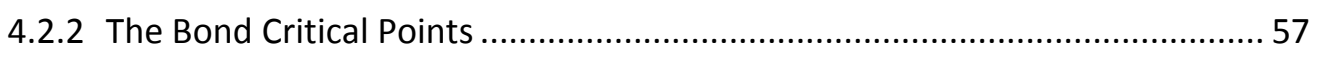

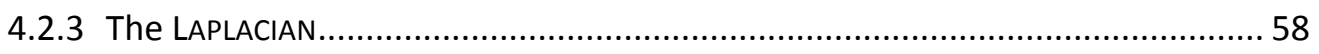

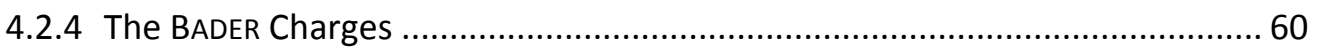

4.2.5 The $3 d$-distribution of the LAPLACIAN ................................................. 62

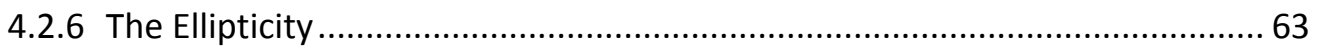

4.2.7 The Static Deformation Density ...................................................... 66

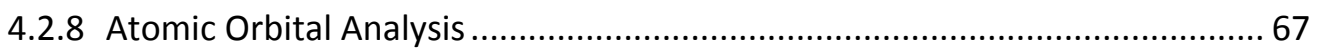

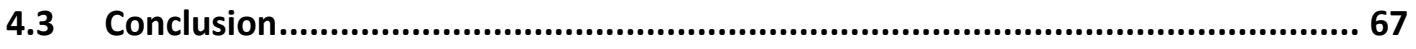

5 ELECTRON DENSITY STUDIES ON TRANSITION METAL COMPOUNDS OF BORON 69

5.1 Transition Metal Compounds of Boron - Classification and Chemistry.............. 69

5.2 Bonding in Transition Metal Borylene Complexes............................................ 72 


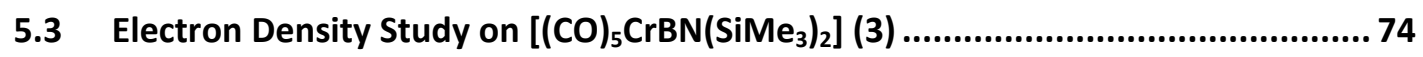

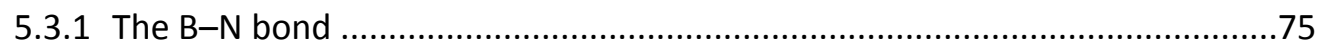

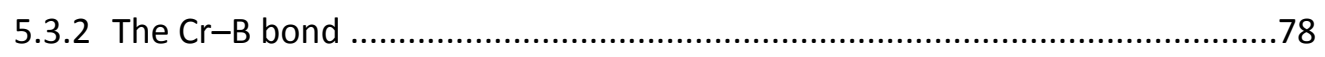

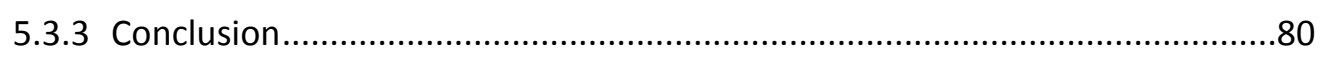

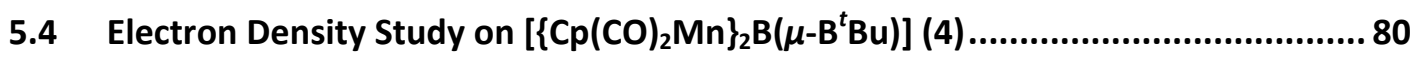

5.4.1 Coordination of the Bridging Borylene Ligand.............................................81

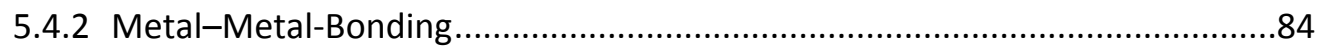

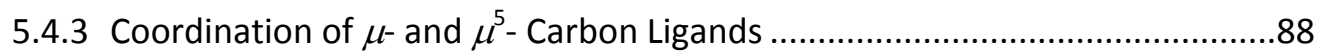

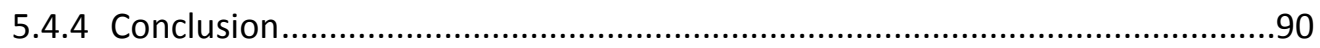

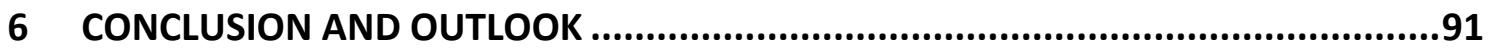

6.1 Experimental Electron Density Studies on LEWIS Acidic Organoboron Complexes 91

6.2 Experimental Electron Density Studies on Transition Metal-Boron Complexes ... 93

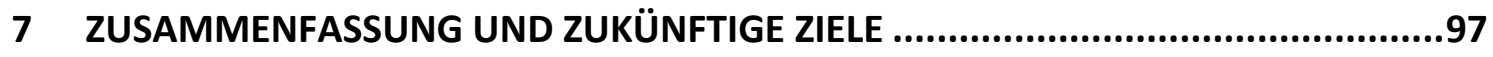

7.1 Experimentelle Elektronendichteuntersuchungen von LEWIS-sauren

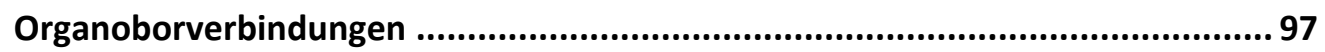

7.2 Experimentelle Elektronendichteuntersuchungen von Übergangsmetall-Bor-

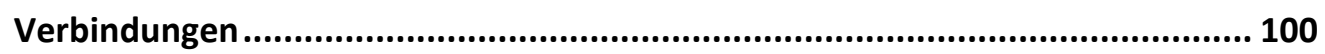

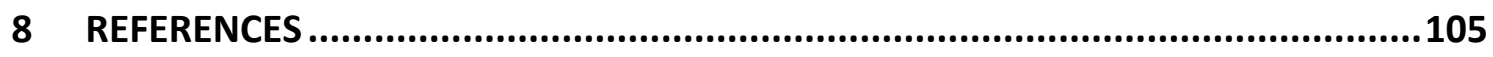





\section{Abbreviations}

\begin{tabular}{|c|c|}
\hline$\AA$ & ÅNGSTROM \\
\hline ADP & anisotropic displacement parameters \\
\hline AP & atom position \\
\hline AO & atomic orbital \\
\hline $\mathrm{BCP}$ & bond critical point \\
\hline $\mathrm{BP}$ & bond path \\
\hline $\mathrm{Bu}$ & butyl \\
\hline $\mathrm{CC}$ & charge concentration \\
\hline $\mathrm{CCP}$ & cage critical point \\
\hline$c f$. & confer; see \\
\hline $\mathrm{CP}$ & critical point \\
\hline $\mathrm{Cp}$ & cyclopentadienyl \\
\hline CSD & Cambridge Structural Database \\
\hline DFG & Deutsche Forschungsgemeinschaft (German research association) \\
\hline DFT & density functional theory \\
\hline DMSDA & difference of mean square displacement amplitudes \\
\hline $\mathrm{e}$ & electron \\
\hline e.g. & exempli gratia; for example \\
\hline ED & electron density \\
\hline EDD & electron density distribution \\
\hline Eq. & equation \\
\hline ESP & electrostatic potential \\
\hline et al. & et alii; and others \\
\hline GoF & goodness of fit \\
\hline $\mathrm{HF}$ & HARTREE-FOCK \\
\hline i.e. & id est; that is \\
\hline IAM & independent atom model \\
\hline IUCR & International Union of Crystallography \\
\hline MEM & maximum entropy method \\
\hline MM & multipole model \\
\hline MO & molecular orbital \\
\hline QTAIM & quantum theory of atoms in molecules \\
\hline $\mathrm{R}$ & hydrogen atom or alkyl or aryl group \\
\hline $\mathrm{RCP}$ & ring critical point \\
\hline SPP & Schwerpunktprogramm (priority program) \\
\hline${ }^{t}$, tert. & tertiary \\
\hline VSCC & valence shell charge concentration \\
\hline VSEPR & valence shell electron pair repulsion \\
\hline
\end{tabular}





\section{LIST OF COMPOUNDS}

\begin{tabular}{|c|c|}
\hline (1) $\left[\left(\mathrm{C}_{6} \mathrm{~F}_{5}\right)_{2} \mathrm{~B}\left(\mathrm{NC}_{4} \mathrm{H}_{4}\right)\right]$ & (2) $\left[\left(\mathrm{C}_{6} \mathrm{~F}_{5}\right)_{2} \mathrm{~B}\left(\mathrm{NC}_{4} \mathrm{H}_{8}\right)\right]$ \\
\hline$\left(\mathrm{C}_{6} \mathrm{~F}_{5}\right)_{2} \mathrm{~B}-\mathrm{N}$ & $\left(\mathrm{C}_{6} \mathrm{~F}_{5}\right)_{2}$ \\
\hline (3) $\left[(\mathrm{CO})_{5} \mathrm{CrBN}\left(\mathrm{SiMe}_{3}\right)_{2}\right]$ & (4) $\left[\left\{\mathrm{Cp}(\mathrm{CO})_{2} \mathrm{Mn}\right\}_{2} \mathrm{~B}\left(\mu-\mathrm{B}^{t} \mathrm{Bu}\right)\right]$ \\
\hline $\begin{array}{c}\mathrm{OC} \\
\mathrm{OC}-\mathrm{CO}=\mathrm{CO}=\mathrm{C}=\mathrm{SiMe}_{3} \\
\mathrm{OC}=\mathrm{CO}=\mathrm{SiMe}_{3}\end{array}$ & 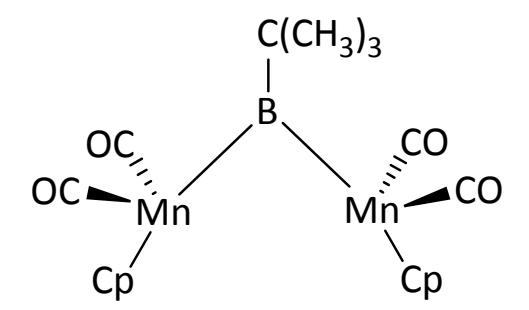 \\
\hline
\end{tabular}





\section{From X-RAY DIFFRACTION EXPERIMENTS TO EXPERIMENTAL ELECTRON DENSITY STUDIES}

Synthetic chemists - no matter if working in the field of organic or inorganic chemistry - are always searching for new, improved compounds. The design of tailormade reagents, precisely adapted to specific applications, is one of the principal aims in chemistry. While the exact synthetic target might differ, the overarching issue is the same: selective replacement of individual atoms or whole groups within a molecule to fine-tune its properties and by these means its reactivity. However, it is still not always predictable, which alterations cause the desired effects. The design of new target molecules is often based on a long process of trial and error. Therefore, a proper understanding of the relation between structure and chemical or physical properties of a compound is vital for the shortening of this development process. Already in 1932, PAULING (Figure 1-1) proposed an interrelation between the structure of a

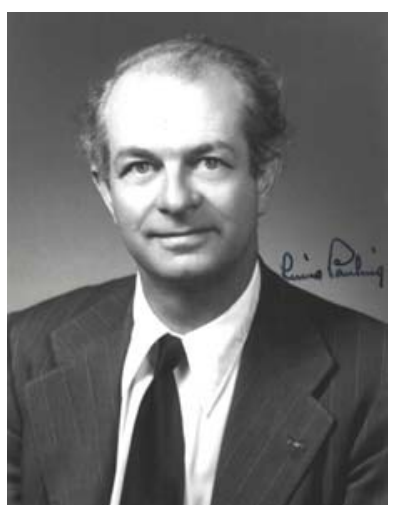

Figure 1-1: LINUS C. PAULING (1901-1994). compound and its properties: ${ }^{[1]}$

"The properties of a compound depend on two main factors, the nature of the bonds between the atoms, and the nature of the atomic arrangement. [...] The satisfactory description of the atomic arrangement in a crystal or molecule necessitates the complete determination of the position of the atoms relative to one another."

The claimed determination of the atom positions was already feasible at that time. In 1912, LAUE et al. had proven the electromagnetic nature of X-rays as well as the lattice structure of crystals by the diffraction experiments they performed. ${ }^{[2,3]}$ With the knowledge of the interrelations between them, first simple structure determinations were within reach. Only one year later, in 1913, BRAGGS' findings ${ }^{[4]}$ made an absolute determination of the lattice constants possible.

The first crystal structure, solved in 1914, was that of sodium chloride ${ }^{[5-7]}$ and led to first conclusions of the bonding situation in this compound. ${ }^{[8]}$ In the same year, the structure of diamond was reported. ${ }^{[9,10]}$ The structures of various other minerals were 
solved in the following years, among them, for example, graphite, which was determined by two groups independently in $1924 .{ }^{[11,12]}$ The first structure of an organic compound, hexamethylenetetramine, was solved in $1923 .{ }^{[13]}$ Additionally, in the 1920s, a multiplicity of studies has been performed on long-chain fatty acids, which are the basic modules of biological membranes. ${ }^{[14-22]}$

Since these first studies, $\mathrm{X}$-ray structure determination has become one of the most important analytical tools in chemistry. At the end of 2008, 469611 structures have been deposited with the Cambridge Structural Database (CSD), which contains more than $66 \%$ of all structures published. ${ }^{[23,24]}$ Interestingly, for years, the annual number of new structures reported has increased along with the total number of crystal structures and is only now stagnant on a high level (Figure 1-2).

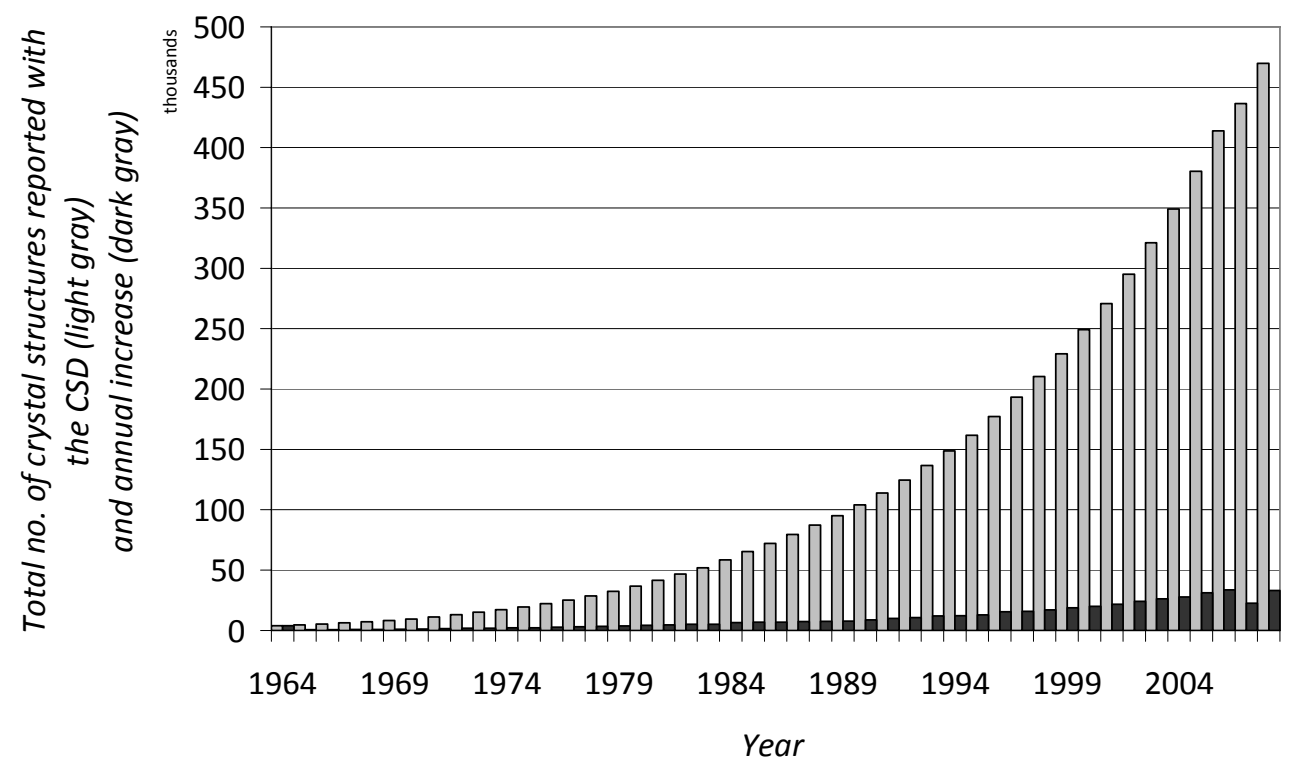

Figure 1-2: CSD growth statistics.

The popularity of this analytical method can be assigned to its unique informative value - no other method provides a complete $3 d$-representation of the molecule - and its ever-growing success is due to the constant progress in data measurement and processing. The availability of area detectors helped saving measuring time and the increasing efficiency of computer hardware saved time, processing the data. Furthermore, the invention of low-temperature devices for crystal application as well as for data collection ${ }^{[25-28]}$ made the method applicable even for very sensitive samples, like e.g. $n$-butyl lithium. ${ }^{[29]}$ 
The result of all these improvements was a fast growing number of small-molecule crystal structures. At the same time, an increase of the complexity of the structures could be observed, as the average number of atoms per structure rose from 27 in 1970 to a current average of $76 .{ }^{[30]}$ But not only the number of atoms per molecule changed, the types of compounds being characterized by crystallographic methods underwent a transformation as well. Thus, the percentage of organic compounds studied has fallen from $55.4 \%$ to $44.6 \%$ of the CSD in 2001, with a corresponding increase in the proportion of organometallic and metal complexes. ${ }^{[30]}$

Another result of all these improvements is an overall increase in data quality, best reflected by the $R$-factor statistics (for a definition of the $R$-factor, see Chapter 2.4.1) over time, which show increasing percentages of structures having $R<0.075$ (from $57 \%$ to $84 \%$ ) and $R<0.050$ (from $30 \%$ to $53 \%$ ) when moving from 1983 to 2008 (Figure 1-3). ${ }^{[24,30]}$

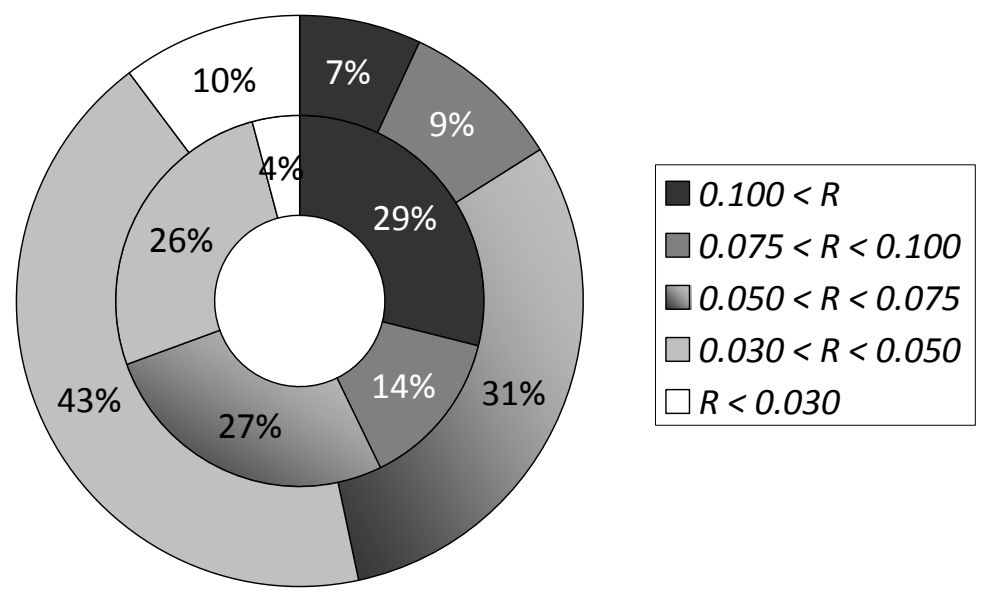

Figure 1-3: $R$-factor distribution in 1983 (inner circle) and in 2008 (outer circle).

A spherical atom approximation is used for almost all X-ray structure determinations. ${ }^{[31,32]}$ Within this approach, maxima in the electron density distribution (EDD) are assumed to be the positions of spherical atoms between which no direct interaction has been taken into account for the calculation of the atomic scattering factors (independent atom model IAM; $c f$. Chapter 2.2). The distances between those spherical atoms - the bond lengths - and the bond angles are utilized to derive information on the type of interactions between them. However, the conclusions drawn can also be misleading, suggesting a bonding that does not hold on a closer inspection. ${ }^{[33,34]}$ 


\section{Already PAULING warned, that ${ }^{[1]}$}

"... There is, of course, a close relation between atomic arrangement and bond type. But [...] it is by no means always possible to deduce the bond type from a knowledge of the atomic arrangement."

However, the theoretical background for a direct examination of the bonding was known as early as X-ray diffraction itself. As X-rays are scattered much stronger by the electrons than by the nuclei of an atom, the result obtained from a diffraction experiment is basically the electron density distribution in a molecule. Especially for light atoms, DeBYE proposed already in 1915, that "it should be possible to determine the arrangement of the electrons in the atoms." ${ }^{[35]}$ Nevertheless, the information contained, was experimentally not accessible for almost half a century. On the one hand, this can be imputed to the inaccuracy of the data and on the other hand to the great success of the spherical independent atom model. As the electron density distribution of an atom is distorted because of its interactions with other atoms, information on these interactions can only be obtained, if the aspherical density is described. At the beginning of the 1960s, DAWSON, ${ }^{[36]}$ STEWART, ${ }^{[37-40]}$ and HIRSHFELD ${ }^{[11,42]}$ started discussing the application of aspherical atoms to describe the bonding contributions. But only the atom-centered finite multipole expansion (multipole model, MM) by HANSEN and COPPENS $^{[43]}$ leveraged the aspherical description of the density. This model was implemented in several refinement programs for the automated use in structure refinement procedures. ${ }^{[44-47]}$ As the multipole model has been applied for all structure refinements in this thesis, more details on the formalism will be given in Chapter 2.3.

Extensive tests have been performed to ensure the general reliability of the results from a multipole refinement based on high-resolution data. The oxalic acid project of the International Union of Crystallography (IUCR) is only one example. ${ }^{[48]}$ Special care was also taken to guarantee the suitability of data from area detectors by PINKERTON et al. ${ }^{[49]}$ as well as by LECOMTE and HoWARD. ${ }^{[50]}$ Currently, the applicability of new X-ray sources, for example the INCOATEC molybdenum and the INCOATEC silver microfocus source, is tested in our group. Due to the highly focused beam, it could be proven for standard structure determinations, that small crystals - exactly fitting the size of the beam - can be measured with the same data quality compared to a standard sealed tube but in a shorter time. ${ }^{[51]}$ If the accuracy of the data measured turns out to fit 
charge density standards, this will open the way to an even broader variety of compounds, those that can not be grown in a sufficient size for experiments with standard equipment.

Additionally, the development of the multipole model and its applications are still not at its end. Several data bases have been established in which the multipole populations of atoms are stored. ${ }^{[52-55]}$ The difference between those data bases lies in the origin of their information. The invariom data base, for example, is a collection of $a b$ initio derived, transferable non-spherical atoms. ${ }^{[53,55]}$ After a routine structure refinement and the corresponding knowledge of $x, y, z$ and the anisotropic displacement parameters of a structure, these invarioms can be imposed on the atom and lead to an aspherical description of the electron density. In other approaches, experimentally derived multipole populations are exploited. ${ }^{[52,54]}$ That way, aspherical densities of molecules, e.g. protein molecules, can be modeled, that would otherwise not be accessible. Efforts to perform charge density studies without high-resolution data using the invariom approach worked well for light atoms but proved to be not successful if heavier atoms were present in the molecule. ${ }^{[56]}$

Additional methods for the description of aspherical electron density are available nowadays. The maximum entropy method (MEM) can be utilized as an alternative to the multipole refinement in order to determine the accurate electron density distribution in a molecule. ${ }^{[57-60]}$ In this approach, the density is calculated on a threedimensional grid with the observed structure factors serving as a constraint in the maximization of the entropy.

As different as these approaches may be, in the end, they offer a common advantage: an accurate model that is not only able to describe the spherical atom density but aspherical density contributions as well. Since these aspherical density contributions stem mainly from bonding effects on the atoms, the modeled density will contain information about the interactions between the atoms.

The possibilities to extract this information from the modeled density have increased to the same degree as the number of approaches to model the density. In the beginning of electron density studies, the examination of the static deformation densities was the main basis of bonding type evaluation. ${ }^{[61-65]}$ Their results provided the first confirmation, that bonding features were indeed accessible by accurate X-ray 
methods. However, it has been shown, that the static deformation density cannot serve as the only mean of analysis, ${ }^{[66]}$ as the result obtained is biased by the modeldependence of the promolecule describing the spherical ED. ${ }^{[67,68]}$ Nevertheless, together with the physical properties directly available from the electron density, the dipole moment and the electrostatic potential, this method already provided very interesting insights into the bonding situations of molecules such as dispiro$[2,2,2,2]$ deca-4,9 diene, in which the conjugation of cyclopropane rings with neighboring double bonds was investigated. ${ }^{[69,70]}$

However, the real breakthrough could only be achieved because of the advent of the topological analysis according to BADER's quantum theory of atoms in molecules (QTAIM). ${ }^{[71]}$ The assumption that all demanded information is inherent in the electron density, lead to the approach to closer examine the observable density itself. However, the distinct density concentrations at the nuclei cache the interesting - albeit very small - features in the bonding regions. A mathematical answer was found for this problem: Small features within a function can be enhanced, if the derivatives are taken and inspected (Figure 1-4). As a consequence, it became more and more common to examine the first- and second-order derivative of the EDD topologically to obtain information on the bonding features within a molecule. Properties of the ED at certain defined points (called the critical points, CPs) within this density distribution can serve as measures for the character of bonds while concurrently a physically meaningful separation of the molecule into its atoms allows the determination of atomic charges. As BADER'S QTAIM is the main basis for all conclusions drawn within this thesis, deeper insight into this theory will be given in Chapter 2.6.
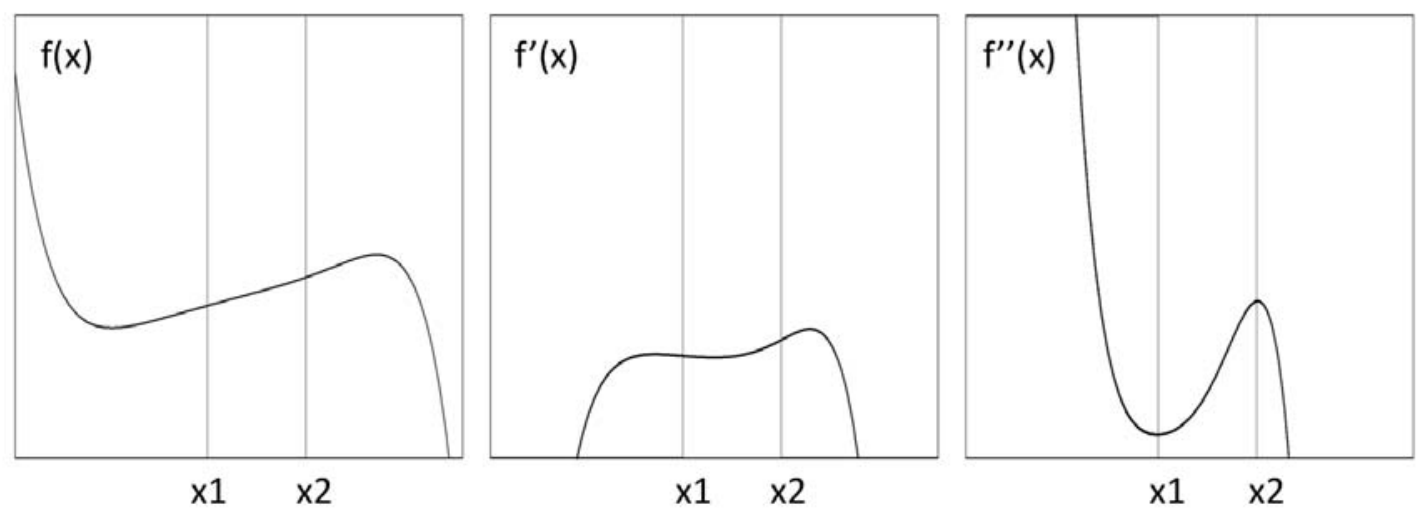

Figure 1-4: Small features within a function can be amplified when inspecting its derivatives. 
Even if the method "QTAIM" has its critics, ${ }^{[72-76]}$ it nevertheless provided a better acceptance of charge density studies. One of the reasons for this development is certainly the nature of the results that can be obtained via this topological analysis. A quantum chemical property, the density, can now be interpreted in classical chemical terms. A classification of bonding in covalent or ionic, in double or single, or in maybe something in-between becomes feasible. Secondly, the QTAIM provides a unique feature, its comparability. As the topological analysis can be performed on theoretically derived densities as well as on experimentally derived ones, the results can straightforwardly be compared. That way, theory and experiment can verify their results, or, respectively falsify them, and in the end offer reliable answers to the questions raised. Together, these features make BADER'S QTAIM the most important tool for the examination of the EDD and the features of bonding that can be derived from it.

Within the framework of BADER'S QTAIM, the link between the characteristics of chemical bonding and the topological properties has been fully achieved for molecules containing light atoms, i.e. those including second period elements. However, the derived correlations cannot be extended straightforwardly to organometallic compounds since bonds to transition metals display a different and much narrower spectrum of topological indices at the CPs. ${ }^{[77]}$ This is due to the different valence electron configuration in transition metals compared to main group elements. Additionally, it has been shown that for very polar bonds an examination of the properties solely at the CPs is not meaningful. ${ }^{[78-82]}$ Therefore new descriptors - though also based on the QTAIM - like e.g. energy densities ${ }^{[83,84]}$ or the source function ${ }^{[85-90]}$ have been introduced. Numerous descriptors are nowadays available for the examination of bonding features. The most important will be described in the Chapters 2.5 and 2.6 of this thesis.

The examination of the ED is currently moving towards "dynamic" aspects, i.e. towards studies of properties that are not solely based on the ground state EDD or on the ground state equilibrium geometry. For example, some first results on excited states have been reported, thanks to the progress in time-resolved crystallography. ${ }^{\text {[91-96] }}$ Much attention is also paid to materials for linear and non-linear optics, trying to derive (hyper)polarizabilities directly from X-ray diffraction. ${ }^{[97]}$ However, the prediction of chemical reactivity from an accurate mapping of the EDD remains the major goal. 
While in the beginning, charge density studies have been relegated to a niche existence, they nowadays attract increasing interest, even in the broad chemical community. ${ }^{[98,99]}$ This has been supported by the establishment of the priority program 1178 "Experimental charge density as the key to understand chemical interactions" of the Deutsche Forschungsgemeinschaft (DFG) in 2005. The network involves more than 25 groups of German universities and research organizations. Within this program, experimental electron density studies are linked to synthetic chemistry, material science, and life science research areas.

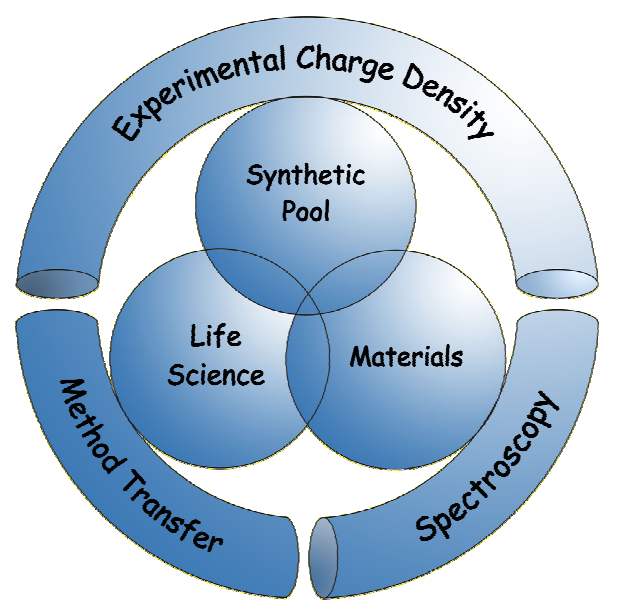

Figure 1-5: Logo of the DFG SPP 1178.

In the recent years, significant progress has been made in each of these fields inside as well as outside the SPP 1178. Among the latest results in the field of life sciences are studies, that advance the understanding of the binding of hormones, namely estrogens, to the human receptors by electron density investigations. ${ }^{[100]}$ In a subsequent study, PINKERTON et al. examined the electronic structure of non-steroidal synthetic estrogens. ${ }^{[101]}$ This knowledge facilitates the estimation of the binding capacities of synthetic estrogens and thus their potential for an application as a drug. Another exemplary study in this field was performed by LUGER et al. on vitamin B12, which is a coenzyme in the human metabolism. ${ }^{[102]}$ Material sciences have, for example, gained information on the bonding in complex carbides ${ }^{[103]}$ as well as in $\alpha$-silicon nitrides ${ }^{[104]}$ via ED studies by SCHERER et al. and YASHIMA et al., respectively. Additionally, the knowledge of the bonding in transition metal complexes has been supplemented by various contributions. In addition to systematic studies on the coordination of the carbonyl ligand to the metal centers, ${ }^{[105]}$ studies on the 
coordination of different carbocyclic rings have been published recently. ${ }^{[06]}$ Additionally, the bonding between transition metal atoms in clusters as well as polynuclear transition metal complexes has been a topic of constant interest. ${ }^{[34,107-110]}$

In our work group, research has been conducted on fundamental questions of chemistry. The concept of hypervalency, for example, was focused by LEUSSER et al. An examination of various compounds containing $\mathrm{S}-\mathrm{N}$ bonds proved the concept to be needless. ${ }^{[33,111,112]}$ This has been verified by the results obtained by DEUERLEIN et al. in his studies on a lithium sulfur ylide. ${ }^{[113,114]}$ In his work, additionally, another bonding situation of constant interest was addressed, that of a formal carbanion to an $\mathrm{Li}_{3}$ triangle, which is a motif well-known throughout lithium organic chemistry (Figure 1-6). ${ }^{[115]}$ Extensive work in this field is and has been done by other members of our work group, as for example by OTT in his PhD thesis. ${ }^{[16]}$

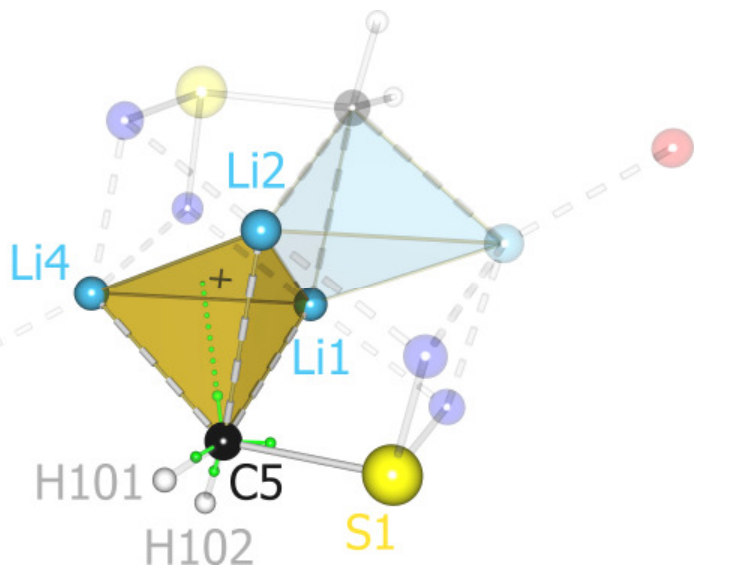

Figure 1-6: Lithium sulfur ylide (reproduced from DEUERLEIN ${ }^{[113]}$ )

The green dots represent valence shell charge concentration (VSCCs). Three of the VSCCs are pointing to the bonding partners ( $\mathrm{H} 101, \mathrm{H} 102$ and $\mathrm{S} 1$ ) while the forth one is directed towards the $\mathrm{Li}_{3}$ triangle.

In contrast, the focus of this thesis is laid on compounds containing boron in different chemical environments. Elemental boron was independently isolated by scientists in two different countries in 1808. The French chemists GAY-LUSSAC and THÉNARD obtained it by a reduction of the oxide with potassium, while Sir DAVY in Great Britain produced it by electrolysis of boric acid. BERZELIUS was the one who suggested the chemical symbol "B" for boron in 1814, as he was the first to recognize its elemental character. DAVy called the new substance "boracium", but the name was later shortened to "boron", presumably because of its appearance in borax and its chemical similarity to carbon (bor(ax + carb)on). Due to the similar-sounding word 
stems, wagging tongues ${ }^{[117]}$ indicated the name "boron" being derived from the word "boring". However, the chemistry of boron proves them wrong.

Boron is the only non-metal in group 13 of the periodic table. As a group 13 element, boron has three valence electrons for bonding. Therefore, compounds with monovalent elements $(\mathrm{E})$ have the formula $\mathrm{BE}_{3}$. These molecules are trigonal-planar and have an $s p^{2}$-hybridized boron atom with a vacant orthogonal $p$-orbital. Thus, in these molecules, boron has only six valence electrons and is therefore electrondeficient or hypovalent with respect to the eight-electron rule. ${ }^{[118]}$

In general, three mechanisms are possible for a saturation of the boron atom's valence shell:

- In boron halides, $\mathrm{BX}_{3}$, the electron deficiency is compensated by the formation of $p_{\pi}-p_{\pi}$ bonds. This type of interaction is assumed for all ligands that have at least one lone pair. This lone pair can donate its electrons into the vacant $p$-orbital of the boron atom. All substituents contribute to this bond formation and therefore, formally, a bond order of $1^{1} / 3$ is observed.

- In cases where the ligand does not have a lone pair, no stabilization of the boron atom is possible via the formation of $p_{\pi}-p_{\pi}$ bonds. This is for example the case with $\mathrm{BH}_{3}$. These molecules form dimers, in which the formation of 3-center 2-electron bonds stabilizes the framework. The hydrogen atom serves as a bridge between two boron atoms and shares its electron with both of them. These kinds of interactions are also known between three boron atoms and lead to the formation of boranes, borates and boranates.

- Instead of an intramolecular saturation as described above, the completion of the valence shell of the boron atom can also be achieved by the addition of a donor molecule which has a lone pair. The boron atom is then rehybridized to $s p^{3}$ and forms a bond with the donor. In this case the $\mathrm{BE}_{3}$ compounds serve as LEWIS acids, the donor molecules as LEWIS bases. The LEWIS acidity of the boron halides $\mathrm{BX}_{3}$ against hard bases increases along $\mathrm{BF}_{3}<\mathrm{BCl}_{3}<\mathrm{BBr}_{3}$. The affinity to form $\pi$-bonds with the boron atom (as described above) decreases in the same direction.

Thus, the chemistry of boron-containing compounds is characterized by the fact, that boron has only three valence electrons, but four valence orbitals for bonding. This 
results in a tendency for many boranes to form multicenter bonds and LEWIS acid-base adducts. The bonding characteristics of such compounds are always under debate. ${ }^{[63,119-126]}$ In the priority program 1178, several projects study the bonding situation of boron in different chemical environments. The bonding in borides is discussed, ${ }^{[103]}$ as well as the bonding and coordination of boron in classical boranes, borates, and boranates. ${ }^{[124,125]}$

In the work leading to this thesis, four different boron-containing complexes were investigated from different points of view. The focus of the investigation depended on the molecule. While in some cases, the bonding situation of the compound was the interesting feature in other cases the emphasis was shifted to the reactivity of the molecule and the reasons for it.

Two of the compounds under investigation show the composition $\left[\left(\mathrm{C}_{6} \mathrm{~F}_{5}\right)_{2} \mathrm{BR}\right]$ and are therefore classical LEWIS acids. However, the change of the ligand $\mathrm{R}$ from $-\mathrm{NC}_{4} \mathrm{H}_{8}$ to $-\mathrm{NC}_{4} \mathrm{H}_{4}$ increases the catalytic potential of the compound considerably. The influence of the ligand $\mathrm{R}$ on the whole electronic system of both compounds was investigated by an experimental electron density study. ${ }^{[127]}$ The results obtained, which rationalize the reasons for this change in reactivity, are discussed in Chapter 4.

In the other two compounds, $\left[(\mathrm{CO})_{5} \mathrm{CrBN}\left(\mathrm{SiMe}_{3}\right)_{2}\right]$ and $\left[\left\{\mathrm{Cp}(\mathrm{CO})_{2} \mathrm{Mn}\right\}_{2} \mathrm{~B}\left(\mu-\mathrm{B}^{t} \mathrm{Bu}\right)\right]$, boron has a very different chemical environment. In these cases, the boron atom is bonded to a transition metal. As boron forms a large number of different transition metal complexes, their classification is achieved by the characterization of the different bonding situations. Borylene complexes, which they are both assigned to be, constitute a rather new class of transition metal compounds of boron. Therefore, the main focus was set on the bonding situation between the boron and the transition metal atom. As the coordination modes of borylene complexes are numerous, two examples were chosen: a terminal borylene complex and a bridging borylene complex (Chapter 5). In the bridging borylene complex, in addition to the bonding of the boron atom to the transition metal, the existence of metal-metal bonding was examined. The difference between supported (i.e. bridged by other groups) and unsupported metal-metal bonds has already been investigated for carbonyl ligands, but this is the first examination of a bridging borylene via an electron density investigation. ${ }^{[34]}$ 



\section{EXPERIMENTAL EleCtron Density StUdies - The BAsics}

Experimental electron density studies are based on high-resolution low-temperature X-ray diffraction experiments. This chapter will shortly outline the theoretical background of such experiments. Firstly, the principles of X-ray diffraction will very briefly be summarized. Two approaches for obtaining the electron density distribution (EDD) of a molecule from X-ray data will be presented. Additionally, a few criteria will be introduced, that allow a judgment of the quality of the refinement. Finally, different methods of extracting information from the modeled density will be discussed.

\subsection{Principles of X-ray Diffraction}

The basis of an X-ray diffraction experiment is the interaction of X-rays with crystalline matter. ${ }^{[3]}$ In general, diffraction occurs when electromagnetic waves impinge on a periodic lattice of scattering material. To observe significant diffraction, the spacing $d$ between the lattice planes of the scatterer and the wavelength $\lambda$ of the incident beam should have the same order of magnitude. As the lattice spacing of single crystals is in the range of $1-100 \AA$, X-ray as well as neutron or electron beams are applicable for these kinds of diffraction experiments.

Whenever electromagnetic waves hit a three-dimensional periodic scatterer, they are diffracted at discrete lattice points. The scattered waves, also called secondary waves, interact with each other. These interferences can be destructive and in their extreme example lead to a total extinction of the secondary wave. However, when the phase shift between the secondary waves is a multiple to $2 \pi$, the interference between the secondary waves is constructive (cf. Figure 2-1). This is the case, when the diffraction condition, expressed by BRAGG's law, is fulfilled. ${ }^{[4]}$

$$
2 d \sin \theta=n \lambda
$$

Here, $d$ is the spacing between the diffracting planes, $\theta$ the incident angle, and $\lambda$ the wavelength of the beam. A diffraction pattern of distinct reflections is obtained by measuring the intensity of the scattered waves as a function of the scattering angle. 


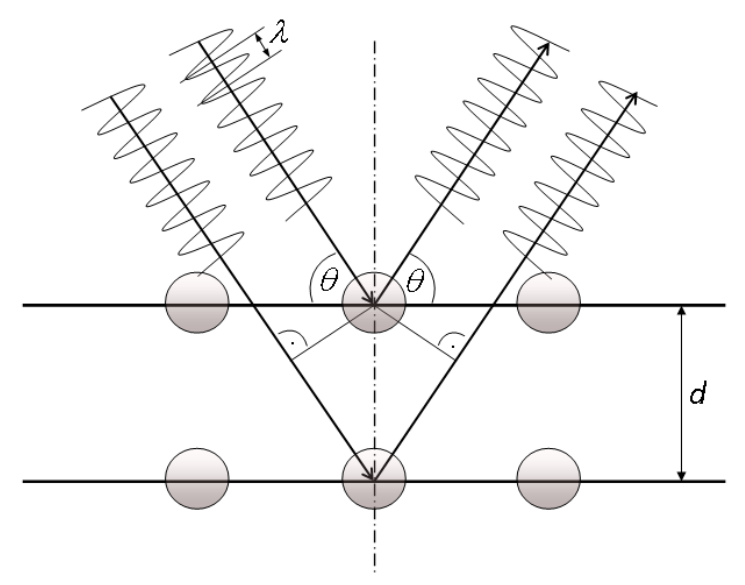

Figure 2-1: Diffraction of waves at a three-dimensional periodic lattice.

The arrangement of the reflections in the reflection pattern contains information on the crystal symmetry, i.e. its space group. The intensities of these reflections are linked to the electron density distribution in the crystal by a FOURIER transformation. This connection between the X-ray intensities $/$ and the elastic scattering amplitudes $F(\mathbf{H})$ is provided by the kinematic theory of scattering by BORN ${ }^{[128]}$ :

$$
l \propto|F(\mathbf{H})|^{2}
$$

$\mathbf{H}=h \mathbf{a}^{*}+k \mathbf{b}^{*}+l \mathbf{c}^{*}$ is defined as the scattering vector, with integral components concerning the reciprocal axis. ${ }^{[129]} F(\mathbf{H})$ is also called the structure factor and can be expressed as the FOURIER transform of the static electron density distribution in the crystal.

$$
F(\mathbf{H})=\int_{V} \rho(\mathbf{r}) \cdot \mathrm{e}^{2 \pi i \mathbf{H r}} d \mathbf{r}
$$

Reversely, the electron density of the crystal is the FOURIER transform of the structure factors. This coherence is used for the structure solution.

$$
\rho(\mathbf{r})=\int_{V} F(\mathbf{H}) \cdot \mathrm{e}^{-2 \pi i \mathbf{H r}} d \mathbf{r}
$$

The integration can - to a good approximation - be replaced by a summation over all structure factors within the volume $V$ of the unit cell.

$$
\rho(\mathbf{r})=\frac{1}{V} \sum_{\mathbf{H}} F(\mathbf{H}) \cdot \mathrm{e}^{-2 \pi i \mathbf{H r}}
$$


Thus, theoretically, via a FOURIER transformation, the electron density $\rho(\mathbf{r})$ can be calculated from the structure factors $F(\mathbf{H})$, which are available from the diffraction experiment via the measured intensities. However, this direct evaluation causes some problems due to experimental shortcomings.

- $\quad$ The observed structure factors are affected by experimental errors. Even if these errors are corrected by different routines, they are nevertheless inherent in the data.

- As only a finite number of reflections can be collected, FOURIER truncation errors occur.

- The phase information is lost during the measurement. This is due to the fact, that the measured intensities are proportional to the squared structure factors.

Therefore, the electron density in the crystal can virtually not directly be calculated from the observed structure factors and has to be modeled. Fortunately, in practice the FOURIER transformation can be bypassed, because quantum mechanics facilitates the construction of a mathematical model of the electron density in a crystal. If the arrangement of the atomic nuclei in the crystal lattice is known, the structure factors can be calculated from a parameterized model. These calculated structure factors $F_{\text {calc }}$ are then compared to the observed structure factors $F_{\text {obs. }}$. By optimizing the parameters of the calculated model $F_{\text {calc }}$ is adjusted to $F_{\text {obs }}$ in a least-squares refinement.

Within the convolution approximation ${ }^{[130]}$ the electron density can be formulated as the sum over the atomic fragments.

$$
\rho(\mathbf{r})=\sum_{j} \rho_{j}^{a t}\left(\mathbf{r}_{j}\right)
$$

A FOURIER transformation leads to another description of the structure factor.

$$
F(\mathbf{H})=\sum_{j} f_{j}(\mathbf{H}) t_{j}(\mathbf{H}) \cdot \mathrm{e}^{2 \pi \mathbf{H r}_{j}}
$$

Here, $f_{j}(\mathbf{H})$ is the atomic form factor (or atomic scattering factor) of the atom $j$ and $t_{j}(\mathbf{H})$ is the temperature factor. $f_{j}$ depends on two factors: the atom type and the scattering angle $\theta$. The scattering power increases with the atomic number of the element due to the growing number of electrons and it decreases with an increasing 
scattering angle. Therefore, each atom in a molecule contributes in a different way to the diffraction pattern, depending on its scattering power and its position in the unit cell. In return, the diffraction pattern contains information on the position of the atoms and the number of electrons, from which the type of the atom can be deduced.

Due to the thermal motion of atoms in a crystal the electron density - and that way, the positions of its maxima - can be assigned less accurately. Therefore, $\rho(\mathbf{r})$ is the time-average of the sum of atomic electron densities, which can be described as pure vibrational states. ${ }^{[131]}$ This can be expressed within the convolution approximation, which assumes the total electron density to be composed of a superposition of density following the motion of the nucleus it is attached to. ${ }^{[130]}$ In most cases, the thermal motion is sufficiently described by a probability function obeying a harmonic approximation.

$$
P_{0}(\mathbf{u})=(2 \pi)^{-3 / 2}(\operatorname{det} \mathbf{U})^{-1 / 2} \cdot e^{-1 / \mathbf{u}^{\prime} \mathbf{u}^{-1} \mathbf{u}}
$$

$\mathbf{u}$ is the nuclear displacement vector and $\mathbf{U}$ the mean square displacement amplitude (MSDA), respectively. Sometimes, however, the thermal vibrational motion is described insufficiently by the harmonic approximation. In those cases the GRAM-CHARLIER-expansion can be applied to model small anharmonicities. ${ }^{[132]}$

\subsection{The Independent Atom Model}

Thus, from the diffraction experiment, the electron density distribution in the unit cell of a single crystal is available. However, as already explained above, the density has to be modeled. The independent atom model (IAM) is one approach to derive the cal-

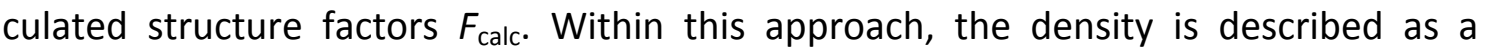
superposition of spherical atomic densities that via a FOURIER transformation gives the spherical atomic scattering factors.

$$
f_{j}(\mathbf{H})=\int_{V_{j}} \rho_{j}^{a t}\left(\mathbf{r}^{\prime}\right) \cdot e^{2 \pi i H r^{\prime}} d V_{j}
$$


There are up to nine parameters per atom that can be altered to adjust $F_{\text {calc }}$ to $F_{\text {obs: }}$ : three positional parameters $(x, y$, and $z)$, and six anisotropic displacement parameters $\left(U_{\mathrm{ij}}\right)$ for non-hydrogen atoms or one isotropic displacement parameter $\left(U_{\text {iso }}\right)$ usually used only for hydrogen atoms, respectively.

From a chemical understanding, the density is accumulated around the nuclei of the atoms. Therefore, the maxima of the electron density distribution in the unit cell can be interpreted to be the atom positions of the molecule. The assumption of a spherical distribution of the density around these nuclei is adequate to obtain a reasonable model of the structure, i.e. the connectivities between the atoms. However, bonding effects as well as lone pairs are not considered (cf. Figure 2-2).

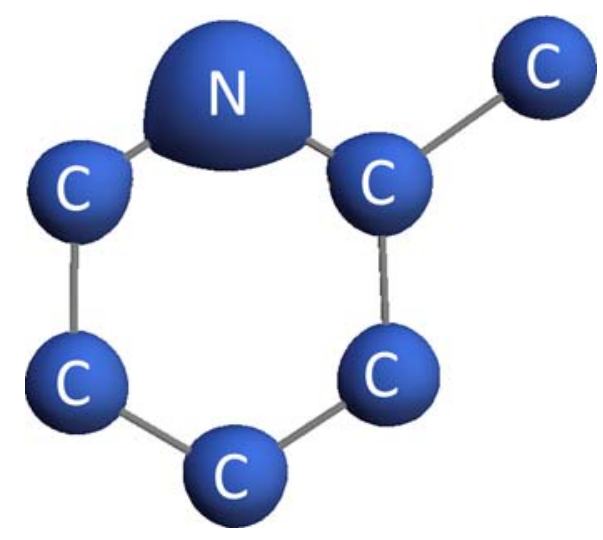

Figure 2-2: Electron density $\rho(\mathbf{r})$ of a coordinated picolin-ring modeled with the IAM approach (taken from ref. 99).

This shortcoming of the model is negligible for heavy atoms with a dominant contribution of spherically arranged core electrons. For lighter atoms, however, the determined parameters, especially the temperature factors, are biased. ${ }^{[133]}$ This can most easily be explained in the case of the hydrogen atoms. The hydrogen atom has only one (valence) electron, which is in most cases involved in bonding. Due to the bonding, the probability density of the hydrogen's electron is at least as high in the bonding region as around the core. If the core position is assumed to be the maximum of the EDD, which is the center of the electron cloud, the $\mathrm{R}-\mathrm{H}$ bond distance is estimated too small. This has to be compensated by fixing the hydrogen atoms at distances derived from neutron diffraction experiments. ${ }^{[134]}$

This effect can be mitigated if only information from higher BRAGG angles $(\sin \theta / \lambda \geq 1.00 \AA)$ is used for the determination of the atom coordinates, as the 
decrease of the scattering power is more significant for the disperse valence electrons than for the core electrons. That way, reliable structural parameters for all nonhydrogen atoms are obtained, leading to results that are in good agreement with those from other methods, e.g. neutron diffraction. ${ }^{[135-138]}$

The IAM model serves as starting geometry for the multipole refinement which is described in the next chapter. Thus, bias-free results of the independent atom modeling are of great importance.

\subsection{The Multipole Model}

The independent atom model, as described above, assumes the atoms to be spherical and neglects any aspherical density distributions from bonding or lone pairs. An extension of this description was introduced by STEWART ${ }^{[37,39,40]}$ and later modified by HANSEN and COPPENS. ${ }^{[43]}$ Within their nucleus-centered finite multipole model, the atomic density $\rho(\mathbf{r})$ is divided into three components:

$$
\rho(\mathbf{r})=\rho_{c}(\mathbf{r})+P_{v} \rho_{v}(\kappa \mathbf{r})+\rho_{d}\left(\kappa^{\prime} \mathbf{r}\right)
$$

The spherical core density $\rho_{\mathrm{c}}(\mathbf{r})$ and the spherical valence density $\rho_{\mathrm{v}}(\kappa \mathbf{r})$ add up to the density of the IAM, if $\kappa$ is assumed to be one and $P_{\mathrm{v}}$ is set to $N_{\mathrm{v}}$, which is the total number of valence electrons. In the end, the asphericity of the electron density is only described by the aspherical valence density term $\rho_{\mathrm{d}}\left(\kappa^{\prime} \mathbf{r}\right)$ (cf. Figure 2-3).

$\kappa$ and $\kappa^{\prime}$ represent radial scaling parameters that allow for an expansion or a contraction of the spherical valence density and the aspherical valence density, respectively. The core and the spherical valence densities, $\rho_{c}(\mathbf{r})$ and $\rho_{v}(\kappa r)$, are calculated from HARTREE-FOCK $(\mathrm{HF})^{[139]}$ or relativistic $\mathrm{HF}^{[140]}$ atomic wave functions. Their values are tabulated in the literature. ${ }^{[132]}$ The radial functions of the aspherical deformations density, $\rho_{\mathrm{d}}\left(\kappa^{\prime} \mathbf{r}\right)$ are usually taken as simple SLATER-type functions with energy-optimized exponents $\alpha_{1}$.

$$
\mathbf{R}_{l}(\mathbf{r})=\frac{\alpha_{l}^{n_{l}+3}}{\left(\mathbf{n}_{l}+2\right) !} \mathbf{r}^{n_{l}} e^{-\alpha_{l} r}
$$


Since the spherical harmonic functions are FOURIER transform invariant, the pseudoatom scattering factor takes the form

$$
f(\mathbf{H})=f_{c}(\mathbf{H})+P_{v} f_{v}\left(\frac{\mathbf{H}}{\kappa}\right)+4 \pi \sum_{l=0}^{I_{\max }} i^{l}\left\langle j_{l}\left(\mathbf{H} / \kappa^{\prime}\right)\right\rangle \sum_{m=0}^{+1} P_{l m} d_{l m \pm}(\beta, \gamma)
$$

where $f_{\mathrm{c}}$ and $f_{\mathrm{v}}$ are the FOURIER transforms of $\rho_{\mathrm{c}}$ and $\rho_{\mathrm{v}}$, respectively, $\left\langle j_{l}\right\rangle$ is the $t^{\text {th }}$ order FOURIER-BESSEL transform of $R_{l}$

$$
\left\langle j_{l}\right\rangle=\int j_{l}(2 \pi S \mathbf{r}) R_{l}(\mathbf{r}) d \mathbf{r}
$$

and $d_{1 \mathrm{~m} \pm}(\beta, \gamma)$ are spherical harmonics expressed in reciprocal space polar coordinates.

That way, within the multipole model, in addition to the nine conventional parameters - the positional $(x, y, z)$ and thermal parameters $\left(U_{\mathrm{ij}}\right)$ of the IAM - the charge density parameters $P_{\mathrm{v}}, P_{\mathrm{Im}}, \kappa$ and $\kappa^{\prime}$ are optimized in the least-squares refinement based on the measured structure factors. This results in up to 36 parameters for each non-hydrogen atom.

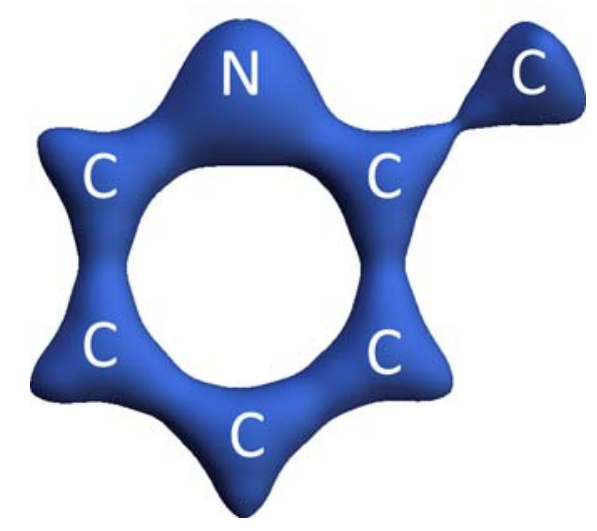

Figure 2-3: Electron density $\rho(\mathbf{r})$ of a coordinated picolin-ring modeled with the MM approach (taken from ref. 99).

To obtain a reasonable reflection-to-parameter ratio, which should be at least higher than 10, more data has to be measured in comparison to a classical structure refinement. Therefore, as a rule of thumb, X-ray data up to a resolution of $\sin \theta / \lambda \geq 1.00 \AA$ has to be available. This data should be of extraordinary quality in order to avoid bias. 


\subsection{Quality Criteria of the Refinements}

\subsubsection{R-Values}

During the least-squares refinement, the difference between the observed and the calculated structure factors is minimized. How well this adjustment worked, is expressed by the $R$-values $R 1$ and $w R 2$. If the model is refined against $F^{2}$, the $w R 2$ is more significant. $w_{H}$ denotes a weighting scheme.

$$
\begin{gathered}
R 1=\frac{\sum_{H} w_{H}\left(\left|F_{o b s}\right|-\left|F_{c a l c}\right|\right)}{\sum_{H} w_{H}\left|F_{o b s}\right|} \\
w R 2=\frac{\sum_{H} w_{H}\left(\left|F_{o b s}\right|^{2}-\left|F_{c a l c}\right|^{2}\right)^{2}}{\sum_{H} w_{H}\left|F_{o b s}\right|^{4}}
\end{gathered}
$$

\subsubsection{Residual Density}

The residual density is another indicator for the quality of the refinement. It represents the difference between the modeled and the observed electron density. The smaller the difference is, the better does the model describe the molecular density. As the IAM does the modeling with spherical atoms which do not account for ED in bonding regions, strong residuals are left after the refinement. Especially the bonding regions show residual density that is not modeled while at the atomic position the density is overinterpreted, which leads to negative residuals. If - after the IAM refinement - the major residuals are located in bonding regions, the main model bias is the missing description of the ED deformations due to atom interactions that is inherent to the IAM. It can thus be assumed, that the information on the density in the bonding regions is contained in the data, thus promising good data quality for a successful multipole refinement.

Due to the decreased thermal motion at lower temperature, low-temperature data sets often show a better data quality and thus the residual density mainly located where expected (Figure 2-4). 

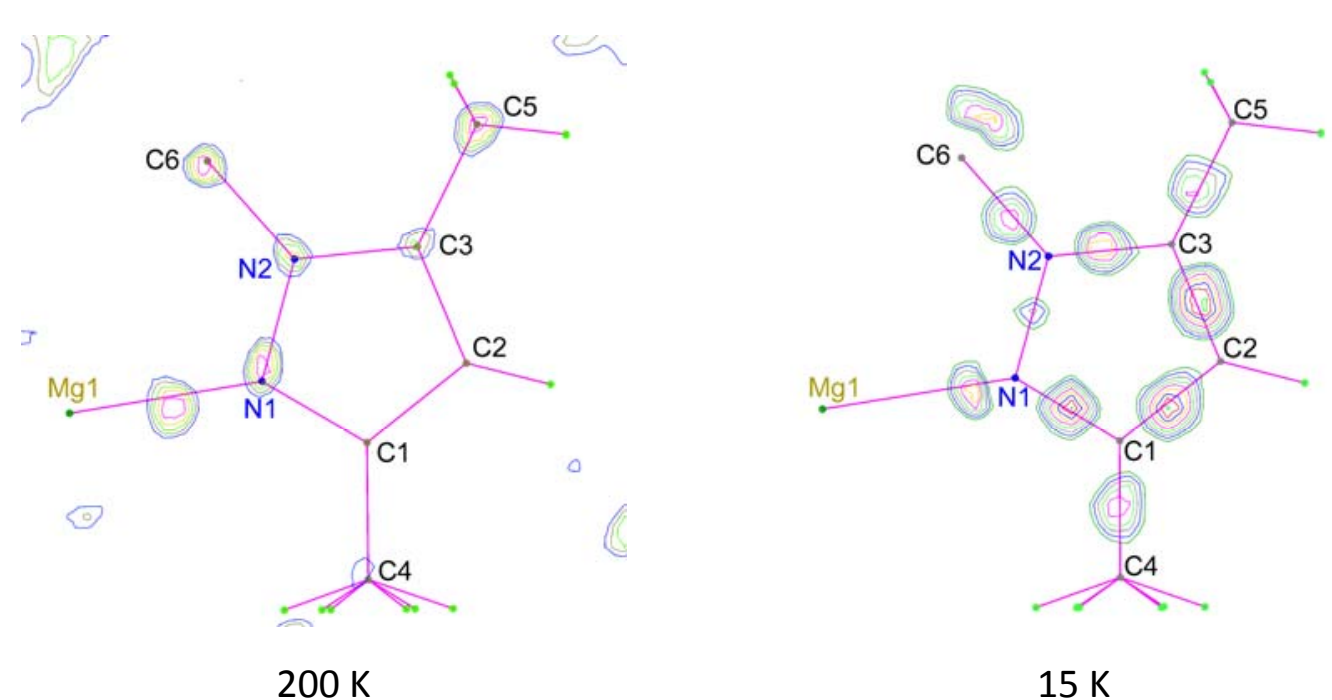

$15 \mathrm{~K}$

Figure 2-4: Residual density distributions of a pyrazolyl ring after an IAM refinement of data measured at $200 \mathrm{~K}$ and at $15 \mathrm{~K}$ (taken from STERN ${ }^{[141]}$ )

The most important test to judge on the success of the model and the quality of the fit is to evaluate the residual ED through a FoURIER summation $\left(F_{\text {obs }}-F_{\text {calc }}\right)$. This provides a direct-space representation of the extent to which the model accounts for the observations. A featureless residual map is a necessary condition for the adequacy of a model, but it is far from being a sufficient one to judge its physical significance.

After the multipole refinement, these residuals should be accounted for and therefore the new residual density map should be flat and featureless. If any residual density is left, it should be randomly distributed. It can then be assigned to experimental noise. Errors in the model can be concluded from residual densities in proximity to the core, while residual densities in larger distances to atom positions are indicative of bad data quality.

\subsubsection{Goodness of Fit}

Next to the weighted $R$-values, the Goodness of Fit $(\mathrm{GoF}, S)$ is another important quality criterion. It shows the relation between the deviation of $F_{\text {calc }}$ from $F_{\text {obs, }}$ and thus the over-determination of refined parameters.

$$
S=\sqrt{\frac{\sum\left(w_{H}\left(F_{o b s}^{2}-F_{c a l c}^{2}\right)^{2}\right)}{(n-p)}}
$$


Here, $n$ is the number of reflections, $w_{H}$ is the weighting scheme applied and $p$ is the number of parameters.

For a correct structure refinement with an adapted weighting scheme, $S$ should be one. Higher values for the GoF are due to a systematic underestimation of the uncertainties of the reflections at higher BRAGG angles. Therefore, the quality of the model seems to be worse than expected from the quality of the data. In addition, the GoF for a multipole refinement is usually higher than one due to the weighting scheme applied. This is due to the dependence of $S$ from the number of the observations and variables. For high resolution data, this ratio is unfavorable with respect to the calculated $S$.

\subsubsection{HIRSHFELD-Test}

Another quality criterion is the test on the thermal motion parameters. This test is called DMSDA (difference of mean-square displacement amplitudes), rigid-bond, or HIRSHFELD test. ${ }^{[142]}$ The thermal parameters are tested against the rigid-body motion model. ${ }^{[143]}$ If $z_{A, B}^{2}$ denotes the mean square displacement amplitude of atom $A$ in the direction of atom $B$, for every covalently bonded pair of atoms $A$ and $B$ the following equation should be fulfilled

$$
\Delta_{A, B}=z_{A, B}^{2}-z_{B, A}^{2} \approx 0
$$

This implies, that the two bonded atoms should librate nearly equally in the bond direction. However, this rule is only strictly obeyed for atoms of the same mass. When a proper deconvolution of the electron density from thermal motion is given the DMSDAs are smaller than $1 \cdot 10^{-3} \AA^{2}$ for atoms with equal masses. This value can be higher for hetero-nuclear bonds. If this value is significantly exceeded for homo-nuclei bonds, bias by unresolved valence density asphericities or an unrecognized disorder is indicated. Verification of the model and the anisotropic displacement parameters by this test strengthens the confidence in the experimentally determined ED. 


\subsection{Functions and Moments Derived from Electron Density Distributions}

Once a charge density distribution has been obtained experimentally, various chemical and physical properties can be derived. These properties directly depend on the EDD. The properties used in this thesis will be presented in the following two subchapters.

\subsubsection{Static Deformation Density}

A direct inspection of the modeled density $\rho(\mathbf{r})$ itself is not very meaningful in almost all cases because the density is dominated by the core electrons and the effects of bonding are only slightly visible. Therefore, difference densities are widely applied to amplify the features of bonding. A commonly used function is the static deformation density $\nabla \rho_{\text {static }}(\mathbf{r})$, which is defined as the difference between the thermally averaged density from the multipole model $\rho_{\mathrm{MM}}(\mathbf{r})$ and the spherically averaged density from the independent atom model $\rho_{\mathrm{IAM}}(\mathbf{r})$.

$$
\Delta \rho_{\text {static }}(\mathbf{r})=\rho_{\mathrm{MM}}(\mathbf{r})-\rho_{\mathrm{IAM}}(\mathbf{r})
$$

This deformation density is based on the functions and populations from the aspherical multipole refinement and does therefore not include the effect of thermal smearing.

In a deformation density map, accumulations of density are visible in bonding as well as in the lone-pair regions. This is expected, as these features are only described within the MM and not within the IAM. Thus, deformation density maps can be used to confirm long-used chemical concepts. Additionally, these maps have great diagnostic potential and are routinely used to check the quality of an analysis by a comparison of the static deformation densities from X-ray data with that calculated theoretically. By comparing experimental densities with those from periodic theoretical calculations, shortcomings in either method become apparent. For example, expected features cannot always be seen. Elements with more than halffilled valence shells lack bonding features in the deformation densities due to the 
neutral spherically averaged reference atom which contains more than one electron in each orbital of the valence shell. ${ }^{[144,145]}$

The static deformation density is, in contrast to FoURIER densities, not limited to the finite resolution of the experimental data set. This leads to a high dependence on the basis set of functions applied in the refinement, and thus introduces bias. To reduce this bias, special care has to be taken for the quality of the reference molecule.

\subsubsection{Electrostatic Potential}

Nucleophilic and electrophilic regions in a molecule represent possible reaction sites for electrophiles or nucleophiles, respectively. As the electrostatic potential (ESP) provides information on their spatial arrangement in a molecule, its determination is of particular chemical interest.

The ESP at a given point in space is defined as the energy required for bringing a positive unit of charge from infinite distance to this point. It can be calculated, independent from the crystal environment, applying the formalism of SU and COPPENS. ${ }^{[146]}$ For an atom, composed from a positive charge at a certain point, the nucleus, and a continuous distribution of negative electronic charge around this point, the ESP can be expressed as follows:

$$
\Phi(\mathbf{r})=\sum_{j} \frac{Z_{j}}{\left|R_{j}-\mathbf{r}^{\prime}\right|}-\int \frac{\rho(\mathbf{r})}{\left|\mathbf{r}-\mathbf{r}^{\prime}\right|} d \mathbf{r}
$$

Here, $Z$ is the charge of the nucleus $j$ located at $R$. The first term of the equation describes the nuclei contributions, from which the second part, the electron distribution term, is subtracted.

As electrostatic forces are relatively long-range forces, they determine the path a reactant uses to reach the reactive parts of a molecule. Hence, in chemical terms, nucleophilic reagents are attracted to regions with positive potential while electrophiles approach the negative. 


\subsection{3 d-orbital Populations}

The radial functions applied within the multipole refinement resemble the radial functions of the orbitals. However, they are not equivalent. Therefore, the multipole populations do in general not directly correspond to the orbital populations in a given system. Nevertheless, for transition metals, there is a possibility to calculate the $d$-orbital population from the least-squares multipole population coefficients. ${ }^{[147]}$

This relation is based on the assumption, that the $d$-orbitals can be represented by single SLATER type orbitals and that the overlap between metal atom and ligand orbitals is small. Therefore, the multipolar density at the transition metal atom can - to a good approximation - be calculated from the population of the outer valence shells of the atom. The relationship between $d$-orbital occupancies and multipole population parameters is derived from the equivalence of two alternative descriptions of the atomic electron density.

The $d$-electron density may be expressed in terms of the atomic orbitals as

$$
\rho_{d}=\sum_{i} \sum_{j \geq i} P_{i, j} \phi\left(d_{i}\right) \phi\left(d_{j}\right)
$$

with $\phi\left(d_{i}\right)$ being the atomic $d$-orbital basis set. In the multipolar expression, the $3 d$-density is expressed in terms of the density-normalized spherical harmonic functions $\mathrm{d}_{/ m p}$ as

$$
\rho_{d}=\sum_{l=0}^{I_{\max }} \kappa^{\prime 3} R_{l}\left(\kappa^{\prime} r\right) \sum_{m=0}^{l} \sum_{p} P_{I m p} d_{I m p}\left(\frac{\mathbf{r}}{r}\right)
$$

Assuming, that the radial dependence of the density is equal in both descriptions, equating Eq. 2-20 with 2-21 leads to

$$
\mathbf{P}_{i j} \mathbf{Y}_{i j}=\mathbf{P}_{I m p} \mathbf{d}_{I m p}
$$

Here, $\mathbf{Y}_{i j}$ is the 15-element column vector of the angular part of the $\phi\left(d_{i}\right) \phi\left(d_{j}\right)$ orbital products, $\mathbf{P}_{i j}$ is the row vector of the 15 unique elements of the symmetric $5 \times 5$ matrix of the coefficients of the 15 spherical harmonic density functions $d_{\operatorname{lmp}}$ with $I=0,2$, or 4 . Density functions with other than even I values do not contribute to the $d$-orbital density. 
The spherical harmonic functions constitute a complete set of functions in the spherical point group. A product of two harmonics must therefore be a linear combination of spherical harmonic functions that can in general be written as $\mathbf{Y}_{i j}=\mathbf{L} \mathbf{d}_{\text {Imp }}$. The elements of the matrix $\mathbf{L}$ are the coefficients of each density function. $A$ complete set of the equations for $\mathrm{I} \leq 2$ is tabulated in the literature. ${ }^{[129]}$

The equivalence for the density in Eq. 2-22 can also be written as

$$
\mathbf{P}_{i j} \mathbf{Y}_{i j}=\mathbf{P}_{i j} \mathbf{L d}_{I m p}=\mathbf{P}_{I m p} \mathbf{d}_{I m p}
$$

Therefore, the relation between the coefficients $\mathbf{P}_{i j}$ and $\mathbf{P}_{I m p}$ can be formulated as

$$
\mathbf{P}_{I m p}=\mathbf{P}_{i j} \mathbf{L}
$$

or in a different way be defined as

$$
\mathbf{P}_{l m p}^{T}=\mathbf{L}^{T} \mathbf{P}_{i j}^{T} \equiv \mathbf{M P}_{i j}^{T}
$$

The $d$-orbital occupancies are derived from the experimental multipole populations by the inverse expression ${ }^{[147]}$

$$
\mathbf{P}_{i j}^{T}=\mathbf{M}^{-1} \mathbf{P}_{l m p}^{T}
$$

The matrix $\mathbf{M}^{-1}$ is a $15 \times 15$ matrix and also tabulated in the literature. ${ }^{[129]}$ In all but triclinic point groups, site-symmetry restrictions limit the allowed functions.

\subsection{The Quantum Theory of Atoms in Molecules}

While most theoretical calculations are based on the wave function, BADER's quantum theory of atoms in molecules ${ }^{[71]}$ is based on a physical observable, the electron density distribution $\rho(\mathbf{r})$. It is available from X-ray diffraction experiments as well as from quantum chemical calculations. BADER's theory was originally designed for the examination of theoretical electron density distributions. However, it provides the possibility to analyze experimentally derived EDD as well. The different descriptors of the EDD provided by the QTAIM are presented in the following chapters. 


\subsubsection{Topological Atoms and Atomic Charges}

BADER'S quantum theory of atoms in molecules (QTAIM) is based on the assumption, that the properties of a molecule can be described as the sum of the properties of its atoms. Therefore, an unambiguous definition of an atom is compulsory.

Mathematically, the density $\rho(\mathbf{r})$ of a molecule is a scalar field and its topology is best examined by an analysis of its gradient vector field. The gradient is defined as:

$$
\nabla \rho(\mathbf{r})=\mathbf{i} \frac{\partial \rho}{\partial x}+\mathbf{j} \frac{\partial \rho}{\partial y}+\mathbf{k} \frac{\partial \rho}{\partial z}
$$

Here, $\mathbf{i}, \mathbf{j}, \mathbf{k}$ are the unit vectors of the CARTESIAN coordinate system. A gradient path (also called trajectory) is always perpendicular to the contour lines of $\rho(\mathbf{r})$ and follows the largest increase in $\rho(\mathbf{r})$ (Figure 2-5). Therefore, it must originate from a minimum or saddle point (minimum in at least one direction) and terminate at a maximum or saddle point (maximum in at least one direction) of $\rho(\mathbf{r})$. All trajectories ending at one maximum belong to the same basin, which represents an atom in a molecule. This basin is bordered by a surface, which is not crossed by any trajectory.

$$
\nabla \rho(\mathbf{r}) \cdot n(\mathbf{r})=0
$$

As all points of this surface have a vanishing scalar product of $\rho(\mathbf{r}) \cdot n(\mathbf{r})$, with $n(\mathbf{r})$ being the normal vector to the surface, it is called the zero flux surface. It represents the border of an atomic basin and that way defines the shape of the atom.
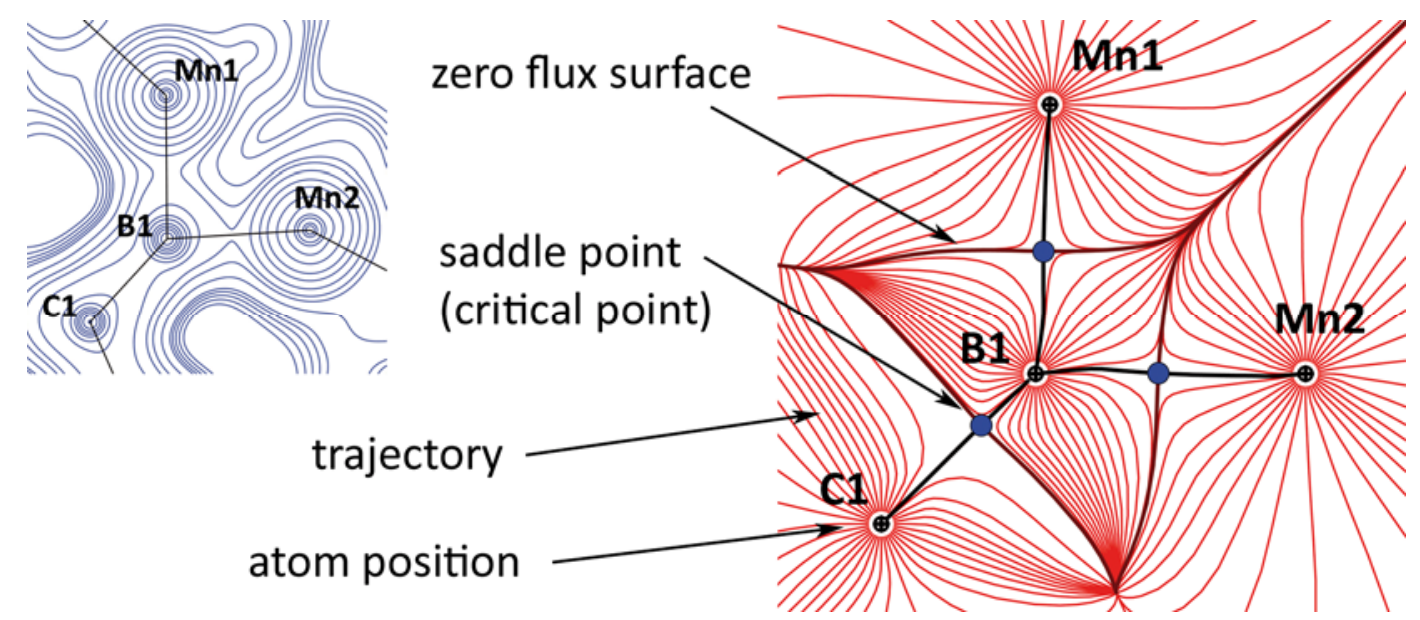

Figure 2-5: Electron density $\rho(\mathbf{r})$ in the $\mathrm{Mn}_{2} \mathrm{~B}$ plane of $\mathbf{4}$ (left) and corresponding gradient vector field (right) with the trajectories (right, red) being perpendicular to the contour lines of $\rho(\mathbf{r})$ (left, blue). 
This mathematical definition of an atom allows an integration of the electron density over the volume of the atomic basin. The result of this integration is the charge of the topological atom. As the volume of this topological atom depends on the bonding situation of the atom, for example on the electronegativity of the neighboring atom, these charges originate from bond polarization effects as well as from charge transfer between the atomic cores. Therefore, charges following BADER's partitioning scheme are higher than those obtained by other methods. ${ }^{[148,149]}$

All determined integrated charges have to sum up to the overall charge of the total fragment (electroneutrality), which is -in the case of a molecule-zero. The electroneutrality-criterion has to be fulfilled to have a reliable integration. Another quality criterion is the LAGRANGIAN, which is indicative of the accuracy of the integrated charge. The value of the LAGRANGIAN should ideally be below $1 \cdot 10^{-4}$ a.u. for hydrogen atoms, below $1 \cdot 10^{-3}$ a.u. for second row atoms and might exceed this limit for atoms of higher rows. ${ }^{[47]}$

\subsubsection{Critical Points}

The definition of the atomic basins already contained another crucial element of BADER'S QTAIM. The start and end points of a gradient path are extreme values in $\rho(\mathbf{r})$. These extrema (maxima, saddle points, or minima in the electron density) all have a vanishing gradient of $\rho(\mathbf{r})$. They are called critical points (CPs) and can be divided in core-, bond-, ring-, and cage-critical points, depending on the nature of the extremum. The inspection of the nature of the extremum can be performed with the help of the second-order derivative of the density. The nine second-order derivatives of $\rho(\mathbf{r})$ form the HESSIAN matrix.

$$
H(\mathbf{r})=\left(\begin{array}{lll}
\frac{\partial^{2} \rho(\mathbf{r})}{\partial^{2} x^{2}} & \frac{\partial^{2} \rho(\mathbf{r})}{\partial x \partial y} & \frac{\partial^{2} \rho(\mathbf{r})}{\partial x \partial z} \\
\frac{\partial^{2} \rho(\mathbf{r})}{\partial y \partial x} & \frac{\partial^{2} \rho(\mathbf{r})}{\partial^{2} y^{2}} & \frac{\partial^{2} \rho(\mathbf{r})}{\partial y \partial z} \\
\frac{\partial^{2} \rho(\mathbf{r})}{\partial z \partial x} & \frac{\partial^{2} \rho(\mathbf{r})}{\partial z \partial y} & \frac{\partial^{2} \rho(\mathbf{r})}{\partial^{2} z^{2}}
\end{array}\right)
$$


In its diagonalized form, the HESSIAN matrix provides the three eigenvalues $\lambda_{1}, \lambda_{2}, \lambda_{3}$ (with $\lambda_{1} \leq \lambda_{2} \leq \lambda_{3}$ ), which indicate the curvature of $\rho(\mathbf{r})$ along the main curvature axes at the point $r$.

$$
D\left(\mathbf{r}_{\mathrm{CP}}\right)=\left(\begin{array}{ccc}
\frac{\partial^{2} \rho(\mathbf{r})}{\partial^{2} x^{2}} & 0 & 0 \\
0 & \frac{\partial^{2} \rho(\mathbf{r})}{\partial^{2} y^{2}} & 0 \\
0 & 0 & \frac{\partial^{2} \rho(\mathbf{r})}{\partial^{2} z^{2}}
\end{array}\right)=\left(\begin{array}{ccc}
\lambda_{1} & 0 & 0 \\
0 & \lambda_{2} & 0 \\
0 & 0 & \lambda_{3}
\end{array}\right)
$$

A critical point in $\rho(\mathbf{r})$ is classified by the rank $m$ (the number of non-zero eigenvalues $\lambda_{i}$ ) and the signature $n$ (the algebraic sum of the signs of the eigenvalues $\lambda_{\mathrm{i}}$ ) of the HESSIAN matrix. For a rank $m=3$, there are only four possible types of CPS with $(m, n)$ (Table 2-1).

Table 2-1: Classification of critical points in $\rho(\mathbf{r})$.

\begin{tabular}{|c|c|c|c|c|}
\hline$(m, n)$ & topology in $\rho(r)$ & $\lambda_{\mathrm{i}}$ & interpretation & type \\
\hline$(3,-3)$ & local maximum & all $\lambda_{1}<0$ & atomic position & $\begin{array}{l}\text { atom position } \\
\text { (AP) }\end{array}$ \\
\hline$(3,-1)$ & $\begin{array}{l}\text { maximum in two directions } \\
\text { minimum in one direction }\end{array}$ & $\begin{array}{l}\text { two } \lambda_{1}<0 \\
\text { one } \lambda_{1}>0\end{array}$ & chemical bond & $\begin{array}{l}\text { bond critical } \\
\text { point }(B C P)\end{array}$ \\
\hline$(3,+1)$ & $\begin{array}{l}\text { maximum in one direction } \\
\text { minimum in two directions }\end{array}$ & $\begin{array}{l}\text { one } \lambda_{1}<0 \\
\text { two } \lambda_{1}>0\end{array}$ & $\begin{array}{l}\text { center of a ring of } \\
\text { connected atoms }\end{array}$ & $\begin{array}{l}\text { ring critical point } \\
(\mathrm{RCP})\end{array}$ \\
\hline$(3,+3)$ & local minimum & all $\lambda_{1}>0$ & $\begin{array}{l}\text { center of a cube of } \\
\text { connected atoms }\end{array}$ & $\begin{array}{l}\text { cage critical point } \\
\text { (CCP) }\end{array}$ \\
\hline
\end{tabular}

Within this nomenclature, a local maximum is therefore a $(3,-3)$ critical point. Starting from this point, the density decreases in each direction, thus, the curvature is negative in all three space directions. These points which are the endpoints of all neighboring gradient paths (see above) are called attractors and are usually associated with the atom position. 
There are two possible kinds of saddle points within the electron density distribution. The first kind of saddle point has two negative and one positive eigenvalue. These points are called $(3,-1)$ critical points. This implies a maximum of $\rho(\mathbf{r})$ in two and a minimum in one direction, which can be found along bonds between two atoms (bond critical point, $\mathrm{BCP}$ ). The density increases from the $\mathrm{CP}$ towards each atom position but decreases in the two other directions. The gradient paths following the maximum of the density from the CP to the core position is called the bond path (BP). All bond paths of a molecule represent the molecular graph. In terms of the QTAIM, a $\mathrm{BCP}$ and its associated BP are the necessary and sufficient condition for the existence of a chemical bond. ${ }^{[71,150]}$

The second possible kind of saddle point in $\rho(\mathbf{r})$ is characterized by two positive and one negative eigenvalue. Thus, these $(3,+1)$ critical points appear, when the density is minimal in two directions and decreases perpendicular to this plane. Such a scenario is often found in the center of ring systems, e.g. benzene. Here, in the center of the ring, a $(3,+1)$ critical points is found, as the value of $\rho(\mathbf{r})$ starting from this CP is increasing in each direction of the $C_{6}$ ring and decreasing perpendicular to it. $(3,+1)$ critical points are therefore called ring critical points (RCPs).

Local minima in $\rho(\mathbf{r})$, where all three eigenvalues are positive, always appear in the middle of a cage structure. These $(3,+3)$ critical points are therefore called cage critical points (CCPs).

The reliability of the number of CPs found in a structure can be checked by the POINCARÉ-HOPF equation. ${ }^{[151,152]}$

$$
\mathrm{n}_{\mathrm{AP}}-\mathrm{n}_{\mathrm{BCP}}-\mathrm{n}_{\mathrm{RCP}}-\mathrm{n}_{\mathrm{CCP}}=1
$$

\subsubsection{The LAPLACIAN}

As already pointed out before, the topology of the total electron density is dominated by the contributions of the core electrons. Therefore, manifestations of paired electrons from bonding or lone pairs are difficult to detect. The amplification of small changes in the topology of the EDD is achieved via the second-order derivatives as formulated in the HESSIAN matrix. The LAPLACIAN $\nabla^{2} \rho(\mathbf{r})$ is the trace of the HESSIAN matrix. 


$$
\nabla^{2} \rho(\mathbf{r})=\frac{\partial^{2} \rho(\mathbf{r})}{\partial x^{2}}+\frac{\partial^{2} \rho(\mathbf{r})}{\partial y^{2}}+\frac{\partial^{2} \rho(\mathbf{r})}{\partial z^{2}}=\lambda_{1}+\lambda_{2}+\lambda_{3}
$$

The value of the LAPLACIAN displays whether a charge concentration $\left(\nabla^{2} \rho(\mathbf{r})<0\right)$ or depletion $\left(\nabla^{2} \rho(\mathbf{r})>0\right)$ is present. Maxima in the negative LAPLACIAN, $(3,-3)$ critical points in $\nabla^{2} \rho(\mathbf{r})$, are therefore indicative of local charge concentrations, called VSCCs (valence shell charge concentrations). These concentrations stem from bonding electron pairs or non-bonding charge concentrations (lone-pairs). ${ }^{[153]}$

The spatial arrangement of the VSCCs can be used to determine the density-related bonding geometry of an atom. ${ }^{[154-157]}$ Hybridization can thus much better be understood than from the traditional interatomic vectors as VSCCs stand for bonding as well as non-bonding contributions. The use of the density-related bonding angles leads to a higher agreement with the ones anticipated from the VSEPR theory. ${ }^{[158-161]}$

During the formation of a bond, the VSCCs of the corresponding atoms are induced to turn towards each other. Covalent bonds are characterized by an overlapping of the valence shells, more specific the VSCCs, of the bonding partners. This results in an accumulation of charge density $\left(\nabla^{2} \rho\left(r_{\mathrm{BCP}}\right)<0\right)$ in the bonding region and therefore at the BCP. Because of this interaction between the valence shells, covalent bonds are also called open shell (or shared) interactions.

The formation of ionic bonds does not induce an alignment of the VSCCs of the bonding partners. On the contrary, there is a charge depletion at the electropositive atom and a charge concentration at the more electronegative atom. The BCP is shifted towards the charge depletion at the electropositive atom $\left(\nabla^{2} \rho\left(r_{\mathrm{BCP}}\right)>0\right)$. Graphically only one VSCC is visible, which is attributed to the electronegative atom. Due to the missing overlap one speaks of closed-shell interactions.

In the case of a covalent but very polar bond, the BCP is shifted towards the less electronegative atom. Both VSCCS are visible, but - depending on the strength of the polarization - a more or less pronounced coalescence of the VSCCs is observed.

The characterization of bonds by the sign of the LAPLACIAN at the BCP is not always unambiguous. This is especially the case for weak bonds. The reason for this is the flat shape of the function for the ED along the bond path. Therefore, the minimum, defined as the BCP, can only be estimated within a certain error tolerance and the BCP 
shows a positional uncertainty. Thus, if regarding the value of the LAPLACIAN at this discrete point without caring for the environment, misinterpretations are not excluded. Especially for a very polar bond, where the BCP does not lie in the middle of the bond path but is shifted towards the less electronegative atom, the LAPLACIAN can have a zero crossing close to the BCP. If the value of the LAPLACIAN at the BCP in polar bonds is close to zero, no clear classification of the bonding is feasible. For the characterization, the LAPLACIAN distribution along the whole BP should therefore be regarded.

\subsubsection{The Ellipticity}

Apart from the sum of eigenvalues, the LAPLACIAN, the curvature of $\rho(\mathbf{r})$ can give interesting insights into the bonding situation. This curvature can be inspected by an examination of the proportion of the eigenvalues, as represented by the ellipticity.

$$
\varepsilon=\frac{\left|\lambda_{1}\right|}{\left|\lambda_{2}\right|}-1
$$

$\lambda_{1}$ and $\lambda_{2}$ are perpendicular to the bond axis and are the negative eigenvalues of the HESSIAN matrix. As $\lambda_{1}$ is defined to be larger or equal $\lambda_{2}, \varepsilon$ is always positive or zero. An ideal single bond ( $\sigma$-bond) has a perfect rotational symmetry. $\lambda_{1}$ equals $\lambda_{2}$ and $\varepsilon$ at the $\mathrm{BCP}$ is zero. Values for $\varepsilon$ that are larger than zero indicate multiple bonding or electronic depletion.

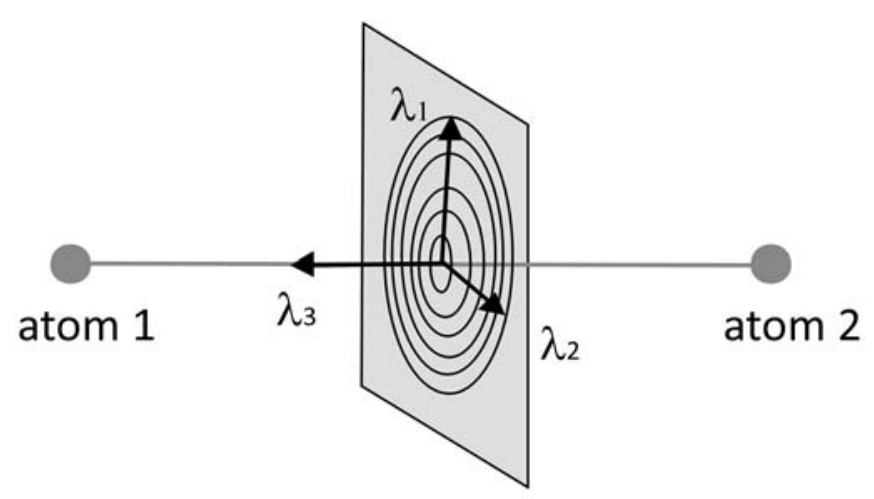

Figure 2-6: Spatial orientation of the eigenvalues $\lambda_{\mathrm{i}}$. 
For example, $\varepsilon$ increases from ethane (0.00), to benzene (0.23), to ethene (0.45). Thus the ellipticity delivers information on the bond order. For triple bonds rotational symmetry is again present and $\varepsilon$ equals zero.

The ellipticity of a bond can be inspected at the BCP as well as along the whole bond path. For very polar bonds, however, the examination along the whole bond path is compulsory to estimate the reliability of the value. BADER et al. showed, that values for this property change regularly along the whole path in heteronuclear bonds. ${ }^{[162]}$

\subsubsection{The Source Function}

BADER and GATTI showed, that it is possible to regard the electron density at any point $\mathbf{r}$ within a molecule to consist of contributions from a local source operating at all other points $r^{\prime}$ of the space. ${ }^{[85]}$

$$
\rho(\mathbf{r})=\int \mathrm{LS}\left(\mathbf{r}, \mathbf{r}^{\prime}\right) \cdot d r^{\prime}=\int_{\Omega} \mathrm{LS}\left(\mathbf{r}, \mathbf{r}^{\prime}\right) \cdot d \mathbf{r}^{\prime}+\sum_{\Omega^{\prime} \neq \Omega} \int_{\Omega^{\prime}} \mathrm{LS}\left(\mathbf{r}, \mathbf{r}^{\prime}\right) \cdot d r^{\prime}
$$

where the local source (LS) is expressed as:

$$
\operatorname{LS}\left(\mathbf{r}, \mathbf{r}^{\prime}\right)=-\left(\frac{1}{4} \pi\right) \cdot \frac{\nabla^{2} \rho\left(\mathbf{r}^{\prime}\right)}{\left|\mathbf{r}-\mathbf{r}^{\prime}\right|}
$$

The term $\left(4 \pi \cdot\left|\mathbf{r}-\mathbf{r}^{\prime}\right|\right)^{-1}$ is called a GREEN's function or an influence function. The effectiveness of how the cause $\nabla^{2} \rho(\mathbf{r})$ gives rise to the effect $\rho(\mathbf{r})$ depends on the reciprocal of the distance between the element of the LAPLACIAN of the density $\nabla^{2} \rho\left(\mathbf{r}^{\prime}\right) \mathrm{d} \mathbf{r}^{\prime}$ and the point of interest given by $\mathbf{r}$.

The integral of $\operatorname{LS}\left(\mathbf{r}, \mathbf{r}^{\prime}\right)$ over the basin of an atom or group of atoms, has been called the source function (SF) contribution, $S(r, \Omega)$, from that atom or group of atoms to $\rho(\mathbf{r})$,

$$
\int_{\Omega} \mathrm{LS}\left(\mathbf{r}, \mathbf{r}^{\prime}\right) \cdot d \mathbf{r}^{\prime} \equiv S(\mathbf{r}, \Omega)
$$

and the electron density at any point within the atom can be thus viewed as determined solely by an internal SF self-contribution and by SF contributions from the remaining atoms or groups of atoms within a molecule: 


$$
\rho(\mathbf{r})=S(\mathbf{r}, \Omega)+\sum_{\Omega^{\prime} \neq \Omega} S\left(\mathbf{r}, \Omega^{\prime}\right)
$$

This equation affords an interpretation of the source function as giving a measure of the relative importance of an atom's or group's contribution to the density at any point.

\subsubsection{The Electronic Energy Density}

The electronic energy density $E(\mathbf{r})$ of the electron density distribution is defined as

$$
E(\mathbf{r})=G(\mathbf{r})+V(\mathbf{r})
$$

In this equation, $V(\mathbf{r})$ is the potential energy, including exchange, at the point $\mathbf{r}$ and $G(\mathbf{r})$ is a local one-electron kinetic energy density.

It is common to express the LAPLACIAN field by the function $L(\mathbf{r})$, defined as

$$
L(\mathbf{r}) \equiv-\left(\frac{\hbar}{4 m}\right) \nabla^{2} \rho(\mathbf{r})
$$

The relation between $L(\mathbf{r})$ and the components of the local energy density $E(\mathbf{r})$ is given by the equation

$$
-L(\mathbf{r})=\left(\frac{\hbar}{4 m}\right) \nabla^{2} \rho(\mathbf{r})=2 G(\mathbf{r})+V(\mathbf{r})
$$

The latter expression gives an exact explicit relationship between the second derivative of the electron density, $\nabla^{2} \rho(\mathbf{r})$, the electronic kinetic energy density $G(\mathbf{r})$ (calculated using the KIRZHNITS approximation ${ }^{[163]}$ ) and the electronic potential energy density $V(\mathbf{r})$.

The electronic energy density is a straight criterion for the recognition of the atomic interaction type: $E(\mathbf{r})<0$ at the BCP is observed in shared-type (covalent) atomic bonding, while $E(\mathbf{r}) \geq 0$ is observed in purely closed-shell (ionic) interactions. ${ }^{[66]}$ 


\section{EXPERIMTENTAL SECTION}

The electron density distributions of all compounds in this thesis are the results of high-resolution low-temperature X-ray diffraction experiments performed at an inhouse facility. The requirements on the accuracy of the data for a subsequent multipole refinement and a meaningful topological analysis are extremely high. As good data requires a good crystal, the efforts to conserve the quality of the crystals are presented in this chapter. A few words will also be spent on the data acquisition as well as on the data reduction and refinement procedures.

\subsection{Crystal Application, Data Collection and Data Reduction}

The single crystals under examination were grown from solutions of the respective compounds at low temperatures. Usually, these crystals are low-melting and sensitive to moisture and oxygen. Therefore, the crystals were removed from a SCHLENK flask under argon atmosphere and handled in perfluorinated polyether oil under a cold $\mathrm{N}_{2}$ gas stream with the help of an X-Temp 2 device. ${ }^{[26,28]}$ Suitable single crystals were selected and prepared under a polarization microscope (for the detection of twinning and the presence of satellites). Each oil-coated single crystal was then mounted on a glass fiber glued to a magnetic pin. ${ }^{[25]}$ To facilitate and accelerate this procedure, a table for the crystal application was build in the course of this thesis (Figure 3-1).

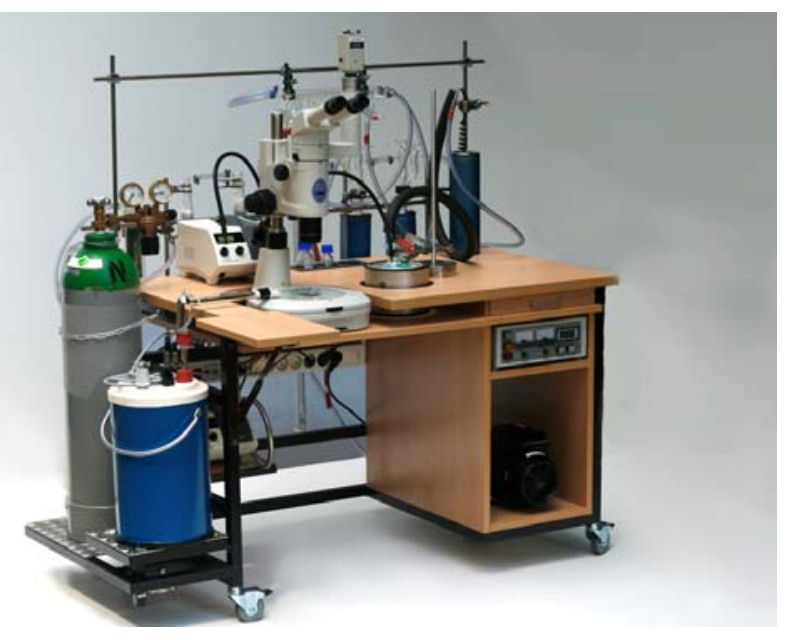

Figure 3-1: Table for crystal application. 
The table has two desk boards at different heights. While the lower one is continuous, the upper one has several cutouts that ensure a safe positioning of the equipment (Figure 3-2).

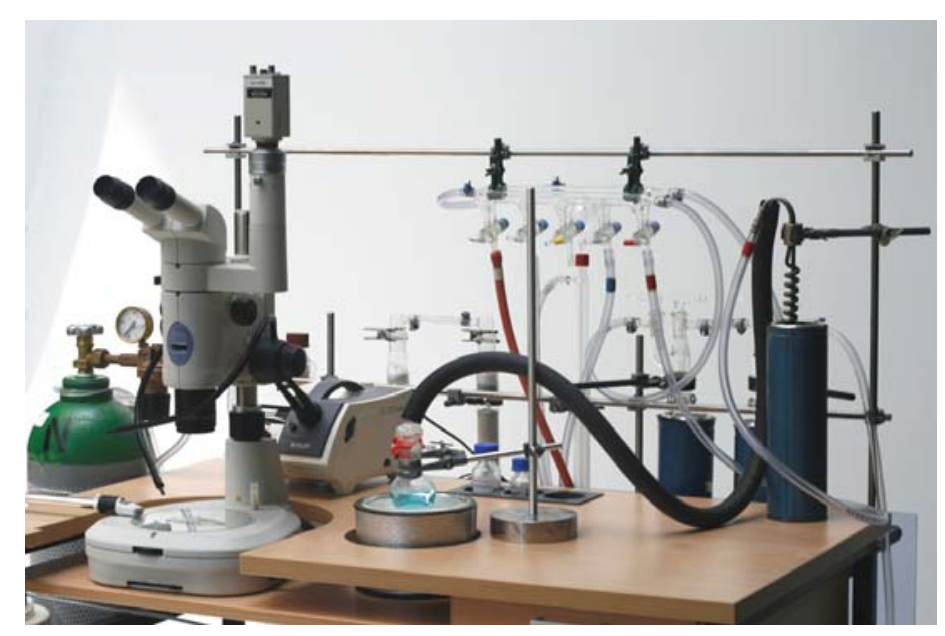

Figure 3-2: Table board with equipment.

The distance between the two desk boards fits exactly the height of the foot of the microscope, for which a cutout has been made in the upper desk board (Figure 3-3, 1). Next to it, a cutout for a standard dish-shaped DEWAR flask (Figure 3-3 and Figure 3-4, 2) has been left. The DEWAR can be filled with a coolant solution in which the flask containing the crystals can be immerged. That way, the crystals can be kept below their melting temperature during the application procedure. To have both hands for working, the flask can be fastened to a goose-neck or a tripod (Figure 3-3, 3) which has been attached to the table. After the successful crystal application, the DEWAR can easily be removed to depollute the coolant. Apart from keeping the crystals at the right temperature, they have to be protected against moisture and oxygen. However, the flask has to be opened in order to remove the crystals. Therefore, dry gas (argon or nitrogen) is blown over the sample, while the flask is open. To provide the conditions for working under an inert gas atmosphere, all premises have been taken for the installation of a SCHLENK line. A framework for the fastening of the line has been attached to the table (Figure 3-3 and Figure 3-4, 4) as well as racks for the gas bottle (Figure 3-3 and Figure 3-4, 5) and the pump (Figure 3-4, 6). To ensure the dryness of the gas, a gas drying system was fixed at the back side of the table (Figure 3-5). To protect the drying system against collision damage, a pane of acrylic glass (Figure 3-3, 7) was installed behind it at the very back side of the table. 


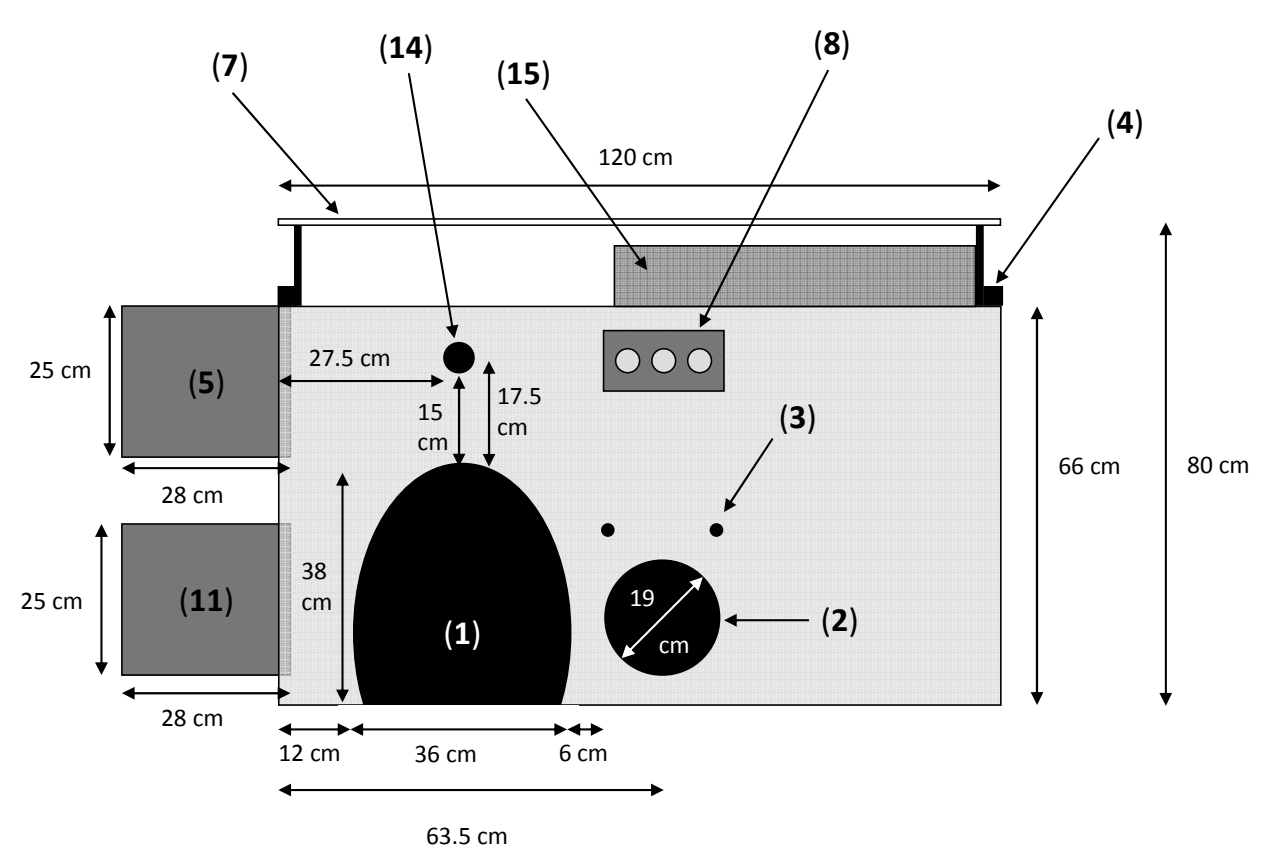

Figure 3-3: Construction plan of the crystal application table (top view).

(1) Cutout for microscope; (2) cutout for dish-shaped DEWAR flask; fastening facility for (3) flask and (4) SCHLENK line; (5) tray for gas bottle; (7) pane of acrylic glass; (8) Bottle holder; (11) tray for cooling device; (14) feed through for light conductor; (15) cable channel.

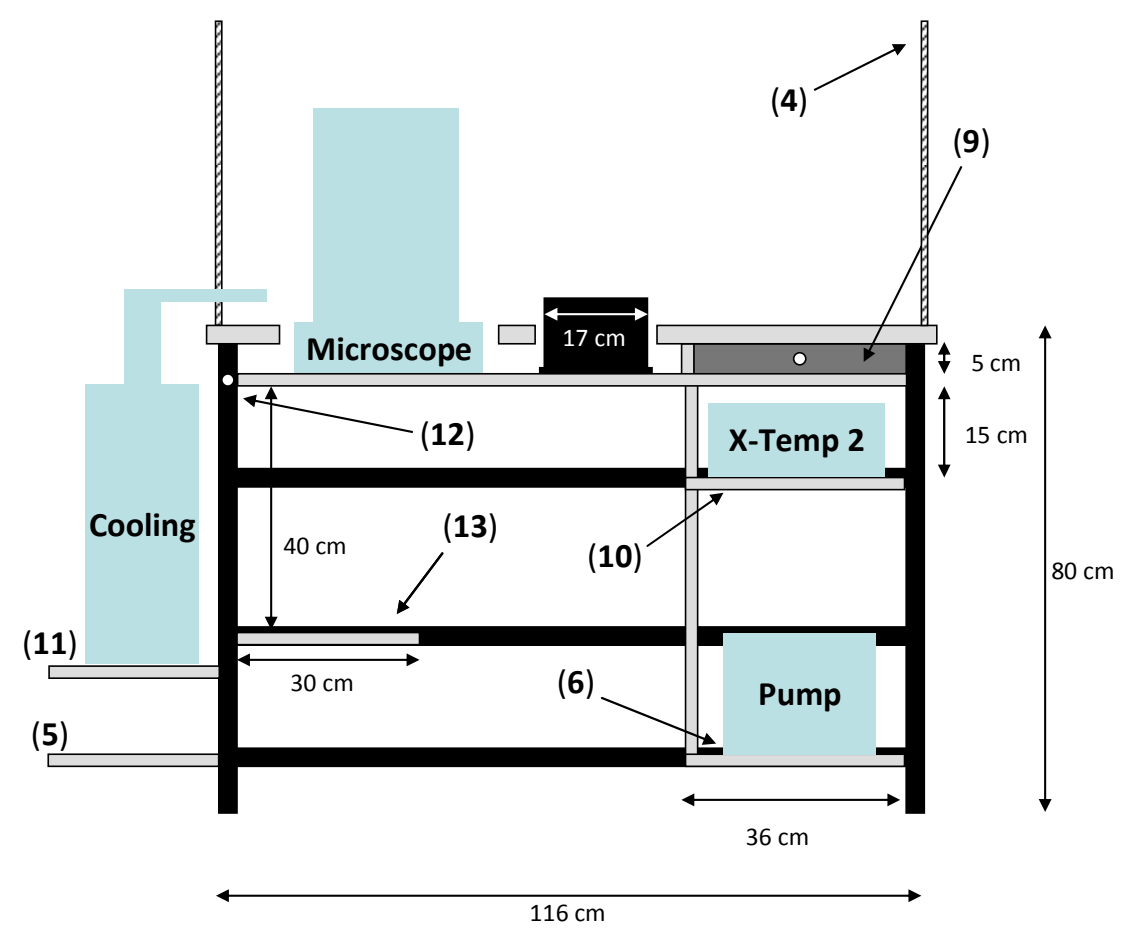

Figure 3-4: Construction plan of the crystal application table (front view).

(4) Fastening facility for SCHLENK line; tray for (5) gas bottle and (6) pump; (9) drawer; tray for (10) X-Temp 2 and (11) cooling device; (12) small table board for faster mounting; (13) tray for additional light source for microscope. 
After the crystals are removed from the flask, they are placed on a microscope slide in a drop of oil. The oil needed for crystal application is stored in small bottles. A countersunk tablet (Figure $3-3,8$ ) provides space for three bottles to prevent them from being knocked over. As these bottles tend to get sticky on the outside, the bottle holder can be taken out for cleaning purposes. Additionally, a drawer (Figure 3-4, 9) has been placed between the two desk boards, where the fine instruments (scalpel, application needle, forceps, etc.) can be stored within reach.

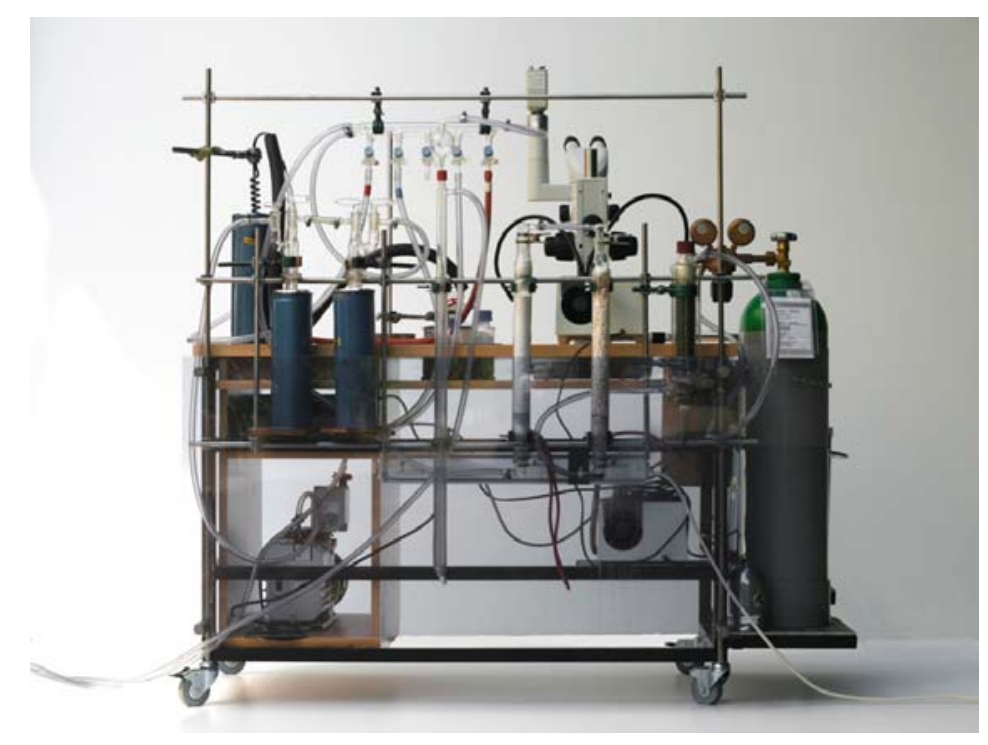

Figure 3-5: Back view of the table for crystal mounting with gas drying system.

To ensure the cooling during the manipulations under the microscope, the X-Temp 2 device is utilized. A rack has been installed for the control unit (Figure 3-4, 10) as well as for the cooling device itself (Figure 3-3 and Figure 3-4, 11). The tray for the cooling is height-adjustable to ensure that the cold gas stream hits the crystals on the microscope slide. Crystals that are extremely sensitive can also be removed from the SCHLENK flask at a small extra table (Figure 3-4, 12). This board is attached close to the cooling so that a cold nitrogen gas stream can be blown over the sample all the time - even on the way from the flask to the microscope.

An additional light source for the microscope was placed under the table (Figure 3-4, 13) and the light conductor was run through both desk boards (Figure 3-3, 14). However, it turned out that a placement of the additional light source on the table is much more comfortable (see Figure 3-1, Figure 3-2, and Figure 3-5, where one of the additional light sources is placed behind the microscope). 
The table has been equipped with wheels, to allow for a movement of the whole assembly towards the front of the hood of the diffractometer. This is also the reason, why all the instrumentation was fixed to the table. Additionally, a cable channel (Figure 3-3, 15) for the electric cables was installed to prevent them from getting tangled up when moving the table. By moving the table, the distance between the microscope and the hood of the diffractometer can be shortened, which reduces the time, when the crystal is only protected against moisture and oxygen by a thin film of oil without any cooling. This table was used for the application of all crystals examined within this thesis.

After the transfer from the microscope to the diffractometer, the crystals were shock-cooled together with the coating oil in the low-temperature gas stream of the diffractometer's cryo-system. The amorphous frozen oil served as glue and protected the sensitive compounds, together with the nitrogen gas stream, from moisture and oxygen during the measurement. The cooling was accomplished with a Kryoflex open flow nitrogen cooling device attached to the diffractometer. To minimize thermal motion, all compounds were measured at the lowest possible temperature.

All the data, used in this thesis, were collected on a rotating anode. The BRUKER TXS Mo rotating anode is mounted on a three-circle D8 goniometer and equipped with INCOATEC Helios mirror optics and an APEX II detector (Figure 3-6). This setup provides very intense and brilliant, monochromatic $\operatorname{MoK}(\alpha)$ radiation $(\lambda=0.71073 \AA$ ).

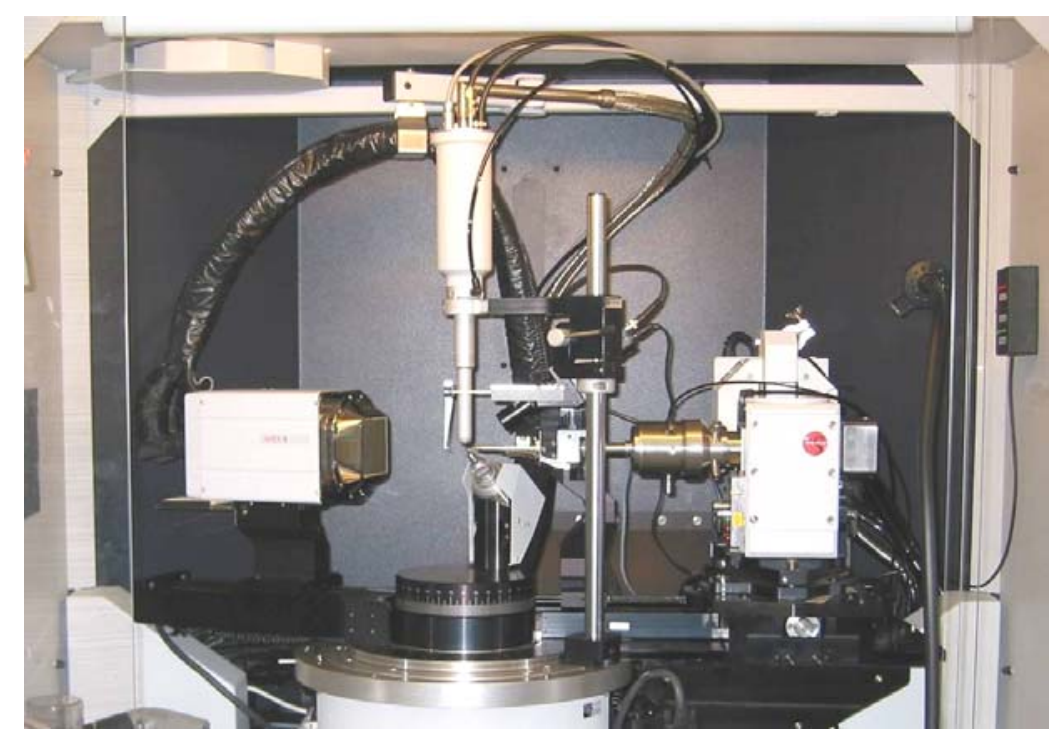

Figure 3-6: BRUKER TXS Mo rotating anode equipped with an APEX II CCD detector and INCOATEC Helios mirror optics as monochromator. 
In contrast to a standard diffraction experiment where data up to a diffraction angle of $\sin \theta / \lambda=0.624 \AA$ is sufficient, for electron density studies data up to a diffraction angle of at least $\sin \theta / \lambda=1.08 \AA$ have to be collected. The reflections at high BRAGG angles are needed in order to get reliable atomic positions. Furthermore, the additional data is necessary to get a reasonable data-to-parameter ratio because of the larger number of parameters in a multipole refinement. What is more, high redundancies of the low-angle reflections (from which the more diffuse parts of the EDD are extracted) are indispensable to get the best estimate of the scattering factors.

However, the size of the APEX II detector limits the recorded resolution range of a single image. At a detector position of $2 \theta=-31^{\circ}$ at $5.0 \mathrm{~cm}$ detector-to-sample distance a range of $\sin \theta / \lambda$ from 0 to $0.70 \AA^{-1}$ is covered. Hence, the reflections had to be recorded with two different detector positions in order to gain the desired high- and low-order data. The second detector position was chosen to ensure maximum overlap of the reflections and thus sensible scaling of the data was possible. All scans of the data collections were performed in an $\omega$-scan mode with a stepsize of $-0.3^{\circ}$ at fixed $\varphi$-angles. Details of the data collections are presented in Table 3-1 to Table 3-4.

The data collection was monitored with the APEX2 software package, ${ }^{[164]}$ which was also used for the cell determination. The collected frames were integrated with SAINT ${ }^{[165]}$ using the $3 d$ profiling method described by KABSCH. ${ }^{[166]}$ The integration routine was repeated several times using optimized integration parameters and orientation matrices in each step.

Absorption correction, scaling, and merging of the individually integrated data subsets was performed with SADABS 2006/4. ${ }^{[167]}$ SADABS provides an empirical absorption correction based on the relation of symmetry-equivalent reflections. SADABS 2006/4 is a version of SADABS modified for charge density purposes in a way, that all batches can be corrected for absorption at one time correctly and that an optimal scaling and merging result is obtained. Additionally, the $h k l$-file output is compatible with XD2006. $^{[47]}$ XPREP $^{[168]}$ was used to determine the space group prior to the SADABS data procession, being crucial for a correct treatment. 


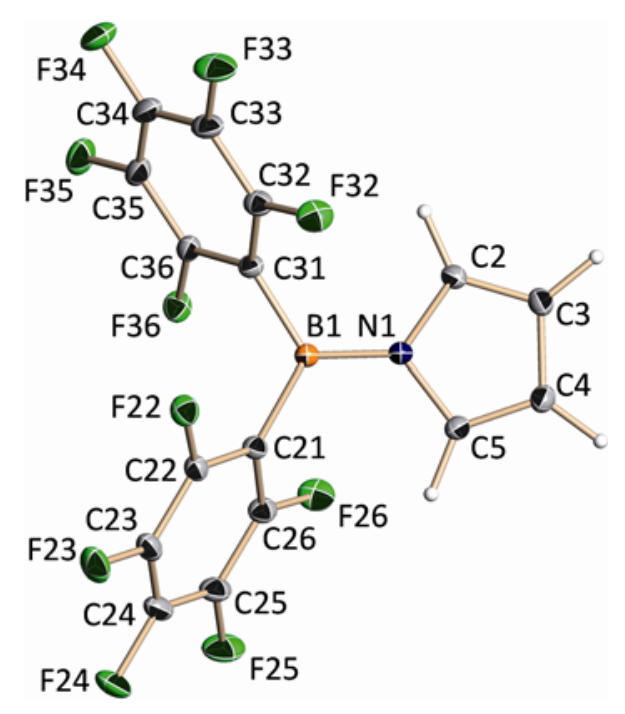

Figure 3-7: Molecular structure representation of $\left[\left(\mathrm{C}_{6} \mathrm{~F}_{5}\right)_{2} \mathrm{~B}\left(\mathrm{~N}_{4} \mathrm{H}_{4}\right)\right]$ (1) with anisotropic displacement parameters depicted at the $50 \%$ probability level.

Table 3-1: Crystallographic data for the low- and high-order data collection of $\left[\left(\mathrm{C}_{6} \mathrm{~F}_{5}\right)_{2} \mathrm{~B}\left(\mathrm{~N}_{4} \mathrm{H}_{4}\right)\right](\mathbf{1})$.

\begin{tabular}{ll|ll}
\hline \multicolumn{3}{l}{ identification code: stefan } & \multicolumn{3}{l}{} \\
\hline$a[\AA]$ & $17.056(2)$ & crystal dimension $\left[\mathrm{mm}^{3}\right]$ & $0.40 \times 0.40 \times 0.30$ \\
$b[\AA]$ & $11.7116(16)$ & crystal system & monoclinic \\
$c[\AA]$ & $7.5590(10)$ & space group & $C 2 / \mathrm{c}$ \\
$\beta\left[^{\circ}\right]$ & $92.120(2)$ & $V\left[\AA^{3}\right]$ & $1508.9(4)$ \\
molecular weight $[\mathrm{g} / \mathrm{mol}]$ & 411.01 & formula & $\mathrm{C}_{16} \mathrm{~F}_{10} \mathrm{BNH}_{4}$ \\
\hline
\end{tabular}

\begin{tabular}{ll|ll}
\hline \multicolumn{2}{c}{ low order data } & \multicolumn{2}{c}{ high order data } \\
\hline distance $_{\text {detector-to-sample }}[\mathrm{cm}]$ & 5.0 & distance detector-to-sample $[\mathrm{cm}]$ & 4.0 \\
exposure time $[\mathrm{s}]$ & 15 & exposure time $[\mathrm{s}]$ & 180 \\
\hline
\end{tabular}

\begin{tabular}{ll|ll}
\hline overall & \multicolumn{3}{l}{} \\
\hline data coll. temperature $[\mathrm{K}]$ & $100(2)$ & $\mathrm{F}(000)$ & 808 \\
$\mu\left[\mathrm{mm}^{-1}\right]$ & 0.193 & $\mathrm{~T}_{\min } / \mathrm{T}_{\max }$ & $0.8673 / 0.9824$ \\
reflections collected & 58070 & reflections unique & 8169 \\
$\mathrm{R}_{\text {int }}$ & 0.0235 & redundancy & 6.94 \\
\hline
\end{tabular}




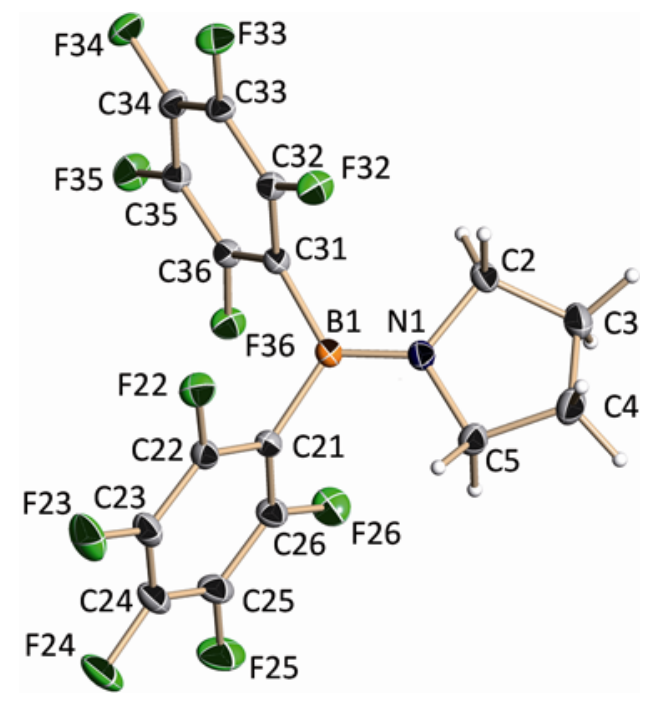

Figure 3-8: Molecular structure representation of $\left[\left(\mathrm{C}_{6} \mathrm{~F}_{5}\right)_{2} \mathrm{~B}\left(\mathrm{~N}_{4} \mathrm{H}_{8}\right)\right]$ (2) with anisotropic displacement parameters depicted at the $50 \%$ probability level.

Table 3-2: Crystallographic data for the low- and high-order data collection of $\left[\left(\mathrm{C}_{6} \mathrm{~F}_{5}\right)_{2} \mathrm{~B}\left(\mathrm{~N}_{4} \mathrm{H}_{8}\right)\right]$ (2).

\begin{tabular}{ll|ll}
\hline \multicolumn{4}{l}{ identification code: erkan } \\
\hline$a[\AA]$ & $9.716(2)$ & crystal dimension $\left[\mathrm{mm}^{3}\right]$ & $0.20 \times 0.20 \times 0.10$ \\
$b[\AA]$ & $17.515(4)$ & crystal system & monoclinic \\
$c[\AA]$ & $10.362(2)$ & space group & $P 2(1) / c$ \\
$\beta\left[^{\circ}\right]$ & $115.927(3)$ & $V\left[\AA^{3}\right]$ & $1585.8(6)$ \\
molecular weight $[\mathrm{g} / \mathrm{mol}]$ & 415.04 & formula & $\mathrm{C}_{16} \mathrm{~F}_{10} \mathrm{BNH}_{8}$ \\
\hline
\end{tabular}

\begin{tabular}{ll|ll}
\hline \multicolumn{2}{c}{ low order data } & \multicolumn{2}{c}{ high order data } \\
\hline distance $_{\text {detector-to-sample }}[\mathrm{cm}]$ & 5.0 & distance $_{\text {detector-to-sample }}[\mathrm{cm}]$ & 4.0 \\
exposure time $[\mathrm{s}]$ & $5 / 10$ & exposure time $[\mathrm{s}]$ & 90 \\
\hline
\end{tabular}

\begin{tabular}{ll|ll}
\hline overall & \multicolumn{3}{l}{} \\
\hline data coll. temperature $[\mathrm{K}]$ & $100(2)$ & $\mathrm{F}(000)$ & 824 \\
$\mu\left[\mathrm{mm}^{-1}\right]$ & 0.184 & $\mathrm{~T}_{\min } / \mathrm{T}_{\max }$ & $0.9200 / 0.9567$ \\
reflections collected & 139643 & reflections unique & 17010 \\
$\mathrm{R}_{\text {int }}$ & 0.0302 & redundancy & 8.19 \\
\hline
\end{tabular}




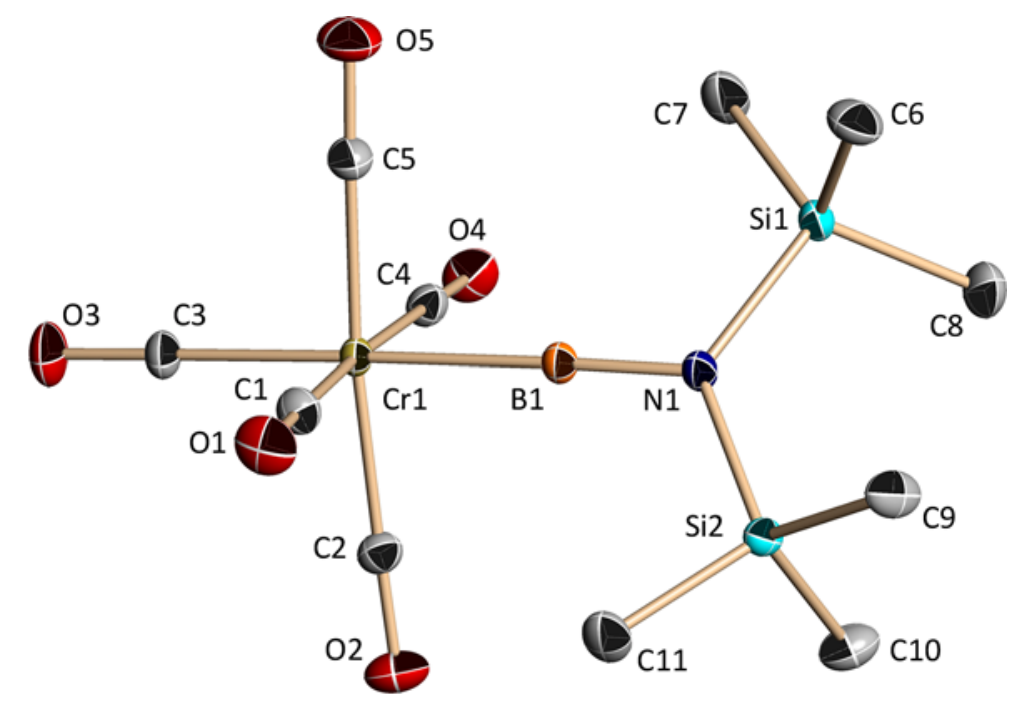

Figure 3-9: Molecular structure representation of $\left[(\mathrm{CO})_{5} \mathrm{CrBN}\left(\mathrm{SiMe}_{3}\right)_{2}\right]$ (3) with anisotropic displacement parameters depicted at the $50 \%$ probability level and hydrogen atoms omitted for clarity.

Table 3-3: Crystallographic data for the low- and high-order data collection of $\left[(\mathrm{CO})_{5} \mathrm{CrBN}\left(\mathrm{SiMe}_{3}\right)_{2}\right](3)$.

\begin{tabular}{lc|ll}
\hline \multicolumn{3}{l}{ identification code: anker } & \multicolumn{3}{l}{} \\
\hline$a[\AA]$ & $9.0780(7)$ & crystal dimension $\left[\mathrm{mm}^{3}\right]$ & $0.200 .15 \times 0.10$ \\
$b[\AA]$ & $9.1347(7)$ & crystal system & triclinic \\
$c[\AA]$ & $11.8768(9)$ & space group & $P \overline{1}$ \\
$\alpha 109.2850(10), \beta 97.4700(10), \gamma 102.2800(10)\left[{ }^{\circ}\right]$ & $V\left[\AA^{3}\right]$ & $886.68(12)$ \\
molecular weight $[\mathrm{g} / \mathrm{mol}]$ & 363.25 & formula & $\mathrm{C}_{11} \mathrm{H}_{18} \mathrm{BCrNO}_{5} \mathrm{Si}_{2}$ \\
\hline
\end{tabular}

\begin{tabular}{l|ccc}
\hline & low order data & med-order data & high order data \\
\hline distance $_{\text {detector-to-sample }}[\mathrm{cm}]$ & 5.0 & 5.0 & 4.0 \\
exposure time $[\mathrm{s}]$ & $5 / 8$ & $30 / 45$ & 60 \\
\hline
\end{tabular}

\begin{tabular}{ll|ll}
\hline \multicolumn{3}{l}{ overall } & \multicolumn{3}{l}{} \\
\hline data coll. temperature $[\mathrm{K}]$ & $100(2)$ & $\mathrm{F}(000)$ & 376 \\
$\mu\left[\mathrm{mm}^{-1}\right]$ & 0.795 & $\mathrm{~T}_{\min } / \mathrm{T}_{\max }$ & $0.7804 / 0.8395$ \\
reflections collected & 216978 & reflections unique & 24056 \\
$\mathrm{R}_{\text {int }}$ & 0.0263 & redundancy & 8.73 \\
\hline
\end{tabular}




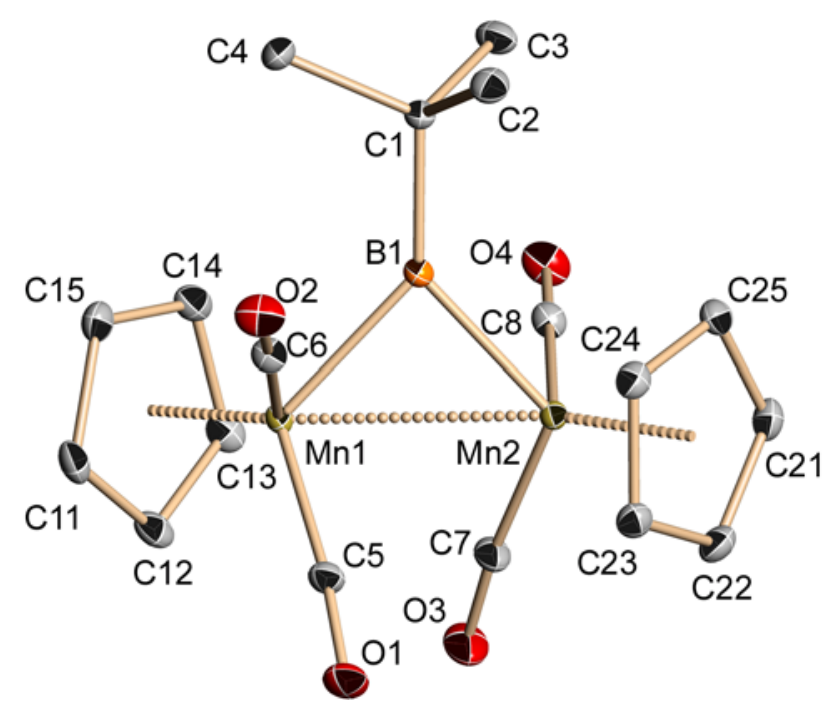

Figure 3-10: Molecular structure representation of $\left[\left\{C p(C O){ }_{2} M n\right\}_{2}\left(\mu-B^{t} B u\right)\right](4)$ with atomic displacement parameters depicted at the $50 \%$ and hydrogen atoms omitted for clarity.

Table 3-4: Crystallographic data for the low- and high-order data collection of $\left[\left\{\mathrm{Cp}(\mathrm{CO})_{2} \mathrm{Mn}\right\}_{2}\left(\mu-\mathrm{B}^{t} \mathrm{Bu}\right)\right](4)$.

\begin{tabular}{ll|ll}
\hline \multicolumn{4}{l}{ identification code: burz_ed } \\
\hline$a[\AA]$ & $8.5084(4)$ & crystal dimension $\left[\mathrm{mm}^{3}\right]$ & $0.25 \times 0.22 \times 0.20$ \\
$b[\AA]$ & $13.2181(6)$ & crystal system & monoclinic \\
$c[\AA]$ & $15.6351(7)$ & space group & $\mathrm{P} 2(1) / \mathrm{n}$ \\
$\beta\left[^{\circ}\right]$ & $95.9230(10)$ & $V\left[\AA^{3}\right]$ & $1749.01(14)$ \\
molecular weight $[\mathrm{g} / \mathrm{mol}]$ & 420.02 & formula & $\mathrm{C}_{18} \mathrm{H}_{19} \mathrm{BMn}_{2} \mathrm{O}_{4}$ \\
\hline
\end{tabular}

\begin{tabular}{l|ccc}
\hline & low order data & med-order data & high order data \\
\hline distance $_{\text {detector-to-sample }}[\mathrm{cm}]$ & 6.0 & 6.0 & 6.0 \\
exposure time $[\mathrm{s}]$ & 5 & 10 & 30 \\
\hline
\end{tabular}

\begin{tabular}{ll|ll}
\hline overall & \multicolumn{3}{l}{} \\
\hline data coll. temperature $[\mathrm{K}]$ & $100(2)$ & $\mathrm{F}(000)$ & 856 \\
$\mu\left[\mathrm{mm}^{-1}\right]$ & 1.463 & $\mathrm{~T}_{\min } / \mathrm{T}_{\max }$ & $0.7508 / 0.8049$ \\
reflections collected & 183988 & reflections unique & 23866 \\
$\mathrm{R}_{\text {int }}$ & 0.0312 & redundancy & 7.67 \\
\hline
\end{tabular}




\subsection{IAM Refinement}

The IAM refinement was performed following a common procedure for all compounds. The structures were solved with direct methods using SHELXS. ${ }^{[169]}$ A conventional IAM refinement with all data was performed against $F^{2}$ with SHELXL-97. ${ }^{[170]}$ The refined IAM served as starting model for the subsequent multipole refinements. The positional and anisotropic displacement parameters of all non-hydrogen atoms were refined with high-order data $\left((\sin \theta / \lambda)_{\min }=1.00 \AA^{-1}\right)$. The bias introduced from bonding densities is very small beyond the applied limit. ${ }^{[138]}$ These parameters were kept fixed during the subsequent refinement steps.

The hydrogen atoms were identified by a difference FOURIER analysis using loworder data $\left((\sin \theta / \lambda)_{\max }=0.50 \AA^{-1}\right)$. Based on the same subset of data, the hydrogen atom positions were refined without the use of any distance restraints, but with an isotropic riding model. This means, that the thermal motion parameters $U_{\text {iso }}$ of the hydrogen atoms were constrained to be $1.5 \cdot U_{\text {eq }}$ of the pivot atom for the methyl groups and $1.2 \cdot U_{\text {eq }}$ for all other atoms, respectively. After convergence, the hydrogen atoms were shifted along their bonding vectors to neutron diffraction distances of $1.085 \AA$ and $1.076 \AA$ for hydrogen atoms bonded to $\mathrm{sp}^{3}$ and $\mathrm{sp}^{2}$ carbon atoms, respectively. ${ }^{[134]}$ The molecular structures with the anisotropic displacement parameters (ADPs) depicted at a $50 \%$ probability level resulting from the IAM refinements are shown in Figure 3-7 to Figure 3-10 (vide supra).

In all refinements the function $M\left(p_{i}, k\right)$ (Eq. 3-1) was minimized. The weighting scheme, usually applied in SHELXL (Eq. 3-2), is optimized for a spherical-atom refinement. As there is no possibility to further refine the weighting scheme during the multipole refinement, any weighting scheme applied would introduce bias into the data. Therefore, only statistical weights (Eq. 3-3) were used.

$$
\begin{gathered}
M\left(p_{i}, k\right)=\sum_{\mathbf{H}} w_{\mathbf{H}}\left[k\left|F_{o b s}(\mathbf{H})\right|^{2}-\left|F_{c a l c}(\mathbf{H})\right|^{2}\right]^{2}=\min \\
w_{H}^{-1}=\sigma_{H}^{2} F_{o b s}^{2}+(g 1 \cdot P)^{2}+g 2 \cdot P \text { with } P=\left(\frac{F_{o b s}^{2}+2 F_{c a l c}^{2}}{3}\right) \\
w_{H}=\frac{1}{\sigma_{H}^{2}}
\end{gathered}
$$




\subsection{Multipole Refinement}

The multipole refinements were not performed according to a standard procedure. However, some basic conditions have been followed in the refinement of all compounds. These common features will be described primarily. Important deviations from a standard procedure will be given for each compound afterwards.

For the description of the overall electron density distribution, including the density deformations due to bonding, the aspherical atom approach of HANSEN and COPPENS ${ }^{[43]}$ was applied. As already described above in more detail, within this framework, the ED is divided into three components: core and spherical valence densities and the valence deformation density.

For all refinements, core and spherical valence densities composed of the relativistic DIRAC-FOCK wave functions reported by SU, COPPENS and MACCHI (bank file SCM) were chosen. ${ }^{[171]}$ Single-zeta orbitals with energy-optimized SLATER exponents were used for the deformation density terms. ${ }^{[140]}$ The radial fit of these functions was optimized by refinement of the expansion-contraction parameters $\kappa$ and $\kappa^{\prime}$. Multipoles up to the hexadecapolar level were used for the description of all nonhydrogen atoms, while the multipolar expansion for the hydrogen atoms was truncated at the dipolar level using only bond-directed dipoles. All multipoles $\left(n_{l}=1\right.$ to 4 ) of one atom shared the same $\kappa$-set (KEEP KAPPA constraint). However, separate $\kappa$ and $\kappa^{\prime}$ were used for different elements and elements in different chemical environments. To derive adequate parameters for the aspherical density distribution of the hydrogen atoms, $\kappa$ and $\kappa^{\prime}$ values suggested by VoLkov et al. ${ }^{[172]}$ were introduced and kept fixed during the refinements.

Atomic coordinates and anisotropic displacement parameters of all non-hydrogen atoms were refined. The $\mathrm{C}-\mathrm{H}$ distances were constrained to standard values determined by neutron scattering experiments: ${ }^{[134]} 1.085 \AA$ and $1.076 \AA$ for hydrogen atoms bonded to $s p^{3}$ and $s p^{2}$ carbon atoms, respectively (RESET BOND). The isotropic thermal motion parameters were refined with a "riding model" $\left(U_{\text {iso }}(H)=1.5 U_{\text {eq }}(C)\right.$ for the $\mathrm{H}$-atoms bonded to $s p^{3}$ and $U_{\text {iso }}(\mathrm{H})=1.2 U_{\text {eq }}(\mathrm{C})$ for those bonded to $s p^{2}$ carbon atoms). In one of the last steps of each refinement the positions of the hydrogen atoms were refined with a with low-order data only $\left((\sin \theta / \lambda)_{\max }=0.50 \AA^{-1}\right)$ to allow for an adjustment of the positions of the hydrogen atoms to the slightly altered positions 
of the pivot atoms. The bond distances of the hydrogen atoms always stayed close to the neutron diffraction determined standard values. However, the hydrogen atoms were again shifted along their bonding vector to the exact neutron diffraction distances and kept fixed to avoid correlations that occur when refining them together with the other parameters.

The multipole refinements were carried out on $F^{2}$ with the full-matrix-least-squares refinement program XDLSM implemented in the XD2006 program package ${ }^{[47]}$ using statistical weights and only those intensities included in the refinement with $I>3 \sigma(I)$.

Several models, differing in the degree of applied chemical constraints and local non-crystallographic symmetry were refined and compared. The complexity of the refined model was increased in a stepwise manner. In the first steps as much chemical and non-crystallographic symmetry constraints as possible were applied. Except for those listed with each molecule, these constraints were discarded in a stepwise manner. All remaining constraints were tested and confirmed. In the final cycles all parameters except $\kappa^{\prime}$ were refined together until convergence was reached. $\kappa^{\prime}$ was not refined together with the other parameters as it tends to cause correlations. Therefore, if refined, it was refined in a block refinement.

Special procedures for each molecule were only applied to meet special requirements of the individual molecules. These are described in the following together with a presentation of the quality criteria of each multipole refinement.

(1) and (2). The mono- and multipole populations of the hydrogen atoms of each heterocycle were constrained to each other. The model which led to the lowest $R$-values $\left(1: R_{\text {all }}\left\{F^{2}\right\}=0.037 ; N_{\text {ref }} / N_{\text {para }}=12.24 ; 2: R_{\text {all }}\left\{F^{2}\right\}=0.0257 ; N_{\text {ref }} / N_{\text {para }}=12.81\right)$, standard deviations, and a flat and featureless residual density distribution (1: -0.144 to $0.252 ; 2$ : -0.168 to 0.187 ) was selected for the discussion.

(3). The $n_{\text {l }}$ values of the SLATER type radial functions were adjusted to recommended values $n_{l}=4,4,6,8(I=1,2,3,4)$ for the third row atom silicon. ${ }^{[43]}$ Recent studies proved that the density functions of third row atoms are fitted better with these $n_{l}$ values while for all other atoms the conventional sets of $n_{\text {, remain sufficient. }}{ }^{[173-175]}$ The model which led to the lowest $R$-values $\left(R_{\text {all }}\left\{F^{2}\right\}=0.0212 ; N_{\text {ref }} / N_{\text {para }}=42.71\right)$, standard deviations, and a flat residual density $(-0.207$ to 0.287$)$ was selected for the discussion. 
(4). The radial terms used for the manganese atoms were the relevant-order FOURIER-BESSEL transforms of the SU and COPPENS wave functions. As the $3 d$ and $4 \mathrm{~s}$ valence orbitals of $3 d$ transition metals show significantly different radial extensions, it was attempted to refine the $4 s$ population independently by the second monopole. All such models were unstable or did not lead to physically meaningful populations. In the model finally used the $4 s^{2}$ scattering contribution is included in the "core" contribution. During the multipole refinement a local non-crystallographic $C_{3}$-axis was assumed along the $B(1)-C(1)$ bond for the tert-butyl-group and the carbon atoms were constrained to each other. The hydrogen atoms bonded to the ring carbon atoms were constrained to be equal as well as the hydrogen atoms of the tert-butyl-group. The model which led to the lowest $R$-values $\left(R_{\text {all }}\left\{F^{2}\right\}=0.0182 ; N_{\text {ref }} / N_{\text {para }}=24.12\right)$, standard deviations, and a flat and featureless residual density $(-0.187$ to 0.516$)$ was selected for the discussion.

\subsection{Theoretical Calculations}

The quantum chemical calculations have been kindly provided by Dr. Julian HENN (Göttingen) and Prof. Dr. S. GRIMME (Münster). To allow for a classification of these results, the methodological approaches that led to these results are summarized here very briefly. Whenever the results from theoretical calculations are discussed in this thesis, their values will be given in italics.

(1) and (2). The quantum chemical calculations have been performed with slightly modified versions of the TURBOMOLE suite of programs. ${ }^{[176]}$ As GAUSSIAN atomic orbital basis, large triple-zeta sets of AHLRICHS et al. ${ }^{[177]}$ have been employed. In standard notation these are $[5 s 3 p 1 d]$ for carbon and fluorine and [3s1p] for hydrogen atoms. For boron and nitrogen atoms, the polarization part of the basis is improved (i.e. to [5s3p2d1f] quality). This basis set provides results very close to the basis set limit in DFT calculations of structures and simple properties like electron densities. All geometries have been fully optimized employing $C_{2}$-symmetry restrictions at the DFT level using the PBEh hybrid density functional. ${ }^{[178,179]}$

(4). A full gas phase optimization was carried out employing the bp exchangecorrelation functional ${ }^{[180,181]}$ and the TZVP basis set ${ }^{[177]}$ with TURBOMOLE. ${ }^{[176]}$ The 
optimization yields an elongated $\mathrm{Mn}-\mathrm{Mn}$ distance, reflecting a flat energy potential surface with respect to small changes in the $\mathrm{Mn}-\mathrm{Mn}$ distance and shortcomings of the density functional.

\subsection{Topological Analysis}

The electron densities obtained by the above described procedures were analyzed according to BADER'S QTAIM ${ }^{[71]}$ with XDPROP $^{[47]}$ for the experimental and with AIM2000 ${ }^{[182]}$ for the theoretical data, respectively. 



\section{Electron Density Studies ON LeWIS Acidic ORGANOBORON COMPLEXES}

\subsection{Chemistry and Applications of LEWIS Acidic Organoboron Complexes}

Organoboron complexes are the organic derivatives of borane $\mathrm{BH}_{3}$, in which formally the hydrogen atoms are replaced by organic substituents. These complexes are important reagents in organic chemistry, applied for example in hydroboration or SUZUKI coupling reactions. ${ }^{[183]}$ Just like the parent boranes, these compounds are strong electrophiles which is due to the electron-deficiency of the boron atom. As a result, these compounds act as LEWIS acids. ${ }^{[184-186]}$ This LEWIS acidity is enhanced, if the organic substituents are chosen to be perfluorated alkyl substituents. As in the boron trihalides $\mathrm{BX}_{3}$, the highly electronegative ligands induce strong LEWIS acidity on the boron atom. However, in contrast to $\mathrm{BX}_{3}$, the perfluoroalkylboranes do not show the same susceptibility towards hydrolysis. Thus, first investigations on perfluorated alkylboranes were carried out already in the 1950 s. $^{[187]}$

However, these compounds show a thermal instability resulting from fluorine migration to the boron atom and leading to an elimination of a perfluoroalkene or difluorocarbene. Consequently, they can only be obtained in combination with $\pi$-donating ligands, e.g. in $\mathrm{B}\left(\mathrm{CF}_{3}\right)\left(\mathrm{NMe}_{2}\right)_{2}$. This $\pi$-donating ability is also attributed to vinyl and aryl groups, though in both cases the LEWIS acidity at the boron atom is somewhat reduced due to the $\pi$-bonding contributions. Thus, pentafluorophenyl ligands were expected to be the ideal compromise between these two tendencies. The first pentafluorophenyl boron compounds were synthesized in the early 1960s by CHAMBERS and MASSEY, who reported the synthesis of e.g. $\mathrm{B}\left(\mathrm{C}_{6} \mathrm{~F}_{5}\right)_{3} \cdot{ }^{[188,189]}$

Tris(pentafluorophenyl)borane, $\mathrm{B}\left(\mathrm{C}_{6} \mathrm{~F}_{5}\right)_{3}$, was originally prepared by reacting pentafluorophenyl lithium with $\mathrm{BCl}_{3}$ at $-78^{\circ} \mathrm{C}$. As the lithium reagent tends to eliminate lithium fluoride explosively at ambient temperatures, the synthesis via the GRIGNARD reagent pentafluorophenylmagnesium bromide and a boron trihalide is nowadays preferred (Scheme 4-1).

$3 \mathrm{C}_{6} \mathrm{~F}_{5} \mathrm{MgBr}+\mathrm{BCl}_{3} \longrightarrow\left(\mathrm{C}_{6} \mathrm{~F}_{5}\right)_{3} \mathrm{~B}+3 \mathrm{MgBrCl}$

Scheme 4-1: Preparation of tris(pentafluorophenyl)borane. 
Tris(pentafluorophenyl)borane turned out to be a capable LEWIS acid, even slightly better than the boron trihalide $\mathrm{BF}_{3}{ }^{[190]}$ It combines high LEWIS acidity with stability. In contrast to other fluorinated boron compounds, which tend to decompose by eliminating $\mathrm{BF}_{3}, \mathrm{~B}\left(\mathrm{C}_{6} \mathrm{~F}_{5}\right)_{3}$ is exceptionally thermally stable, even for several days at temperatures up to $270^{\circ} \mathrm{C}$. It also shows a high stability towards oxidation by molecular oxygen and water. Hydrolysis reactions take place only very slowly by eliminating $\mathrm{C}_{6} \mathrm{~F}_{5} \mathrm{H}$; in fact, some organic reactions catalyzed by $\mathrm{B}\left(\mathrm{C}_{6} \mathrm{~F}_{5}\right)_{3}$ can be carried out in aqueous solution. Additionally it is soluble in many non-coordinating organic solvents.

Many organic transformations are catalyzed by LEWIS acids such as $\mathrm{BF}_{3}, \mathrm{AlCl}_{3}$ or $\mathrm{SnCl}_{4}$. These catalysts are very effective, however they are extremely water-sensitive, and therefore producing hydrogen halides, which are harmful to acid-labile substrates. Additionally their usage is limited due to the reactivity of the element-halogen bonds towards some potential substrates. In contrast, $\mathrm{B}\left(\mathrm{C}_{6} \mathrm{~F}_{5}\right)_{3}$ is water-resistant and has generally stable B-C bonds. An overview of LEWIS acid-catalyzed organic reactions employing $\mathrm{B}\left(\mathrm{C}_{6} \mathrm{~F}_{5}\right)_{3}$ has been published by YАMАMOTо et al. already in $1995 .^{[191]}$ Among those reactions were several examples of $B\left(C_{6} F_{5}\right)_{3}$ catalyzed additions of silyl enol ethers to aldehydes, alkyl chlorides and unsaturated ketones. For various aldol type reactions of ketene silyl acetals with $N$-benzylimines it could even be shown that $B\left(C_{6} F_{5}\right)_{3}$ is catalytically superior to the convential LEWIS acids applied. Additionally, the catalytic abilities of tris(pentafluorophenyl)borane were proven for allylsilylations, DIELS-ALDER reactions and the hydrosilylation of carbonyl functions. ${ }^{[192]}$ All the reactions proceeded at acceptable rates with low catalyst loadings under extremely mild conditions. Although the catalyst is water-resistant, its efficiency increases if it's employed anhydrously.

An additional application of tris(pentafluorophenyl)borane was found in the group 4 metallocene-based homogeneous olefin polymerization, where it acts as a co-catalyst. ${ }^{[193]}$ The role of $\mathrm{B}\left(\mathrm{C}_{6} \mathrm{~F}_{5}\right)_{3}$ is to serve as a powerful LEWIS acid capable of abstracting a methyl group from the metal center and thus creating the active cationic organometallic species responsible for chain propagation. The treatment of a variety of dimethyl zirconocenes that serve as catalyst precursors with $B\left(C_{6} F_{5}\right)_{3}$ leads to the formation of ion pairs (Scheme 4-2). Several products were structurally characterized, providing insights into the nature of ion-ion interactions in these compounds. ${ }^{[194]}$ The 
nature and extent of these interactions is quite essential for controlling the properties of the catalyst.

$$
\begin{array}{cc}
\mathrm{Cp}_{2}^{\prime} \mathrm{Zr}\left(\mathrm{CH}_{3}\right)_{2}+\mathrm{B}\left(\mathrm{C}_{6} \mathrm{~F}_{5}\right)_{3} \stackrel{\mathrm{C}_{6} \mathrm{H}_{6} \text { or } \mathrm{C}_{5} \mathrm{H}_{12}}{\longrightarrow} \mathrm{Cr}_{2}^{+}\left(\mathrm{CH}_{3}\right) \cdots \mathrm{H}_{3} \mathrm{CB}^{-}\left(\mathrm{C}_{6} \mathrm{~F}_{5}\right)_{3} \\
\mathrm{Cp}^{\prime}=\eta^{5}-\mathrm{C}_{5} \mathrm{H}_{5} \\
\eta^{5}-1,2-\mathrm{Me}_{2} \mathrm{C}_{5} \mathrm{H}_{3} \\
\eta^{5}-\mathrm{C}_{5} \mathrm{Me}_{5} \\
\eta^{5}-1,3-\left(\mathrm{SiMe}_{3}\right)_{2} \mathrm{C}_{5} \mathrm{H}_{3}
\end{array}
$$

Scheme 4-2: The reaction of dimethyl zirconocenes with $B\left(C_{6} F_{5}\right)_{3}$ leads to the formation of ion pairs.

Efforts have been made to improve the catalyst's activity for olefin polymerization by a variation of the catalyst precursors that were reacted with $B\left(C_{6} F_{5}\right)_{3}$. Among others, benzyl ${ }^{[195]}$ or acetylide groups ${ }^{[196]}$ instead of alkyl groups can be abstracted by $\mathrm{B}\left(\mathrm{C}_{6} \mathrm{~F}_{5}\right)_{3}$. Even zwitterionic complexes that are active olefin polymerization catalysts are accessible from reactions of organozirconium derivatives with $B\left(C_{6} F_{5}\right)_{3}$ (Scheme 4-3). ${ }^{[197,198]}$
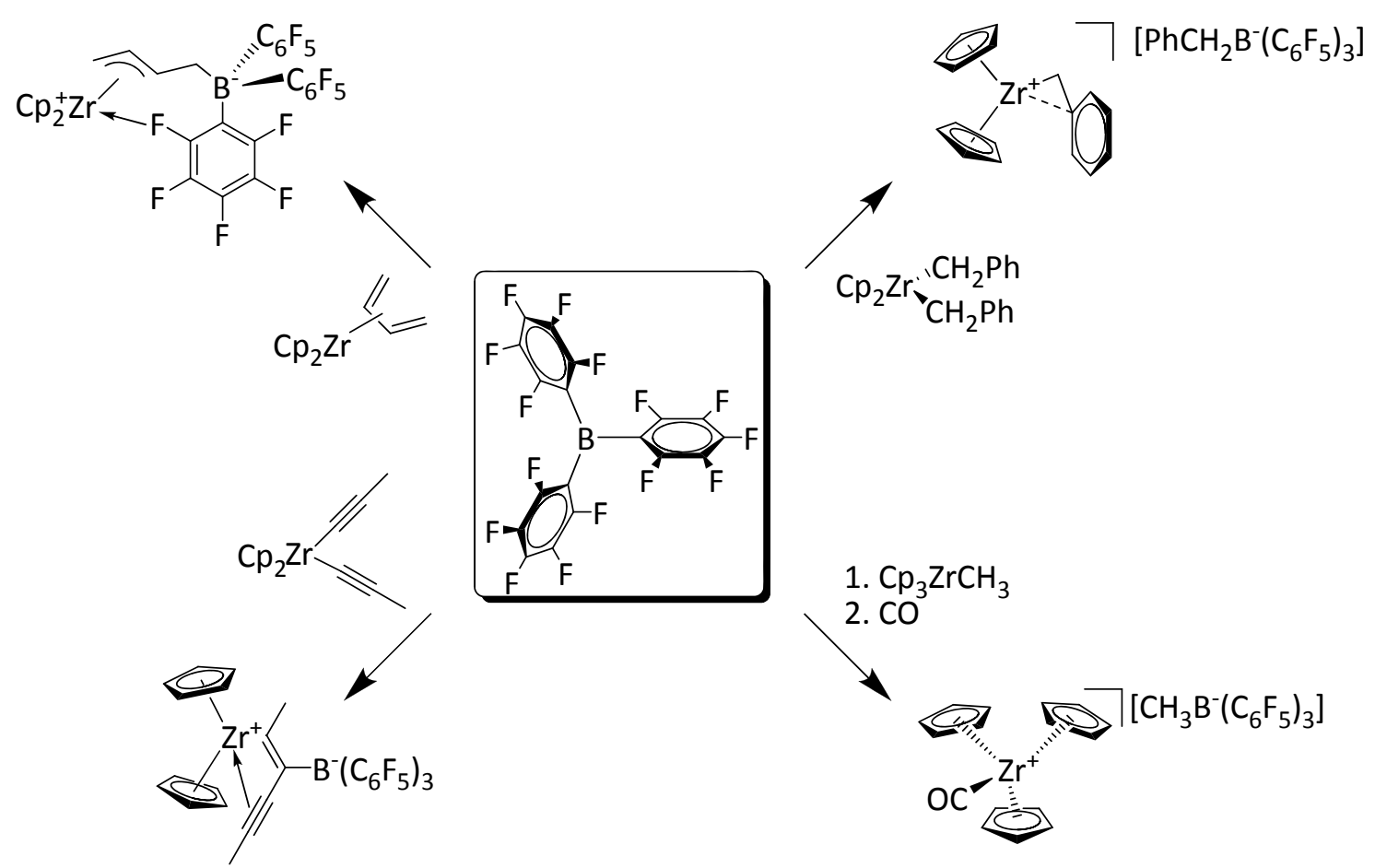

Scheme 4-3: Selection of organozirconium complexes leading to capable olefin polymerization catalysts by reaction with $B\left(\mathrm{C}_{6} \mathrm{~F}_{5}\right)_{3}$. 
The variations of the catalyst precursor can also concern the metal atom. As zirconium is rather LEWIS acid, $\mathrm{B}\left(\mathrm{C}_{6} \mathrm{~F}_{5}\right)_{3}$ should easily be able to abstract alkyl groups from less LEWIS acidic metals to generate the reactive cationic species. This has already been shown for platinum ${ }^{[199]}$ and iron ${ }^{[200]}$ species. Interestingly, methyl abstraction is possible from the complex $\mathrm{Cp}_{2} \mathrm{AlCH}_{3}$ to produce the aluminocenium cation $\left[\mathrm{Cp}_{2} \mathrm{Al}\right]^{+}\left[\mathrm{MeB}\left(\mathrm{C}_{6} \mathrm{~F}_{5}\right)_{3}\right]^{-}$, a potent cationic initiator for isobutylene polymerization. ${ }^{[201]}$ This is a remarkable reaction because it suggests that $B\left(C_{6} F_{5}\right)_{3}$ is, at least under these conditions, a more powerful LEWIS acid than the cationic aluminum species.

But not only can the catalyst precursor be altered. Variations can also be applied to the LEWIS acidic co-catalyst $B\left(C_{6} F_{5}\right)_{3}$. The substitution of the highly electronegative pentafluorophenyl ligand by other, less radical substituents promises to allow a finetuning of the catalytic reactivity. Therefore in the group of ERKER, two pentafluorophenyl compounds were prepared that bear one halogen-free nitrogen-heterocyclic substituent at the boron atom instead of a pentafluorophenyl group (Scheme 4-4). ${ }^{\text {[202] }}$

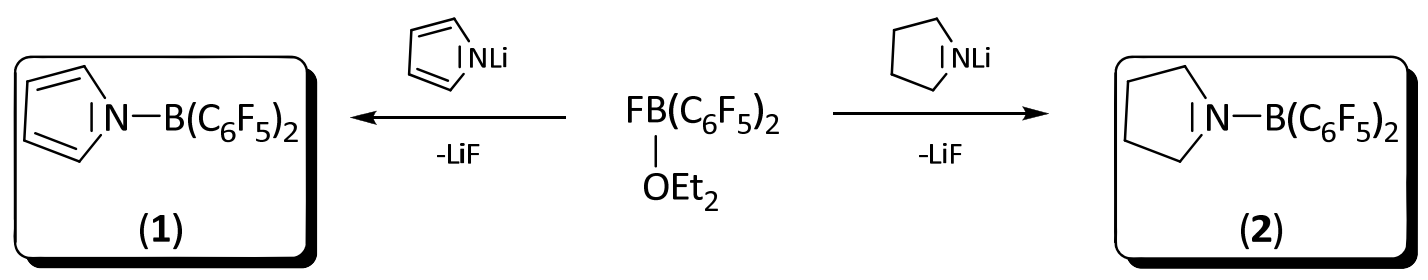

Scheme 4-4: Preparation of $\left[\left(\mathrm{C}_{6} \mathrm{~F}_{5}\right)_{2} \mathrm{~B}\left(\mathrm{NC}_{4} \mathrm{H}_{4}\right)\right](\mathbf{1})$ and $\left[\left(\mathrm{C}_{6} \mathrm{~F}_{5}\right)_{2} \mathrm{~B}\left(\mathrm{NC}_{4} \mathrm{H}_{8}\right)\right](2)$.

It has been examined if these two compounds can be used to prepare capable olefin polymerization catalysts from organozirconium precursors (vide infra). The results of this study were to be explained by the ED study presented within this thesis.

\subsection{Comparative Electron Density Study on $\left[\left(\mathrm{C}_{6} \mathrm{~F}_{5}\right)_{2} \mathrm{~B}\left(\mathrm{NC}_{4} \mathrm{H}_{4}\right)\right](1)$ and $\left[\left(\mathrm{C}_{6} \mathrm{~F}_{5}\right)_{2} \mathrm{~B}\left(\mathrm{NC}_{4} \mathrm{H}_{8}\right)\right](2)$}

The examination of these two pentafluorophenylborane complexes was performed in cooperation with Prof. Dr. G. ERKER from Münster within the framework of the SPP 1178 of the DFG. He kindly provided the crystals of 1 and 2. Prof. Dr. S. GRIMME, 
also from Münster, contributed the theoretically calculated electron densities, which were the basis for the theoretical QTAIM studies (for more details, see Chapter 3.4).

To investigate the electronic structures of $\mathbf{1}$ and $\mathbf{2}$, both molecules were examined with a low-temperature high-resolution X-ray diffraction experiment at an in-house facility. Similar strategies for the subsequent multipole refinements and the analyses were applied to ensure the comparability of the results (for more details see Chapter 3.3). The topological analyses of the electron density distributions obtained from experiment and from quantum chemical calculations are described and discussed in this chapter. Reasons for the different reactivities of the compounds are provided, which are underlined by the atomic orbital analysis, also provided by GRIMME.

\subsubsection{Reactivity of $\left[\left(\mathrm{C}_{6} \mathrm{~F}_{5}\right)_{2} \mathrm{~B}\left(\mathrm{NC}_{4} \mathrm{H}_{4}\right)\right](1)$ and $\left[\left(\mathrm{C}_{6} \mathrm{~F}_{5}\right)_{2} \mathrm{~B}\left(\mathrm{NC}_{4} \mathrm{H}_{8}\right)\right](2)$}

The reaction of electrophilic boranes with metal-alkyl or -hydride complexes has proven to be a versatile method for the generation of electron-deficient early transition metal complexes. ${ }^{[187,194,203-210]}$ The cations formed play an important role in catalysis. $^{[211]}$ Due to their electrophilic nature, these cations require electronic stabilization, often attained by the formation of ion pairs. ${ }^{[194,203-205]}$ Therefore, the nature of the counter ion, and hence the mode of cation generation, ${ }^{[212-214]}$ is quite essential for controlling the features of such species. The electrophilic borane, commonly used in such cases, is the LEWIS acidic tris(pentafluorophenyl)borane $\mathrm{B}\left(\mathrm{C}_{6} \mathrm{~F}_{5}\right)_{3}$ (vide supra). ${ }^{[215-221]}$

However, ERKER et al. reported the bis(pentafluorophenyl)( $N$-pyrrolyl)borane (1) (Figure 4-1, left) to be a valuable alternative to this reagent. ${ }^{[202]}$ The replacement of a perfluorinated phenyl ring by a halogenfree heteroaryl substituent at the boron atom does not change the molecule's reactivity significantly: alkyl anion equivalents are still abstracted from zirconocene complexes and related compounds (Scheme 4-5; reaction 1). ${ }^{[187,194,202-210]}$ In contrast, the analogue of 1 with a saturated heterocycle, the bis(pentafluorophenyl)( $N$-pyrrolidinyl)borane (2) (Figure 4-1, right), does not show this behavior (Scheme 4-5; reaction 2). ${ }^{[202]}$ 


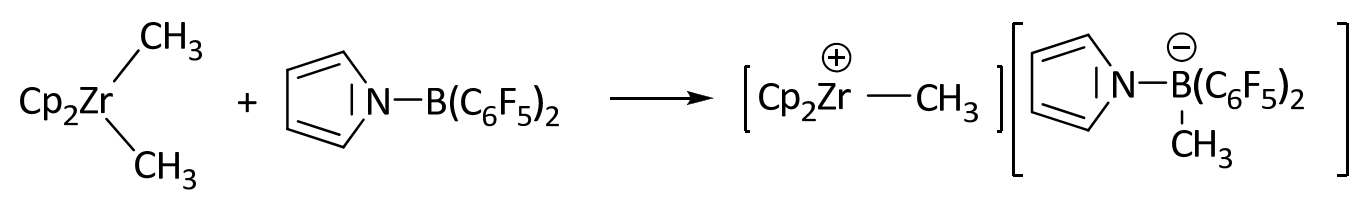

$$
\begin{aligned}
& \mathrm{Cp}_{2} \mathrm{Zr} \searrow_{\mathrm{CH}_{3}}^{\mathrm{CH}_{3}}+\mathrm{N}-\mathrm{B}\left(\mathrm{C}_{6} \mathrm{~F}_{5}\right)_{2} \stackrel{\mathrm{H}}{\longrightarrow}
\end{aligned}
$$

Scheme 4-5: Bis(pentafluorophenyl)( $N$-pyrrolyl)borane (1) abstracts alkyl anions, while bis(pentafluorophenyl)( $N$-pyrrolidinyl)borane (2) only shows decomposition reactions.

This can be attributed to a marked increase in the electrophilic character of the boron atom in $\mathbf{1}$ compared to $\mathbf{2}$. These different reactivities therefore suggest the LEWIS acidity of $\mathbf{1}$ to be more pronounced than that of $\mathbf{2}$. The diverse substitution at the boron atoms in $\mathbf{1}$ and $\mathbf{2}$ evidently has a severe impact on the properties of the boron atoms.

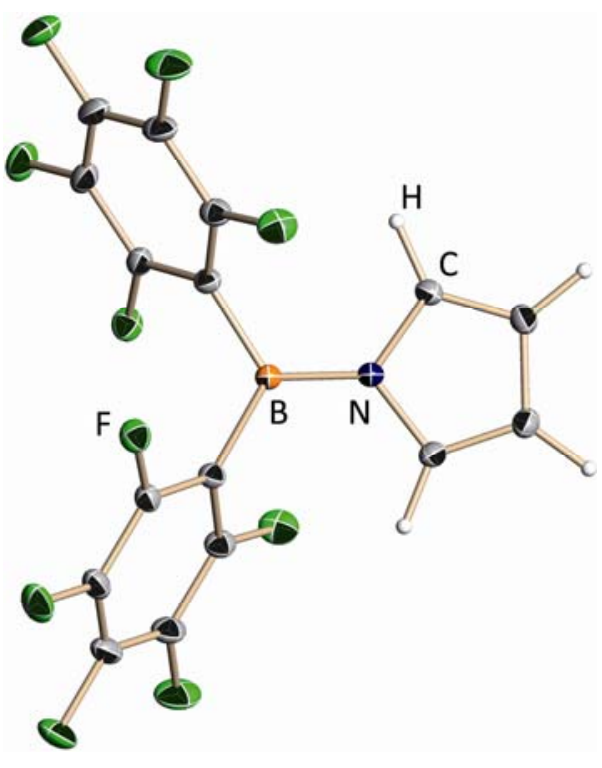

(1)

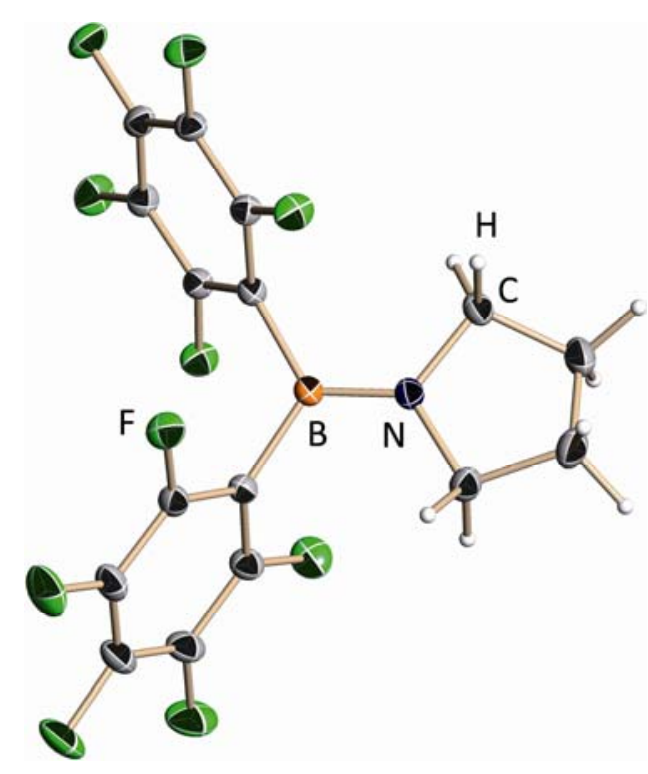

(2)

Figure 4-1: Molecular structure representations of $\left[\left(\mathrm{C}_{6} \mathrm{~F}_{5}\right)_{2} \mathrm{~B}\left(\mathrm{~N}_{4} \mathrm{H}_{4}\right)\right]\left(\mathbf{1}\right.$, left) and $\left[\left(\mathrm{C}_{6} \mathrm{~F}_{5}\right)_{2} \mathrm{~B}\left(\mathrm{~N}_{4} \mathrm{H}_{8}\right)\right](2$, right) with anisotropic displacement parameters depicted at the $50 \%$ probability level.

Since LEWIS acidity usually relies upon an electronic depletion, the reasons for the different reaction patterns should be visible in the electronic structures of the molecules. Electron density distributions are nowadays straightforwardly available ${ }^{[98,99]}$ by a low-temperature high-resolution $\mathrm{X}$-ray diffraction experiment and a subsequent 
multipole refinement. ${ }^{[43]} \mathrm{A}$ topological analysis of the resulting EDD according to BADER's quantum theory of atoms in molecules ${ }^{[71]}$ is a concise tool for the derivation of density-based properties, like bond paths (BPs), the related bond critical points (BCPs) and the LAPLACIAN field, which can serve as measures for atomic and molecular properties. $^{[222-224]}$

\subsubsection{The Bond Critical Points}

In the framework of BADER's QTAIM, a BP, the path of maximum density between two bonded atoms, is a central measure to describe the character of a chemical bond. ${ }^{[150]}$ The topological properties of the EDD along the BP give insight into the bonding situation. ${ }^{[225]}$ A significant difference in the $B-N$ bond (path) lengths of $\mathbf{1}$ and $\mathbf{2}$ is observed (Table 4-1) with the path in $\mathbf{1}$ being $0.04 \AA$ A longer than that in $\mathbf{2}$.

Table 4-1: Selected properties of the B-N bonds in 1 and $\mathbf{2}$.

\begin{tabular}{|c|c|c|c|c|c|}
\hline & Bond length $[\AA ̊]$ & Bond path length $[\AA ̊]$ & $\rho\left(\mathbf{r}_{\mathrm{BCP}}\right)\left[\mathrm{e} \AA^{-3}\right]$ & $\nabla^{2} \rho\left(\mathbf{r}_{\mathrm{BCP}}\right)\left[\mathrm{e} \AA^{-5}\right]$ & $\varepsilon\left(\mathbf{r}_{\mathrm{BCP}}\right)$ \\
\hline 1 & $1.409^{[a]} / 1.415^{[b]}$ & $1.41 / 1.42$ & $1.47 / 1.40$ & $0.50 / 13.48$ & $0.12 / 0.02$ \\
\hline 2 & $1.374 / 1.379$ & $1.38 / 1.38$ & $1.58 / 1.50$ & $6.06 / 17.64$ & $0.20 / 0.15$ \\
\hline
\end{tabular}

[a] Experimental and [b] theoretical results in italics.

The local minimum along the BP is defined as the BCP. The electron density and its derivatives at this point are often used to distinguish between various types of atomic interactions. ${ }^{[222-224]}$ The BCPs of the B-N bonds are located closer to the boron than to the nitrogen atom and also closer to the boron atom than suggested from the nonpolar midpoint (NPMP). In 1 the distance of the BCP from the boron atom is $0.47 \AA$, while the NPMP is located at a distance of $0.79 \AA$ from the boron atom $(0.46$ and $0.76 \AA$ in 2). This reflects the differences in the electronegativities of the atoms involved.

The values of the electron densities, $\rho\left(r_{B C P}\right)$, the LAPLACIANS, $\nabla^{2} \rho\left(r_{B C P}\right)$, and the ellipticities, $\varepsilon\left(\mathbf{r}_{\mathrm{BCP}}\right)$, at the BCPs of the B-N bonds in $\mathbf{1}$ and $\mathbf{2}$ are presented in Table 4-1. At the BCP of the shorter bond path in $2, \rho\left(\mathbf{r}_{\mathrm{BCP}}\right)$ is 0.11 e $\AA^{-3}, \nabla^{2} \rho\left(\mathbf{r}_{\mathrm{BCP}}\right) 5.56$ e $\AA^{-5}$ and 
$\varepsilon\left(r_{\mathrm{BCP}}\right) 0.08$ higher than in 1 . Comparison of the experimental and theoretical data in Table 4-1 reveals a good qualitative agreement for all properties, i.e. in particular all trends between $\mathbf{1}$ and $\mathbf{2}$ are the same. However, the values of the LAPLACIAN (and to a lesser extent the ellipticity) at the BCP deviate strongly which is well known from other comparative studies. ${ }^{[226-228]}$

At first sight, an increase in $\rho\left(\mathbf{r}_{\mathrm{BCP}}\right)$ and $\varepsilon\left(\mathbf{r}_{\mathrm{BCP}}\right)$ is counterintuitive to the simultaneous increase of the positive LAPLACIAN (charge depletion). From text book interpretation this shows an increased, non-cylindrical interatomic EDD in 2, which is coincidently dispersed towards the bonding partners. This is probably due to polarization effects arising from the different electronegativities.

\subsubsection{The LAPLACIAN}

It is well known that for very polar bonds ${ }^{[00,81,112]}$ or interactions with or between metal atoms, ${ }^{[34,77,89,229]}$ especially the values for the LAPLACIAN at the BCPs are susceptible to misinterpretations, as the BCPs lie on a rising edge of the LAPLACIAN distribution (Figure 4-2). This uncertainty already becomes obvious when comparing the values from theory with those from experiment (Table 4-1). ${ }^{[172]}$ To elude this problem, the LAPLACIAN distribution, $\nabla^{2} \rho(\mathbf{r})$, was investigated along the whole B-N bond path.

The LAPLACIAN distributions presented in Figure 4-2 are qualitatively equivalent. $\nabla^{2} \rho(\mathbf{r})$ of $\mathbf{2}$ is slightly compressed in comparison to $\mathbf{1}$, which leads to the observed increase of $\nabla^{2} \rho(\mathbf{r})$ at the BCP. Obviously, the charge concentrations are exclusively located in the nitrogen basins, while they are depleted in the boron basins. Nevertheless, two minima in the interatomic regions, originating from the valence shell charge concentrations, are observed in both molecules. This indicates shared, even though severely polarized, interactions. 


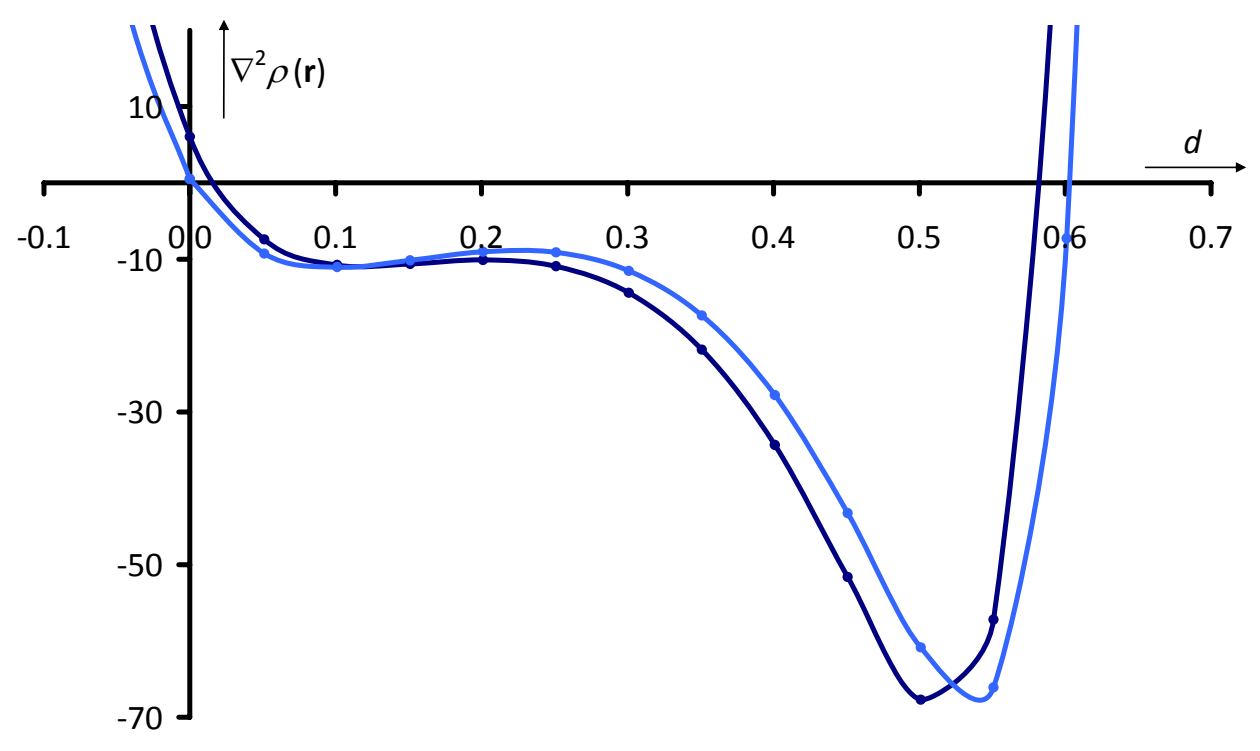

Figure 4-2: $\nabla^{2} \rho(\mathbf{r})$ along the B-N bond path for $\mathbf{1}$ (light blue) and $\mathbf{2}$ (dark blue), with $d$ being the distance from the BCP (at $0.0 \AA$ ) and the boron basins spanning the negative values while the nitrogen basins span the positive ones.

The two-dimensional distribution of $\nabla^{2} \rho(\mathbf{r})$ in the principal mean plane of the boron-heterocycle (Figure 4-3) reveals the expected features of shared and - at least for $\mathrm{B}-\mathrm{N}$ - polarized bonds.

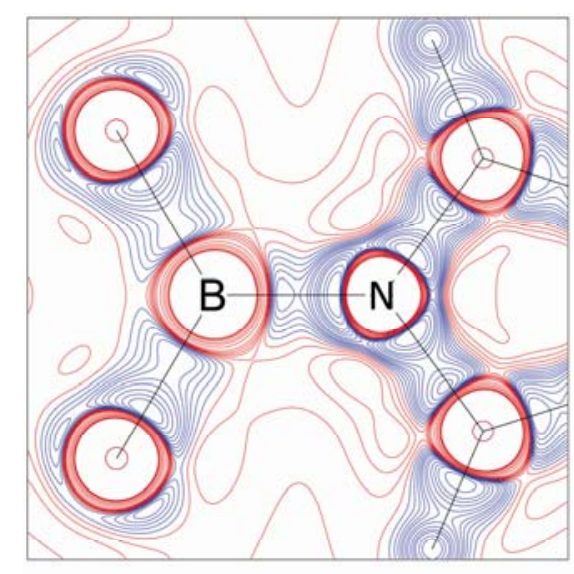

(1)

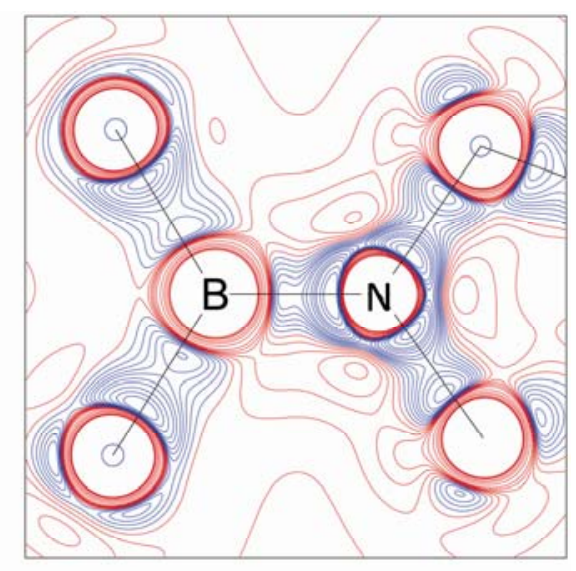

(2)

Figure 4-3: Contour plots of the LAPLACIAN distribution in the $\mathrm{B}-\mathrm{N}-\mathrm{C}_{\text {ortho }}$ planes of $\mathbf{1}$ (left) and $\mathbf{2}$ (right). Red lines represent charge depletions, while blue lines correspond to charge concentrations.

The carbon, nitrogen, and boron atoms form three valence shell charge concentrations (VSCCs) each, oriented towards their bonding partners. Even at the charge-depleted boron atoms, we find three VSCCs. However, the VSCCs directed 
towards the nitrogen atoms are shifted to the nitrogen basins in both molecules. Nevertheless, the B-N bonds in $\mathbf{1}$ and $\mathbf{2}$ show features typical for shared interaction: charge concentrations in the bond region from both atoms forming a saddle shaped distribution with tailing perpendicular to the bond vector.

\subsubsection{The BADER Charges}

The polarization, indicated by the LAPLACIAN distribution, should also be reflected by the charges of the atoms involved. Physically meaningful charges can be determined by the integration of the electron density over the atomic basins separated by the zero flux surfaces. ${ }^{[71]}$ These charges originate from bond polarization effects as well as from charge transfer between the atoms. ${ }^{[114]}$ The integrated charges are given in Table 4-2, together with the atomic net charges, which are calculated from the difference of the number of valence electrons and the refined monopole populations of the atoms.

Table 4-2: Charges in e in $\mathbf{1}$ and $\mathbf{2}$.

\begin{tabular}{|c|c|c|c|c|}
\hline & Integrated charge & Net charge & Integrated charge & Net charge \\
\hline & \multicolumn{2}{|c|}{ of the boron atom } & \multicolumn{2}{|c|}{ of the nitrogen atom } \\
\hline 1 & $+1.966^{[\mathrm{a}]} /+2.090^{[\mathrm{b}]}$ & +0.690 & $-1.358 /-1.638$ & -0.013 \\
\hline 2 & $+2.131 /+2.059$ & +0.321 & $-1.392 /-1.563$ & -0.050 \\
\hline
\end{tabular}

[a] Experimental and [b] theoretical results in italics.

Interestingly, the charges of the nitrogen atoms in both compounds are almost identical. The electronic impact of the substituent merely affects the boron charges. The net charge at the boron atom in $\mathbf{1}$ is more than twice as large as in $\mathbf{2}$. This is an indication for a distinct charge transfer away from the boron atom and the reason for the observed differences in the LEWIS acidities of the two molecules. The increased charge separation and the resulting LEWIS acidity of $\mathbf{1}$ is illustratively mirrored in the graphical representation of the electrostatic potential (ESP) (Figure 4-4). The positive potential at the boron atom is much more pronounced in $\mathbf{1}$ than in $\mathbf{2}$. The expected negative potential at the nitrogen atoms and thus the difference between $\mathbf{1}$ and $\mathbf{2}$ are not as marked as they are at the boron atom. 


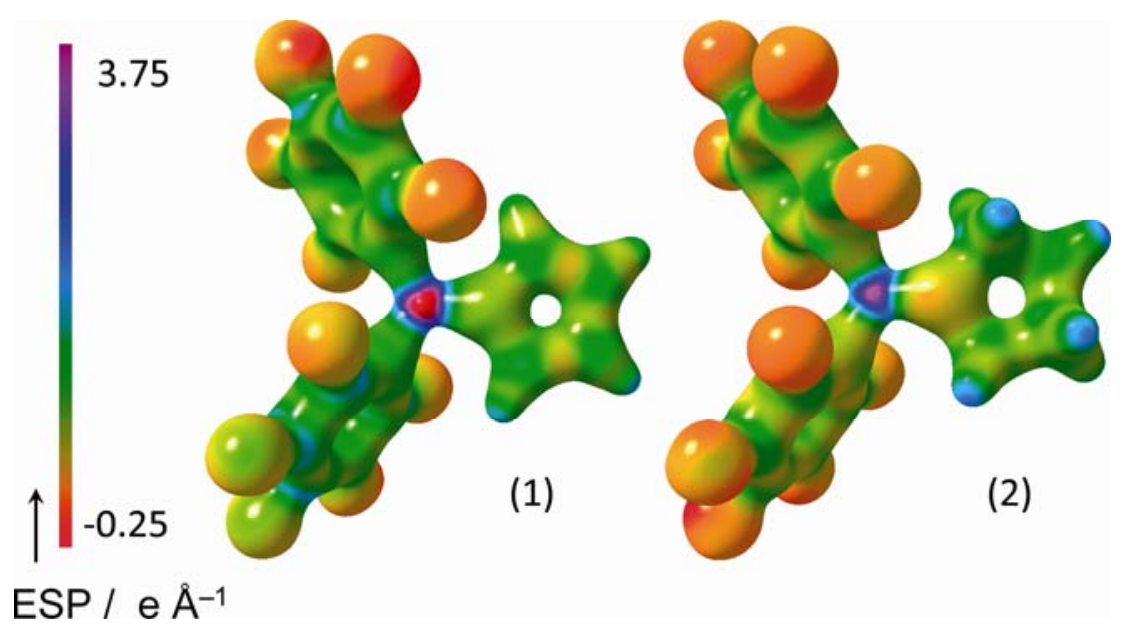

Figure 4-4: Isosurface representation of the electrostatic potential (ESP) ranging from -0.25 to +3.75 e $\AA^{-1}$ mapped on $\rho(\mathbf{r})=0.65$ e $\AA^{-3}$.

The integrated charges of the nitrogen atoms are about one order of magnitude higher than the net charges. The integrated charges of the boron atoms are close to +2 in both molecules, and therefore six to seven times the values of the net charges. This leads to the assumption, that the charge separation within the $\mathrm{B}-\mathrm{N}$ bond is mainly driven by polarization arising from the inductive effect of the substituents instead of charge transfer from the boron to the nitrogen atom.

Insight into the electron shift within the whole molecule is provided by the group charges (the summation over all atomic contributions of the defined group) given in Table 4-3. The net charges as well as the integrated charges display the same picture, even though on different levels of magnitude. The electron-withdrawing effect of the $\mathrm{C}_{6} \mathrm{~F}_{5}$-groups leads to distinct negative charges, which are counterbalanced by the boron atom and the heterocycle in $\mathbf{2}$ but by the boron atom alone in $\mathbf{1}$. The incapability of the pyrrolyl ring to compensate the electron depletion at the boron atom leaves the boron atom in $\mathbf{1}$ more positive than in $\mathbf{2}$.

Table 4-3: Group charges in e in 1 and 2.

\begin{tabular}{|c|c|c|c|c|}
\hline & Integrated Charge & Net Charge & Integrated Charge & Net Charge \\
\hline & \multicolumn{2}{|c|}{ of the heterocycle } & \multicolumn{2}{|c|}{ of the $\mathrm{C}_{6} \mathrm{~F}_{5}$-ring } \\
\hline 1 & -0.571 & +0.011 & -0.776 & -0.350 \\
\hline 2 & +0.041 & +0.735 & $-0.950 /-1.032$ & $-0.476 /-0.578$ \\
\hline
\end{tabular}




\subsubsection{The 3d-distribution of the LAPLACIAN}

The consequence of the positive charge at the boron atom already noticeable in the ESP is echoed in the shape of the reactive surface, which is defined as the isosurface where $\nabla^{2} \rho(\mathbf{r})$ changes sign. Therefore, holes in this spatial distribution (electronic depletions) represent possible sites for nucleophilic attack. In $\mathbf{1}$ the boron atom is only shielded towards the bonding partners, while above and below the $\mathrm{B}-\mathrm{N}-\mathrm{C}_{\text {ortho }}$ plane space is wide open for a potential nucleophilic attack (Figure 4-5). The situation is different in $\mathbf{2}$, where, in addition to the charge concentrations towards the bonding partners, claws are formed from the nitrogen atom, providing additional shielding.

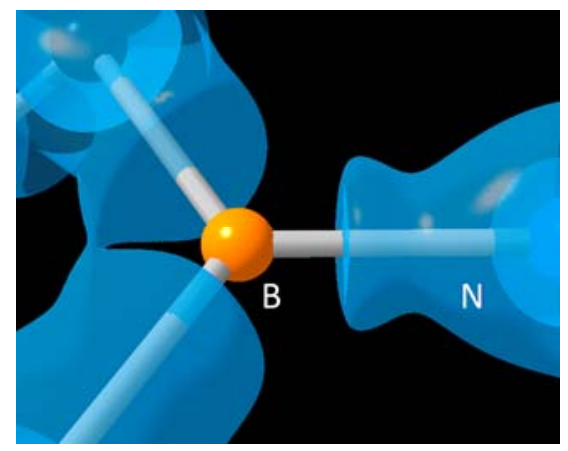

(1)

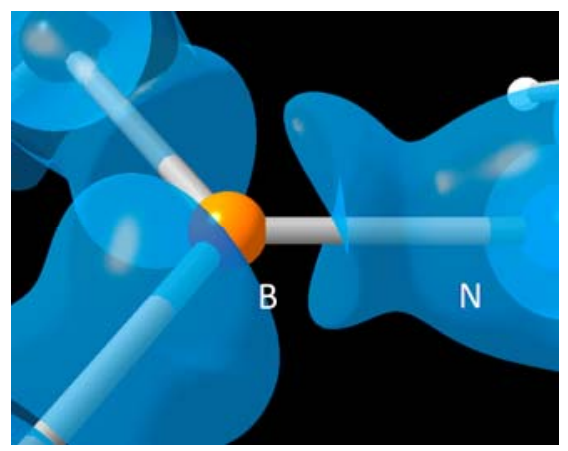

(2)

Figure 4-5: Representation of the reactive surface around the boron atoms in $\mathbf{1}$ (left) and $\mathbf{2}$ (right).

In addition to the reactive surface, the spatial distribution of $\nabla^{2} \rho(\mathbf{r})$ and its local minima, the valence shell charge concentrations (VSCCs), provide information on the valence shell structure of the bonded atoms. The positions and absolute values of the VSCCS around the nitrogen and the boron atoms in $\mathbf{1}$ and $\mathbf{2}$ were determined. Around the nitrogen and the boron atom three VSCCs were found in each molecule. The values at the boron atoms do not differ significantly $\left(-10.9\right.$ to -12.3 e $\left.\AA^{-5}\right)$, but the nitrogen VSCCs mirror the particular atomic contributions to the respective bonds. While in 1 the boron-directed VSCC has a value of -67.7 and the two in-ring VSCCs a value of -73.1 e $\AA^{-5}$, the corresponding values in 2 are $-70.2,-58.3$ (towards C5), and -65.2 e $\AA^{-5}$ (C2). This supports the findings presented above: The charge concentrations around the nitrogen atom in $\mathbf{1}$ are more pronounced reaching into the aromatic ring and, compared to that, slightly reduced towards the boron atom. In $\mathbf{2}$ one can find the reverse situation - the most distinct concentration is orientated towards the boron atom and the less pronounced VSCCs into the heterocycle. 


\subsubsection{The Ellipticity}

Since both molecules differ exclusively in the hetererocyclic substituent, the electron density shift in the B-N bond has to originate there. Obviously, the aromaticity in $\mathbf{1}$ and its impact on the B-N bond density is the key to understand the electronic situation. This is already supported by the geometry of the boron-heterocycle subunit. In both molecules, boron, nitrogen, and the two ortho-carbon atoms are in one plane. At least for $\mathbf{2}$ this is not compulsory, since the anticipated charge localization at the nitrogen atom is expected to induce a bending from partial $s p^{3}$-character.

A tool, which can serve as a measure for any kind of distortion of the EDD along a bond, is the ellipticity $\varepsilon$. Values above zero indicate deviations from cylindrical symmetry, and can originate from $\pi$-contributions. Generally, a severe ellipticity at the $\mathrm{BCP}$ is regarded to be a sign of at least partial $\pi$-bonding or a double bond, while a low ellipticity is typical for a single or a triple bond. ${ }^{[71]}$

As shown by SCHERER et al., an investigation of the ellipticity along the whole bond path should be favored over the mere inspection at the BCP. ${ }^{[230,231]}$ In both presented compounds, $\varepsilon$ is significantly different from zero along the whole B-N bond path (see Figure 4-6).

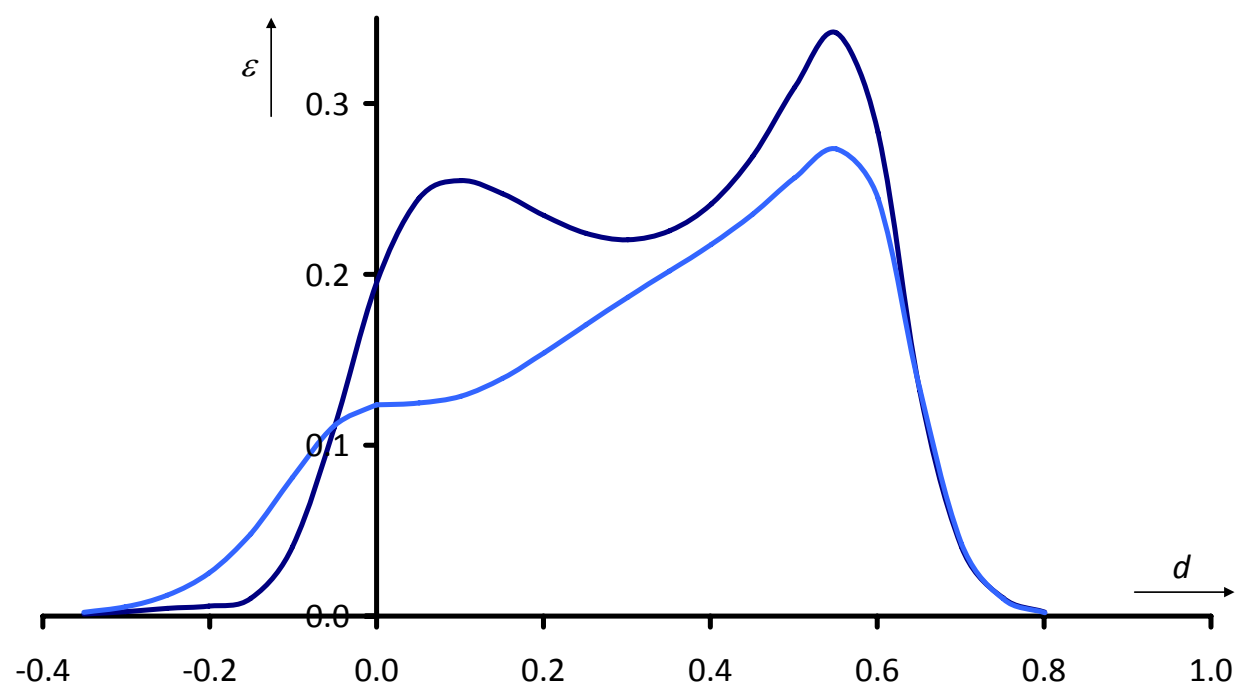

Figure 4-6: Ellipticities along the B-N bond paths for $\mathbf{1}$ (light blue) and $\mathbf{2}$ (dark blue) with $d$ being the distance from the BCP (at $0.0 \AA$ ) and the boron basins spanning the negative values while the nitrogen basins span the positive ones. 
The most distinct deviations from cylindrical symmetry in both molecules are found in proximity to the nitrogen atoms. This is not unexpected, since local charge concentrations from lone pairs or density polarizations are well known to have impact on the bond density distribution. However, it is remarkable, that pronounced ellipticities are spanning the whole bond path. Therefore, $\pi$-contributions to the $\mathrm{B}-\mathrm{N}$ bonds in both molecules have to be assumed. The level differs in $\mathbf{1}$ and $\mathbf{2}$, culminating in an almost two times higher ellipticity at the BCP in $\mathbf{2}$.

A conceivable interpretation of the bonding features found is the assumption of an electron density donation from the nitrogen atom of each heterocycle into the vacant p-orbital of the boron atom. This seems consistent in the case of 2: Due to the - at first sight rather surprising - planarity of the system, the two electrons at the nitrogen atom reside in a non-hybridized $p$-orbital and can easily be donated from the nitrogen atom into the $\mathrm{B}-\mathrm{N}$ bond by interacting with the vacant $p$-orbitals of the boron atom. In molecule 1 , this coupling has to be accomplished by $\pi$-density from the ring system. This picture is actually supported by the absolute values of $\varepsilon$. Even though $\pi$-contribution is observed in both compounds, it is much more pronounced in $\mathbf{2}$ than in 1.

The $\pi$-system of the heterocycle in $\mathbf{1}$ is polarized towards the electronegative nitrogen atom. This is clearly visible in Figure 4-7. The distributions along the $C-C$ bonds show the typical shape of an aromatic bond, while the ellipticity in the $\mathrm{C}-\mathrm{N}$ bond is shifted with respect to the BCP due to the polarizing effect of the nitrogen atom.

In $\mathbf{2}$ the polarization effect in the heterocycle is even more striking. The expected shape for an undisturbed $\sigma$-bond ( $\varepsilon$ close to zero) is found only between one of the $\mathrm{C}_{\text {meta }}-\mathrm{C}_{\text {ortho }}$ bonds (Figure 4-8), while all other bonds show deviations from cylindrical symmetry, probably due to the electron-withdrawing effect of the nitrogen atom. As seen in all other bonds under investigation, the maxima of the ellipticities are located close to the electronegative nitrogen atoms. 


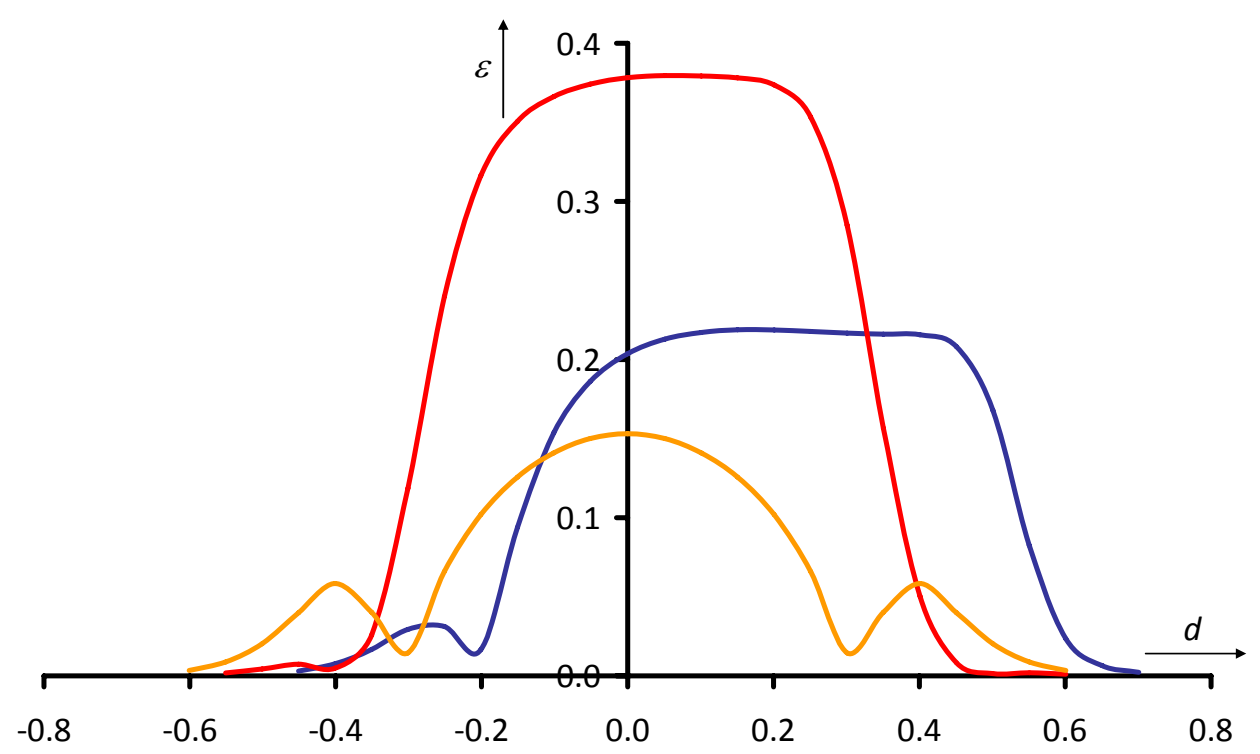

Figure 4-7: Ellipticities along the bond paths in the pyrrolyl-ring in 1; red: $\mathrm{C}_{\text {ortho }}-\mathrm{C}_{\text {meta }}$, blue: $\mathrm{C}_{\text {ortho }}-\mathrm{N}$, yellow: $\mathrm{C}_{\text {meta }}-\mathrm{C}_{\text {meta }}$.

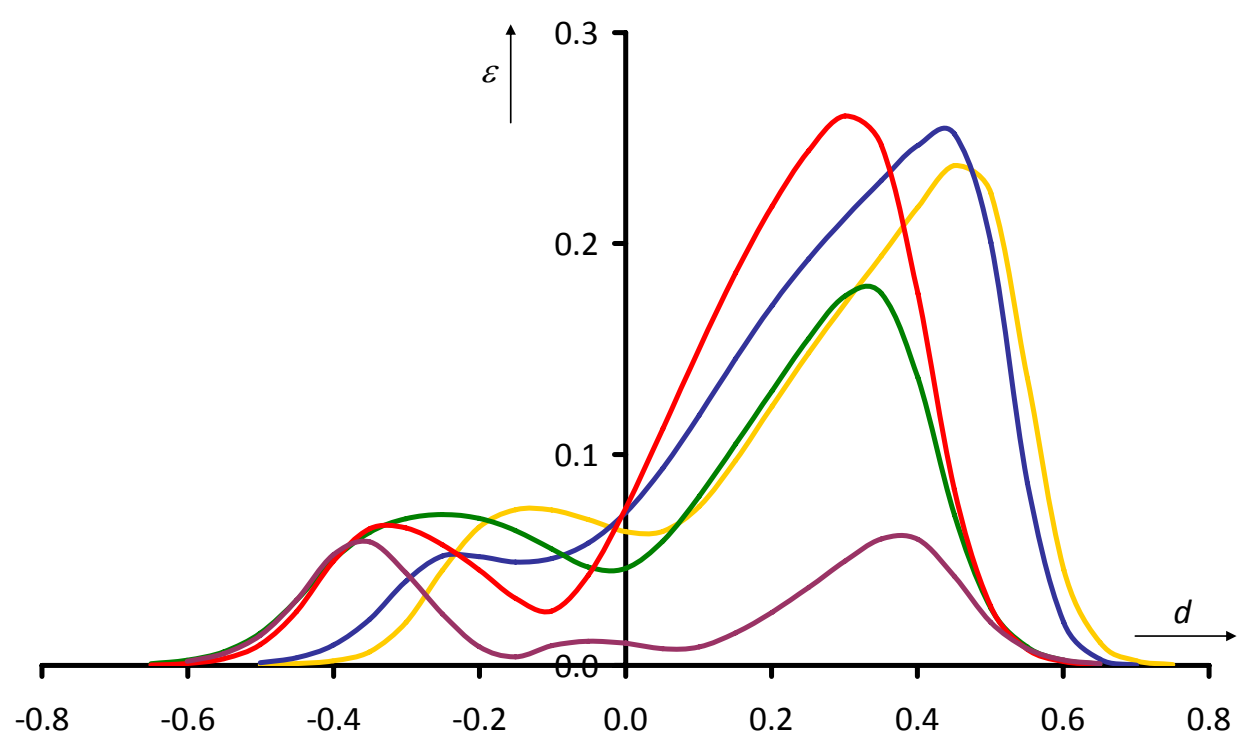

Figure 4-8: Ellipticities along the bond paths in the pyrrolidinyl-ring in 2;

yellow: $C_{\text {ortho }}-N$, blue: $C_{\text {ortho }}-N$, green: $C_{\text {ortho }}-C_{\text {meta }}$, violet: $C_{\text {ortho }}-C_{\text {meta }}$, red: $C_{\text {meta }}-C_{\text {meta }}$. 


\subsubsection{The Static Deformation Density}

The fact, that polarization also induces the bond density not to be cylindrically shaped might fuel the idea that the described shape of the ellipticity distribution along the $\mathrm{B}-\mathrm{N}$ bond paths might rather be caused by polarization than by $\pi$-contributions to the bonding. However, the $3 d$-representation of the static deformation density, $\Delta \rho_{\text {static }}(\mathbf{r})$, calculated from the difference between the modeled density and the density of the promolecule, impressively displays the fundamental differences. While $\Delta \rho_{\text {static }}(\mathbf{r})$ of the $\mathrm{B}-\mathrm{N}$ bonds in both molecules doubtlessly reveals the expected shape of a bond with severe $\pi$-contributions (broadening perpendicular to the $\mathrm{B}-\mathrm{N}-\mathrm{C}_{\text {ortho }}$ planes) (Figure 4-9, upper row), the density distributions in the heterocycles as well as in the polar B-C bonds are cylindrically shaped (Figure 4-9, bottom row). Especially the density distributions of the $\mathrm{B}-\mathrm{C}$ bonds rule out polarization as the single argument for the observed ellipticities.
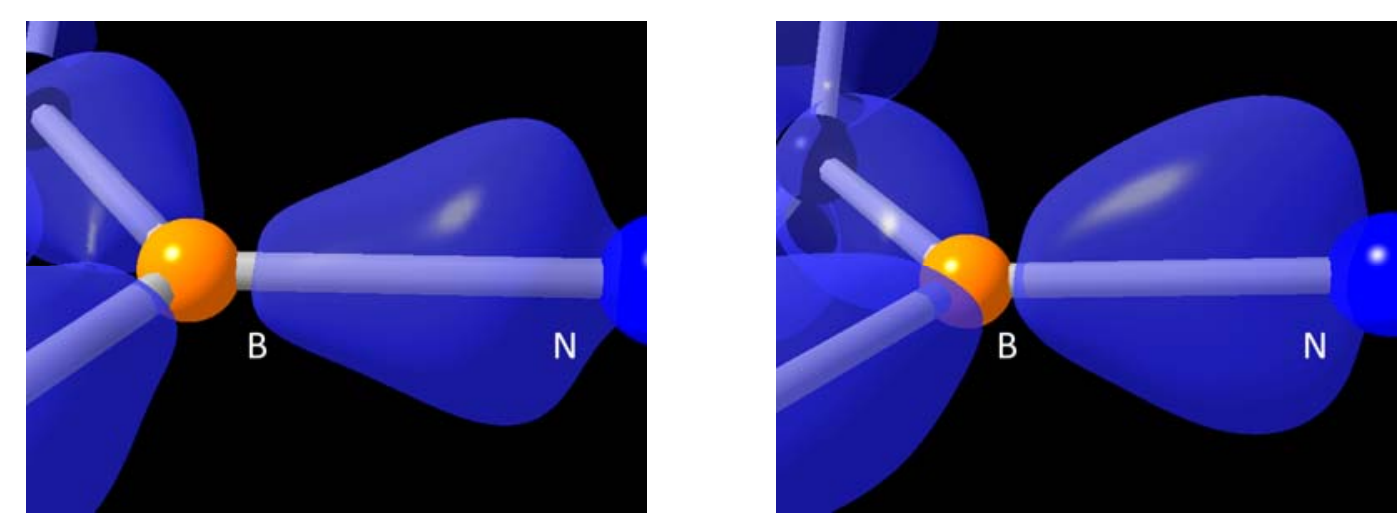

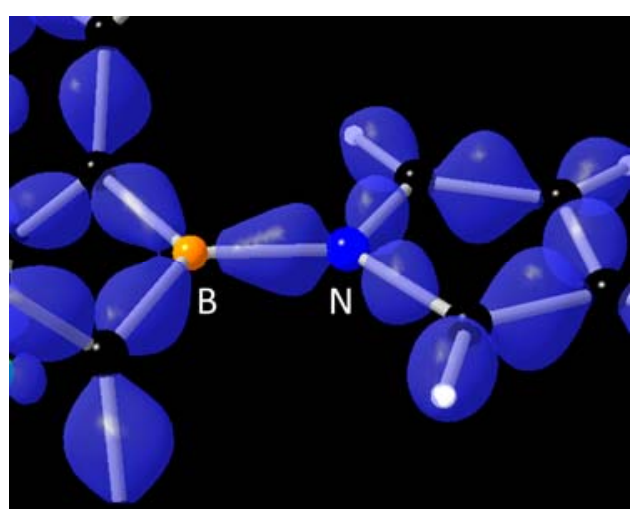

(1)

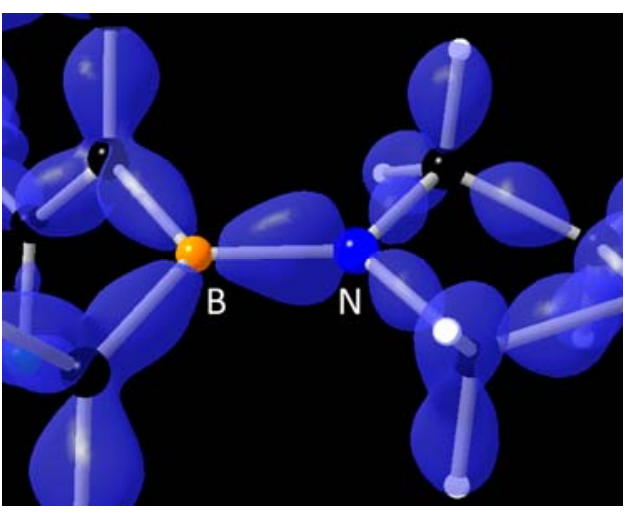

(2)

Figure 4-9: Isosurface representation of $\Delta \rho_{\text {static }}(\mathbf{r})$ at the level of 0.2 e $\AA^{-3}$ all for $\mathbf{1}$ (left) and $\mathbf{2}$ (right). 


\subsubsection{Atomic Orbital Analysis}

The spatial distribution of the localized $\pi$-MOs (Figure 4-10) underlines the findings from the analysis of the experimental charge density. The different extensions of the $\pi$-orbitals from the rings towards the boron atoms are obvious. The MO of $\mathbf{1}$ is expanded further into the ring than in $\mathbf{2}$. In contrast, in $\mathbf{2}$ it appears more concentrated at the nitrogen atom.
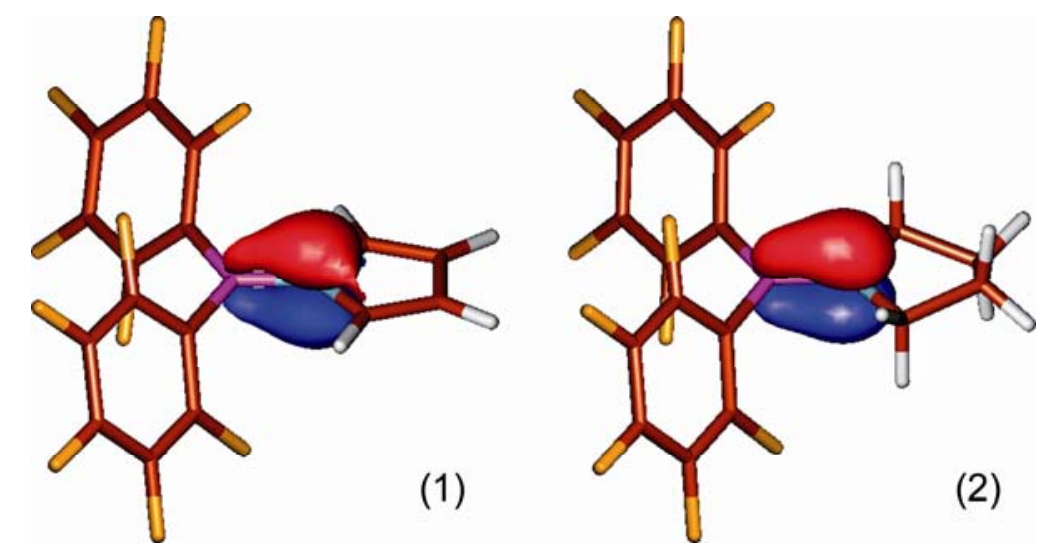

Figure 4-10: Representation of the localized $\pi$-MOs of the B-N bonds of 1 (left) and 2 (right) plotted on an isosurface value of $\pm 0.7 \mathrm{a}_{0}^{-3 / 2}$.

\subsection{Conclusion}

Taking all these findings into account, the electronic situation in both molecules straightforwardly explains the differing reactivities from an electron density point of view. In both molecules, in addition to the $\mathrm{B}-\mathrm{N} \sigma$-bonds, electron density from the nitrogen atoms couples into the B-N bond at different levels. In $\mathbf{1}$ the electron density is restrained to a higher extent in the aromatic system, nevertheless, permitting delocalization over the nitrogen atom into the vacant $p$-orbitals of the boron atom. The charge concentration at the nitrogen atom in $\mathbf{1}$, which is due to the polarization of the $\mathrm{B}-\mathrm{N}$ bond, and the electron-withdrawing effect of the $\mathrm{C}_{6} \mathrm{~F}_{5}$ groups, leads to an increased charge at the boron atom, a resulting positive ESP, and the preference of the nitrogen VSCCS in the ring. In $\mathbf{2}$ we find more electron density shifted from the nitrogen atom into the $\mathrm{B}-\mathrm{N}$ bond, leading to an increased boron-directed VSCC, very distinct $\pi$-contribution to the shortened $\mathrm{B}-\mathrm{N}$ bond, and a less pronounced charge at 
the boron atom with some electronic shielding from nucleophilic attack. Hence the topological analyses of the electron density distributions obtained from experiment and quantum chemical calculations can consistently explain marginal changes in bonding and rationalize different catalytic abilities. 


\section{Electron Density Studies on transition Metal COMPOUNDS OF BORON}

\subsection{Transition Metal Compounds of Boron - Classification and Chemistry}

Boron forms a large number of different compounds with transition metals (TM) in a remarkable structural variety. The compounds, in which boron is directly bonded to one or more metal atoms, can be divided into four major classes. ${ }^{[121,232,233]}$

With about a thousand examples in more than 130 different structural types, the borides are the best described class. ${ }^{[234-236]}$ Metallaboranes ${ }^{[237-239]}$ and metallaheteroboranes, ${ }^{[240-242]}$ of which also several hundred examples have been characterized since the middle of the 1960s, constitute another class. The last long known - even though less numerous - class of compounds in this series are the transition metal complexes with boron-containing ligands derived from conjugated boron heterocycles ${ }^{[243]}$ such as borole ${ }^{[244,245]}$ diborolene ${ }^{[246]}$ borabenzene, ${ }^{[247,248]}$ borazine ${ }^{[249,250]}$ and diazadiboretidine ${ }^{[251]}$. The fourth type of compounds involving direct metal-boron interactions has only become established in the last decade: transition metal compounds of boron. Although first compounds of this type were already known in $1970,{ }^{[252]}$ their existence was structurally only proved about twenty years later by MARDER and MEROLA. ${ }^{[253,254]}$

The nature of the chemical bond between the boron and the transition metal in these compounds is diverse and in many cases still open to questions. The bonding in borides, for example, cannot be described by a single type. Instead, borides show ionic, covalent and metallic bonding contributions in different magnitudes depending on the respective metal atom and the composition of the boride. The metallaboranes and metallaheteroboranes show a similarity to the parent boranes and are therefore electron-deficient. The central triangular motif is made up by three-center, twoelectron bonds, and, in most cases, the compounds can also be described in accordance with WADE's rules. ${ }^{[255,256]}$ As expected, the interactions of the conjugated boron-heterocycles with the central metal atoms in the corresponding complexes are established via $\pi$-bonding. Finally, the transition metal compounds of boron are characterized by electron-precise two-center two-electron bonds between the boron 
and the transition metal atom. This bonding type is well-known for transition metal complexes of related main-group elements such as carbon, and silicon, leading to classes of compounds such as alkyl-, ${ }^{[257,258]}$ alkylidene-, ${ }^{[259,260]}$ silyl-, ${ }^{[261,262]}$ and silylene ${ }^{[263,264]}$ complexes, respectively. The corresponding compounds of boron $^{[232,265,266]}$ and its higher homologues ${ }^{[267]}$, however, were not fully characterized until 1990. ${ }^{[253,254]}$

Depending on the coordination number of the boron atom and the number of boron-transition metal bonds, the compound class of transition metal complexes of boron can again be subdivided into four groups: borane- (I), boryl- (II) and bridged (III) as well as terminal (IV) borylene complexes (Scheme 5-1). ${ }^{[233]}$<smiles>[R][R]([R])[Y19]</smiles>

I<smiles></smiles>

Ila<smiles>[R]B([R])[W]</smiles>

II<smiles>[R]B([W])[W]</smiles>

III<smiles>[R]B=[W]</smiles>

IV<smiles>[R]B([14CH3])[14CH3]</smiles>

IVa<smiles></smiles>

V<smiles>[R]B([Y16])[14CH3]</smiles>

VI<smiles>[R][B-]([R])([Y14])I</smiles>

IIla<smiles>[R]B([Y19])[14CH3]</smiles>

VII<smiles>[Y19]=BN</smiles>

VIII<smiles></smiles>

IX

Scheme 5-1: Coordination modes of transition metal complexes of boron.

Depending on the LEWIS acidity of the boron atom, LEWIS acid-base adducts of boryl (IIa), bridging borylene (IIla), and terminal borylene complexes (IVa) have been characterized. Additionally, a number of compounds with unusual coordination modes 
of boron-based ligands have been reported, including bridging boryl complexes (V), hetero-dinuclear (VI) and semi-bridging borylene complexes (VIII) and compounds that contain a boron atom that is bonded to no other ligands than two (VIII) or three (IX) transition metal centers.

The interest in transition metal complexes of boron is not only restricted to synthesis, and characterization. Additionally, the importance of this research area is fuelled by the versatile applications these complexes have. Boryl complexes, for example, are important reagents in the metal-mediated borylation of unsaturated organic substrates ${ }^{[268-275]}$ or $\mathrm{C}-\mathrm{H}$ bonds ${ }^{[276-283]}$ and, hence, are becoming increasingly important in organic synthesis. Additionally, borylated organic species have lately been used as building blocks for the synthesis of $\pi$-conjugated boron-based materials with potential applications in optoelectronic or sensor devices. ${ }^{[284-286]}$ Transition metal borylene complexes, in particular, represent longstanding targets of interest, owing to their close relationship to fundamental organometallic compounds such as carbonyl or carbene complexes. ${ }^{[120,287]}$ Recently, it could be shown, that the reaction of an alkene with the terminal borylene $\left[(\mathrm{CO})_{5} \mathrm{CrBN}\left(\mathrm{SiMe}_{3}\right)_{2}\right]$ under photolytical conditions leads to a regioselective $\mathrm{C}-\mathrm{H}$ insertion of the borylene complex. ${ }^{[288]}$ In addition to the photochemically induced borylene transfer, knowledge about the reactivity of terminal borylene complexes is restricted to only one report by ROPER. ${ }^{[289]}$

With the successful synthesis of examples from every class of transition metal complexes of boron, the attention is shifted to the understanding of the bonding situation in these compound classes.

The borane complexes (I) are characterized by a fourfold-coordination of the boron atom. This coordination is adopted, because the borane complexes represent LEWIS acid-base adducts of acidic boranes $\mathrm{BR}_{3}$ and basic transition metal complexes. NMR studies support the assumption of a fourfold-coordination at the boron atom and structural investigations by X-ray diffraction methods indicate tetrahedral geometries for the boron atoms as well.

The group of boryl complexes (II) is the largest among the transition metal complexes of boron. Boryl complexes show a threefold-coordinated boron atom. The $s p^{2}$-hybridized boron atom adopts a trigonal-planar coordination and forms $\sigma$-bonds with the metal fragment $M L_{x}$ as well as with both ligands $R$. The resulting electron 
deficiency at the boron atom is possibly compensated by the competitive $\pi$-donation from $M L_{x}$ and $R$ into the vacant $p$-orbital of the boron atom. Therefore, the electronic situation at the boron atom is influenced by the metal fragment $M L_{x}$ as well as by the boron-bonded ligand R. This situation is also known for the isoelectronic cationic carbene complexes. ${ }^{[290,291]}$ As the synthesis of these compounds was more and more successful, a large number of spectroscopic and structural data are nowadays available, providing some insight into the nature of the transition metal-boron bond in boryl complexes. More recently, theoretical investigations proved to be another important source of information. [292-295]

As the synthesis of the borylene complexes was more challenging, even more theoretical studies have been performed on the borylene complexes. There are two possible coordination modes of the borylene ligand to the transition metal: either bridging between two metal atoms with a threefold-coordinated boron atom (III) or terminal to one metal atom with the formation of a formal double bond and a decrease of the coordination number to two (IV). Up to now, both bridging and terminal borylene complexes have been realized. Although being still rare, borylene complexes have attracted considerable interest ${ }^{[296-298]}$ and have been subject to various theoretical studies which addressed especially the nature of the metal-boron linkage in terminal borylene complexes (vide infra).

\subsection{Bonding in Transition Metal Borylene Complexes}

Numerous examples in the past decade proved the isolobal borylene B-R moieties to be valuable alternatives to the ubiquitous carbonyl $\mathrm{C}=\mathrm{O}$ ligand in organometallic chemistry. ${ }^{[121,122,232,233,299,300]}$ The nature of the metal-boron bond, especially in terminal borylene complexes, has been subject to many studies. ${ }^{[120,287,301-305]}$

By computational studies, the borylene ligands were identified to give thermodynamically more stable transition metal complexes than the carbonyl concerning a homolytic cleavage of the respective metal-element bond. ${ }^{[120,123,287]}$ This can be assigned to the increased $\sigma$-donating ability of the borylene moieties in comparison to the $\mathrm{CO}$ ligand, while the $\pi$-accepting capability of both groups is roughly the same. The reason for this is a much higher energy of the $\sigma$-donor orbital and a 
comparable energy of the $\pi^{*}$-orbital, with the arrangement of these frontier orbitals at the boron and the carbon atom being similar (Figure 5-1). ${ }^{[120]}$

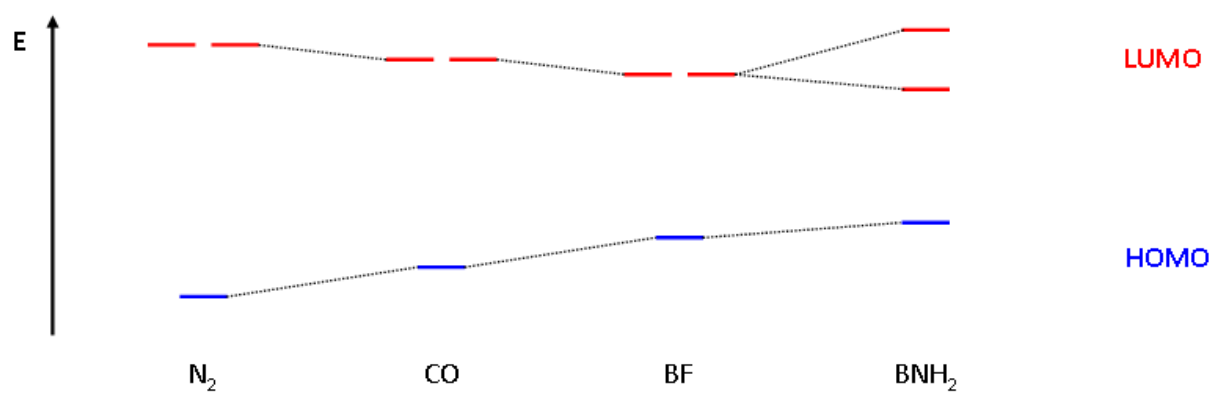

Figure 5-1: Qualitative representation of the valence orbital energies of ligands isolobal to CO.

On the other hand, the high polarity and the small HOMO-LUMO gap of the uncoordinated borylene ligand suggest a low kinetic stability. Increasing the HOMOLUMO gap by complexation also increases the kinetic stability to a certain extent, but the imbalance between $\sigma$-donation and $\pi$-acceptance leads to a positive charge at the boron atom and thus advances nucleophilic attack.

This kinetic instability may be overcome by a steric protection of the BR ligand's reactive frontier orbitals. Such protection may be provided by sterically demanding ligands in the metal complex. Additionally, a lessening of the kinetic instability might be achieved by reducing the build-up of charge on the coordinated BR ligand by restoring the balance between $\mathrm{M}-\mathrm{B} \sigma$-donation and $\mathrm{B}-\mathrm{M} \pi$-back-donation. Interestingly, EHLERS et al. could show, that the binuclear metal complex fragments $\left\{\mathrm{Fe}(\mathrm{CO})_{4}\right\}_{2}$ and $\left\{\mathrm{CpMn}(\mathrm{CO})_{2}\right\}_{2}$ have just the right frontier orbitals to achieve this. ${ }^{[120]}$ Complexation with a fragment of the second type results in the formation of the bridging borylene complex described in Chapter 5.3.3.

The nature of the TM-B bond is strongly influenced by the boron-bonded ligand R. Descriptions based on calculations range from an almost purely RB-TM $\sigma$-bonded model, for $\mathrm{R}$ being a good $\pi$-donor, up to a strong TM-BR $\pi$-back-donation in the model when $\mathrm{R}$ is a weaker $\pi$-donor. ${ }^{[287,302,303]}$ Recent studies, however, pointed out that the sum of the covalent interactions does not even give a bond order of 1 , but the nature of the TM-BR bond is mainly ionic. ${ }^{[287,303,305]}$ Therefore, additional knowledge on the bonding interactions between the boron and the transition metal atom in borylene complexes is clearly necessary. 


\subsection{Electron Density Study on $\left[(\mathrm{CO})_{5} \mathrm{CrBN}\left(\mathrm{SiMe}_{3}\right)_{2}\right](3)$}

The examination of the terminal borylene complex was performed in cooperation with Prof. Dr. H. BRAUnSCHWEIG from Würzburg within the framework of the SPP 1178 of the DFG. He provided the crystals of $\mathbf{3}$ that were measured at an in-house facility in Göttingen. A theoretical investigation of this complex has already been published. ${ }^{[123]}$ Additional calculations are being performed by Dr. J. HENN from Göttingen and Dr. M. КоноUт from Dresden, which are, due to their pending status, not discussed in detail in this thesis. Instead, the attempt to perform a topological analysis based on experimental data is presented here.

The experimental data was integrated and corrected for absorption according to the procedures described in Chapter 3. The IAM refinement led to reasonable results so that a multipole refinement was performed subsequently. However, a close inspection of the residual density distribution after the multipole refinement showed that the assumed flat and featureless residual density distribution did in fact show certain features. Residual electron density was found in proximity to the carbon atoms of the $\mathrm{SiMe}_{3}$ groups. The arrangement of the residual density peaks indicated a rotational disorder. However, these residuals were located very close to the atom positions. The positions of the residual density maxima were adopted as the atom positions for a second disordered part of the molecule and an attempt was made to refine a disordered independent atom model of the molecule. However, already the IAM refinement proved to be unstable. The residual density was that close to the atom positions that any IAM refinement led to a merging of the two assumed atom positions of one atom. This was also the reason, why this disorder had not been detected in the precedent IAM refinement. Fixing the atom positions of the smaller disordered part to the positions of the residual density maxima after the multipole refinement allowed for a - though very restricted - IAM refinement. This model was then used for a subsequent multipole refinement. However, any attempt to perform a disordered multipole refinement did not converge. Additionally, a refinement was performed using invarioms for the disordered groups, while the transition metal, the boron and the nitrogen atom were refined freely. These refinements did not converge either.

However, all these facts provided some confidence in the non-disordered multipole refinement. As the residual density distribution after the multipole model shows peaks 
that most probably refer to the smaller part of the disordered molecule, the multipole model must have only described the main part of the molecule. Therefore, an analysis of the electron density distribution after this non-disordered multipole refinement was performed. As the residual density is located around the $\mathrm{SiMe}_{3}$ groups, it was assumed that the results for the $\mathrm{Cr}-\mathrm{B}-\mathrm{N}$ axis might not be influenced. This has already been experienced for the results of an electron density determination of a polyimido sulfur ylide, which showed slight disorder in the coordinated donor molecules that did, however, not influence the central double cube inspected. ${ }^{[113]}$ Therefore, a topological analysis was performed with the feature for the $\mathrm{SiMe}_{3}$ groups being excluded from the discussion. However, the descriptors of this refined model even more need the verification by the theoretical results.

\subsubsection{The B-N bond}

Two possible LEWIS structures have been proposed for $\left[(\mathrm{CO})_{5} \mathrm{CrBN}\left(\mathrm{SiMe}_{3}\right)_{2}\right]$ (3) (Scheme 5-2). While the nature of the $\mathrm{Cr}-\mathrm{B}$ bond was questioned, the $\mathrm{B}-\mathrm{N}$ bond in both cases was assumed to be a double bond. This assumption was encouraged by the geometrical arrangement of the $\mathrm{Cr}-\mathrm{B}-\mathrm{N}$ moiety, which shows an almost linear arrangement, and the trigonal-planar environment of the nitrogen atom. ${ }^{[123]}$ As geometrical considerations have often been misleading, the $\mathrm{B}-\mathrm{N}$ bond was nevertheless closer inspected.
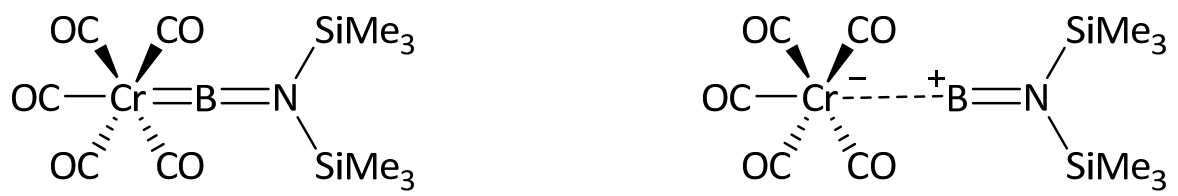

Scheme 5-2: Assumed bonding situation in $\left[(\mathrm{CO})_{5} \mathrm{CrBN}\left(\mathrm{SiMe}_{3}\right)_{2}\right](3)$.

As the nature of a B-N bond was already examined for the borane complexes 1 and 2, the derived bond descriptors were compared. The $B-N$ bond in this terminal borylene complex is shorter than the bond in both LEWIS acidic borane complexes. Thus it is not surprising, that the amount of density is higher at the BCP (cf. Table 4-1 and Table 5-1). 
Table 5-1: Selected properties of the B-N bond in $\mathbf{3}$.

\begin{tabular}{cccccc}
\hline & Bond Length $[\AA]$ & Bond Path Length $[\AA]$ & $\rho\left(\mathbf{r}_{\mathrm{BCP}}\right)\left[\mathrm{e} \AA^{-3}\right]$ & $\nabla^{2} \rho\left(\mathbf{r}_{\mathrm{BCP}}\right)\left[\mathrm{e} \AA^{-5}\right]$ & $\varepsilon\left(\mathbf{r}_{\mathrm{BCP}}\right)$ \\
\hline B-N & 1.352 & 1.353 & 1.590 & 12.031 & 0.04 \\
\hline
\end{tabular}

The comparison of the other properties at the BCP shows that a higher value of the LAPLACIAN was found in $\mathbf{3}$ than in $\mathbf{1}$ and $\mathbf{2}$, while the value of the ellipticity at the BCP turned out to be lower. The lower ellipticity is quite in contrast to the anticipated double bond character of the $\mathrm{B}-\mathrm{N}$ bond in $\mathbf{3}$. Therefore, the ellipticity along the whole $\mathrm{B}-\mathrm{N}$ bond path was inspected.

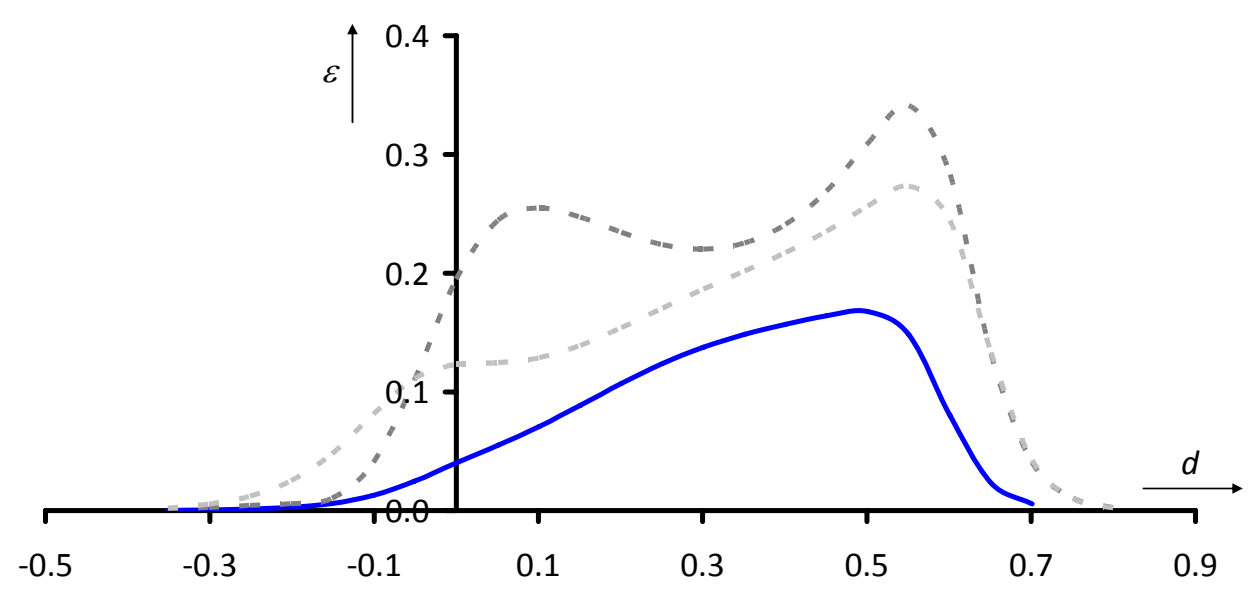

Figure 5-2: Ellipticity along the $\mathrm{B}-\mathrm{N}$ bond

(in gray for comparison reason the distributions in $\mathbf{1}$ and $\mathbf{2}$ ).

Figure 5-2 shows that the ellipticity is rather low along the whole path, thus indicating, that its existence is probably only due to polarization - if not ionicity. While in 1 and $\mathbf{2}$ pronounced $\pi$-bonding contributions exist - leading to bond orders of 1.5 or 2 , respectively - this can be excluded in the case of $\mathbf{3}$.

An investigation of the LAPLACIAN along the whole bond path (Figure 5-3) reflects the shorter bond length in $\mathbf{3}$ and shows a compressed curve in comparison to $\mathbf{1}$ and $\mathbf{2}$. This is also the explanation for the higher value of the LAPLACIAN at the BCP. The strong polarization of the $\mathrm{B}-\mathrm{N}$ bond is reflected by the charges of the boron and the nitrogen atom. The integrated charges of the boron and the nitrogen atom are $1.160 \mathrm{e}$ and -1.785 e, respectively. Again comparing the values found here to the values found in $\mathbf{1}$ 
and $\mathbf{2}$, the charge at the boron atom is lower for this borylene complex. This is not surprising as the pentafluorophenyl groups are strong electron-withdrawing groups that are not present in $\mathbf{3}$. Interestingly, the negative charge at the nitrogen atom is much more pronounced in $\mathbf{3}$, thus indicating an even stronger polarization of the bond.

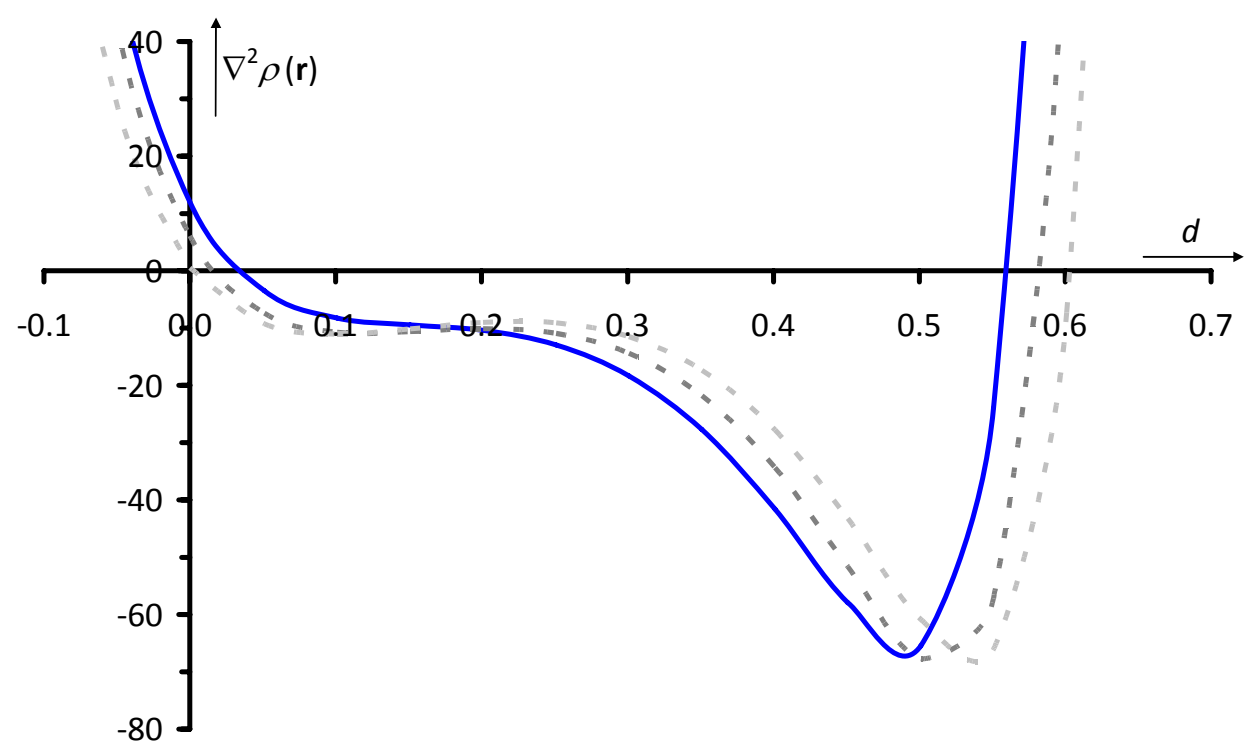

Figure 5-3: LAPLACIAN distribution along the $\mathrm{B}-\mathrm{N}$ bond in $\mathbf{4}$ (blue) (in gray for comparison reason the distributions in $\mathbf{1}$ and $\mathbf{2}$ ).

An investigation of the contour plot of the LAPLACIAN (Figure 5-4) reveals interesting features: while the boron atom exhibits two VSCCS in the direction of the chromium atom, it shows no VSCC towards the nitrogen atom. However, there is a VSCC at the nitrogen atom pointing towards the boron atom. This underlines the description of the B-N bond as being very strongly polarized. This increased polarization can be assigned to the very low $\pi$-character of the $B-N$ bond, which does not allow for a compensation.

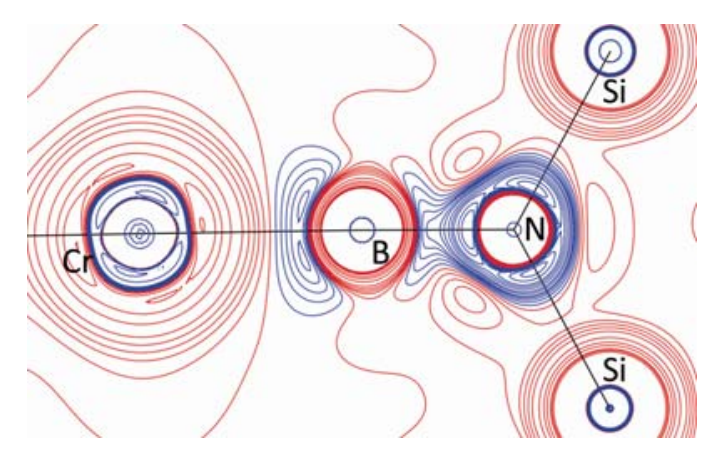

Figure 5-4: Contour plot of the LAPLACIAN distribution in the $\mathrm{Cr}-\mathrm{B}-\mathrm{N}$ plane of 4. 
The preliminary theoretical results agree in the absence of a VSCC at the boron atom directed towards the nitrogen atom. However, all theoretical results, applying different basis sets and functionals concordantly show only one VSCC at the boron atom directed towards the chromium atom in contrast to the two found in the experimental investigation. This indicates that the boron atom might be influenced by the disorder of the $\mathrm{SiMe}_{3}$ groups, which leads to density deformations that influence the LAPLACIAN distribution. However, as theory and experiment agree in the absence of a nitrogen-directed VSCC at the boron atom, the description of the B-N bond as a double bond seems not appropriate. With the results at hand, it should rather be described as a strongly polar, maybe even ionic bond, even if these results still have to be underlined by more theoretical results.

\subsubsection{The $\mathrm{Cr}-\mathrm{B}$ bond}

In the topological analysis of the experimentally derived electron density distribution, seven VSCCS are found at the chromium atom; however, the graphical representation clearly shows a cubic arrangement which would indicate eight VSCCs. As the vertexes of the cube are rounded, it is not surprising, that numerically not all VSCCs can be detected easily. However, the theoretical investigations detect all eight VSCCs and therefore numerically confirm the graphically deduced cubic environment. In fact, the vertexes of the cube correspond to the eight maxima of $-\nabla^{2} \rho(\mathbf{r})$ in the third shell, i.e. "inner-shell" VSCCs. ${ }^{[77]}$ The bond paths pierce through the planes of the cube, which are regions of low (or even negative) charge concentrations, thus charge depletions relative to the other.

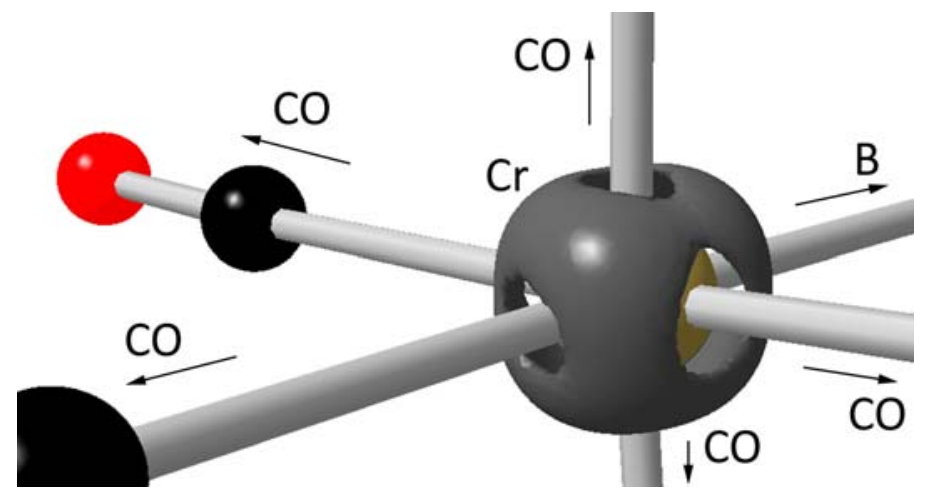

Figure 5-5: Isosurface representation of the Laplacian around the chromium atom in 4. 
As all theoretical calculation agree in the existence of only one VSCC from the boron atom towards the chromium atom (vide supra) and the examined crystals show a disorder, the theoretical description is assumed to be more reliable. The chromiumdirected VSCC of the boron atom faces a charge depletion at chromium atom, as it has been observed for the carbonyl ligands in other transition metal complexes. Thus, the terminal borylene ligand seems to adopt the same coordination mode as a carbonyl ligand. The bonding can thus be interpreted as some kind of donor-acceptor interaction, that is visually represented as a lump (of the borylene) ligand matching a hole (of the metal). ${ }^{[7]}$

Table 5-2: Selected properties of the $\mathrm{Cr}$-ligand bonds in $\mathbf{3}$.

\begin{tabular}{lccccc}
\hline & Bond Length $[\AA]$ & Bond Path Length $[\AA]$ & $\rho\left(\mathrm{r}_{\mathrm{BCP}}\right)\left[\mathrm{e} \AA^{-3}\right]$ & $\nabla^{2} \rho\left(\mathrm{r}_{\mathrm{BCP}}\right)\left[\mathrm{e} \AA^{-5}\right]$ & $\varepsilon\left(\mathrm{r}_{\mathrm{BCP}}\right)$ \\
\hline $\mathrm{Cr}-\mathrm{B}$ & 1.982 & 1.991 & 0.563 & 6.548 & 0.30 \\
$\mathrm{Cr}-\mathrm{C1}$ & 1.898 & 1.900 & 0.787 & 12.553 & 0.19 \\
$\mathrm{Cr}-\mathrm{C2}$ & 1.885 & 1.893 & 0.831 & 12.761 & 0.02 \\
$\mathrm{Cr}-\mathrm{C3}$ & 1.904 & 1.909 & 0.708 & 12.090 & 0.09 \\
$\mathrm{Cr}-\mathrm{C4}$ & 1.886 & 1.888 & 0.810 & 13.010 & 0.18 \\
$\mathrm{Cr}-\mathrm{C5}$ & 1.903 & 1.913 & 0.837 & 11.367 & 0.15 \\
\hline
\end{tabular}

Compared to the $\mathrm{Cr}-\mathrm{C}$ bond of the carbonyl groups in 3, the $\mathrm{Cr}-\mathrm{B}$ bond of the borylene ligand is slightly longer (Table 5-2). At the BCP of the $\mathrm{Cr}-\mathrm{B}$ bond less density is found than at the BCP of the $\mathrm{Cr}-\mathrm{C}$ bond. This can be ascribed to the longer bond path and the smaller number of electrons in the valence shell of the boron atom compared to the carbon atom. The density values of the $\mathrm{Cr}-\mathrm{C}$ bonds lie in the range of other transition metal-carbon bonds, which show values from 0.7 to 0.9 e $\AA^{-3}$. $^{[77]}$ This indicates that even though a discrepancy to theoretical results has been detected, the experimental results are nevertheless trustworthy.

As the transition metal-carbon bonds of the carbonyl groups show cylindrical symmetry of the density along the bond path, detecting $\pi$-back donation is difficult. This symmetrical arrangement cleans out traces of preferential accumulation planes. In the borylene ligand however, the substituents at the boron atom break the cylindrical 
symmetry, which is the reason, why a higher ellipticity is found in the $\mathrm{Cr}-\mathrm{B}$ bond than in the $\mathrm{Cr}-\mathrm{C}$ bonds of 3 .

All these features are compatible with the dative (or semipolar) and therefore intermediate character of these bonds already described for the carbonyl analogue.

\subsubsection{Conclusion}

Despite the disorder of the trimethylsilyl groups in $\left[(\mathrm{CO})_{5} \mathrm{CrBN}\left(\mathrm{SiMe}_{3}\right)_{2}\right](3)$, the electron density study was able to give reasonable answers to the question of the bonding situations of the central, non-disordered part of the molecule.

The very low ellipticity along the $\mathrm{B}-\mathrm{N}$ bond path in $\mathbf{3}$ clearly excludes the description of the B-N bond as a double bond. In contrast, the LAPLACIAN distribution, the charges of the atoms involved in the bonding, and the VSCCs around the boron and the nitrogen atom are indicative of a highly polar, maybe even ionic bond.

The coordination of the borylene ligand was found to resemble that of a carbonyl ligand, showing one VSCC pointing towards the transition metal. However, a discrepancy occurred between theory and experiment, which might be attributed to the disorder present in the molecule. Nevertheless, the bond descriptors for the carbonyl group seemed to be at most slightly biased by the disorder as they closely resembled those known from literature. This gave confidence in the bond descriptors of the $\mathrm{Cr}-\mathrm{B}$ bond, which present this bond as being a dative bond. In contrast to the carbonyl species, where the rotational symmetry of the ligand prevents the detection, $\pi$-back-donating contributions to the bond can be found indicated by the higher ellipticity.

\subsection{Electron Density Study on $\left[\left\{\mathrm{Cp}(\mathrm{CO})_{2} \mathrm{Mn}\right\}_{2} \mathrm{~B}\left(\mu-\mathrm{B}^{t} \mathrm{Bu}\right)\right](4)$}

The examination of this bridged borylene complex was also performed in cooperation with Prof. Dr. H. BRAUNSCHWEIG from Würzburg within the framework of the SPP 1178 of the DFG. Dr. M. BURZLER of his group prepared several batches of crystals of compound 4 that were measured at the HASYLAB (DESY) in Hamburg as well as at an 
in-house facility. Unfortunately, the data collection at the HASYLAB did not result in a data set suitable for an electron density investigation. By contrast, the measurement at the in-house facility led to a data set of excellent quality (see Chapter 3 ), which has been used for the following study. Via a topological analysis, the bonding in the transition metal complex was examined with a special focus on the transition metalboron and the transition metal-transition metal interactions. The theoretical calculations on this compound were provided by Dr. J. HENN from Göttingen (see Chapter 3.4).

\subsubsection{Coordination of the Bridging Borylene Ligand}

The efforts in the research of borylene complexes resulted in the preparation of a variety of borylene complexes. Many different coordination modes for ligands of the type B-R were described and include terminal, hetero-dinuclear, semi-bridging and bridging species. This variety was taken as an experimental proof for the predicted close relationship between borylene and carbonyl ligands.

Despite significant progress in this area, the choice of the boron-bonded substituents that sufficiently stabilize the metal-coordinated borylene ligand is very much restricted to $\pi$-stabilizing heteroatoms such as nitrogen and oxygen atoms. Only very few substituents with little or no $\pi$-stabilization have been reported, such as the sterically very demanding aryl of hypersilyl groups. The tert-butylborylene complex $\left[\left\{\mathrm{Cp}(\mathrm{CO})_{2} \mathrm{Mn}\right\}_{2} \mathrm{~B}\left(\mu-\mathrm{B}^{t} \mathrm{Bu}\right)\right],(4)$, (Figure $\left.5-6\right)$ is the first alkylborylene complex reported. ${ }^{[306]}$

As there have already been a number of theoretical investigations on the bonding situation between the borylene ligand and the transition metal atom, it was past-due to get an experimental affirmation of the findings. Therefore, within this doctoral study an experimental electron density investigation on $\mathbf{4}$ was performed.

The geometrical arrangement of the atoms around the boron atom derived from the $\mathrm{X}$-ray experiment shows no striking features despite an acute $\mathrm{Mn}-\mathrm{B}-\mathrm{Mn}$ angle $\left(87^{\circ}\right.$ instead of the anticipated $120^{\circ}$ for an $s p^{2}$-hybridized boron atom). The $\mathrm{B}-\mathrm{C}$ bond distance $(1.61 \AA)$ lies in the range quoted for tert-butylboranes. ${ }^{[306-308]}$ The two $\mathrm{Mn}-\mathrm{B}$ bonds have identical lengths ( $2.02 \AA)$. The density-related properties at the BCPs of the 
Mn-B bonds are uncontroversial, with density values $\rho\left(\mathrm{r}_{\mathrm{BCP}}\right)$ of 0.61 and 0.65 e $\AA^{-3}$ and LAPLACIAN values $\nabla^{2} \rho\left(\mathrm{r}_{\mathrm{BCP}}\right)$ of 1.22 and 1.19 e $\AA^{-5}$, respectively. The BCPs are shifted about $0.08 \AA$ from the non-polar midpoint ${ }^{[77]}$ towards the boron atom, contradicting the differences in the electronegativities. This is a strong hint of density polarization towards the manganese atoms.

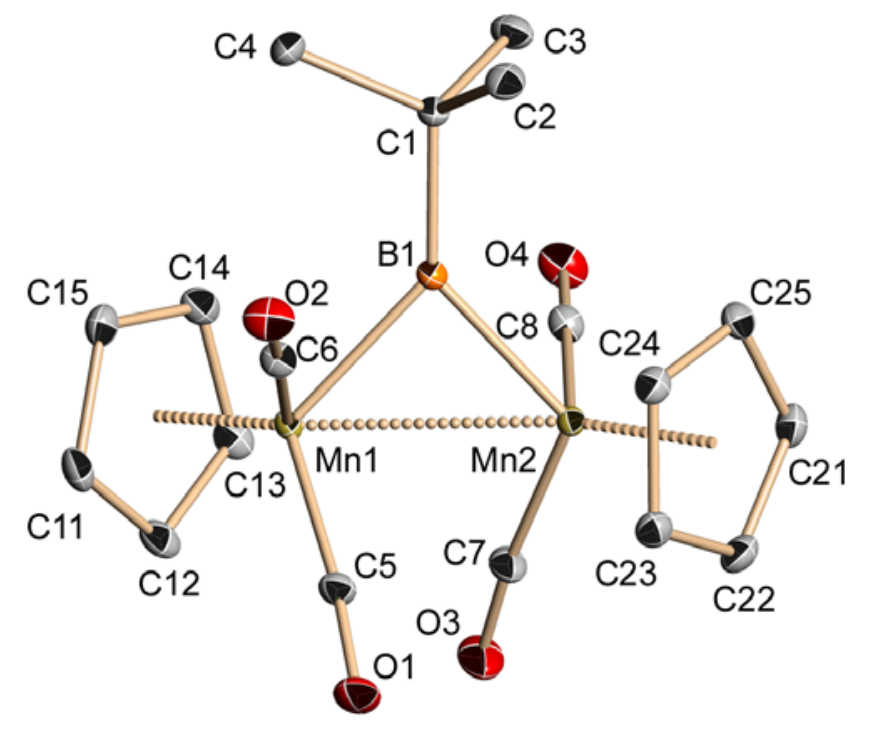

Figure 5-6: Molecular structure representation of $\left[\left\{\mathrm{Cp}(\mathrm{CO})_{2} \mathrm{Mn}\right\}_{2}\left(\mu-\mathrm{B}^{t} \mathrm{Bu}\right)\right](4)$

with atomic displacement parameters depicted at the $50 \%$ and hydrogen atoms omitted for clarity.

The $\mathrm{Mn}-\mathrm{B}$ bond paths are curved (Figure 5-7). Interestingly, the deviations from the straight paths, quantified by the take-off angles (TOAs) for the two $\mathrm{Mn}-\mathrm{B}$ bonds, are in the same range at the boron atom $\left(\mathrm{TOA}_{\mathrm{B} 1 \rightarrow \mathrm{Mn} 1}=5.81^{\circ}, \mathrm{TOA}_{\mathrm{B} 1 \rightarrow \mathrm{Mn} 2}=4.97^{\circ}\right)$ but not symmetrical at the two manganese atoms $\left(\operatorname{TOA}_{\mathrm{Mn} 1 \rightarrow B 1}=7.37^{\circ}, \operatorname{TOA}_{\mathrm{Mn} 2 \rightarrow B 1}=12.11^{\circ}\right)$.

These angles reflect the relative contributions of direct $\mathrm{B} \rightarrow \mathrm{Mn}$ donation in comparison to the $\mathrm{B} \leftarrow \mathrm{Mn}$ back-donation. ${ }^{[77,309]}$ The sum of the TOAs at the boron atom is $10.78^{\circ}$ and thus only half the value found at the manganese atoms $\left(19.48^{\circ}\right)$, indicating a dominant direct symmetrical $\mathrm{B} \rightarrow \mathrm{Mn}$ donation in contrast to less pronounced and non-symmetrical $\mathrm{B} \leftarrow \mathrm{Mn}$ back-donation. 


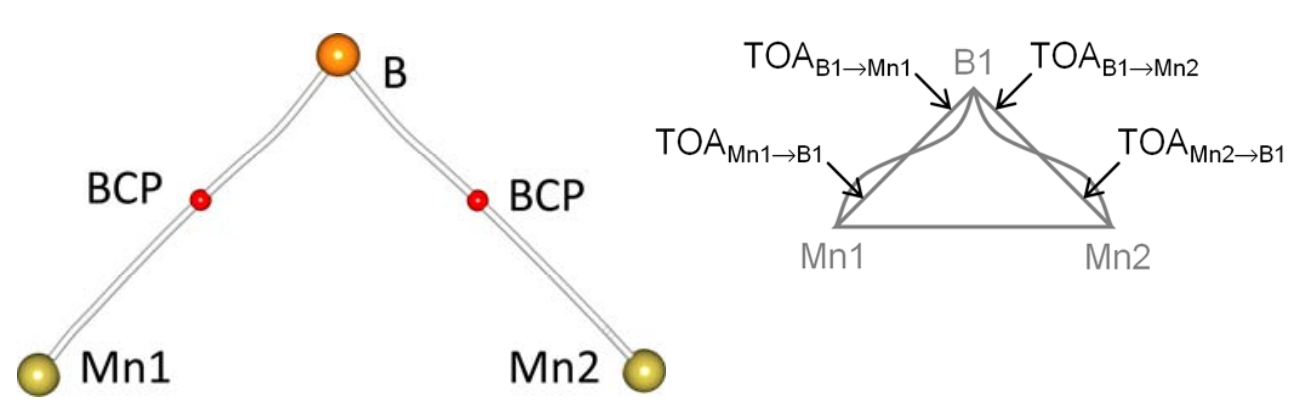

Figure 5-7: The boron atom is linked to the manganese atoms by bond paths with the corresponding bond critical points in $\mathbf{4}$ (red dots; left); definition of the take-off angles (right).

The build-up of positive charge at the boron atom, as predicted by DFTcalculations $^{[306,307]}$, is confirmed by the integrated charge $(+1.04$ e) from the QTAIM analysis of the experimental electron density distribution. This implies a kinetical lability and susceptibility for nucleophilic cleavage of the $\mathrm{Mn}-\mathrm{B}$ bond, which is stabilized by the sterically demanding tert-butyl group. ${ }^{[120,123,287]}$ The integrated charges of the manganese atoms are close to zero, -0.43 e for the central carbon atom of the tert-butyl group $\mathrm{C} 1$, and -0.35 e for the whole tert-butyl group. In sum, the positive charge at the boron atom is only partly counterbalanced by the negative charge of the tert-butyl group, thus leaving the $\mathrm{B}-{ }^{t} \mathrm{Bu}$ moiety with a charge of +0.69 e.

As the bonding situation in $\mathbf{4}$ was described to be of the borylene type, it should resemble that of carbonyl-bridged transition metal complexes. Consequently, one would expect a $3 c-2 e$ bond with an "electron lobe" from the boron atom directed towards the Mn-Mn midpoint. ${ }^{[77,306,307]}$

However, an inspection of the LAPLACIAN distribution $\nabla^{2} \rho(\mathbf{r})$ reveals the differences of the borylene-bridged complex compared to the carbonyl-bridged species: The first features three valence shell charge concentrations (VSCCs) around the boron atom (Figure 5-8). These VSCCs are positioned on the vectors linking the three bonded neighbors, the two manganese atoms and the central carbon atom of the tert-butyl group. 


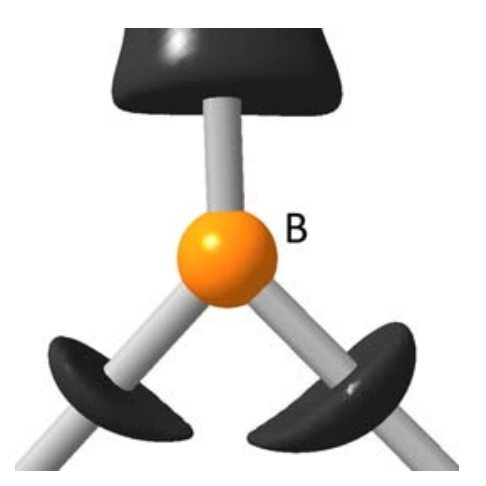

Figure 5-8: Isosurface representation of $\nabla^{2} \rho(\mathbf{r})$ around the boron atom in 4 , showing three valence shell charge concentrations on the bond vectors towards the bonding partners.

In contrast, the LAPLACIAN distribution of symmetrical, $\mu$-bridged species like $\mathrm{CO}_{2}(\mathrm{CO})_{8}$, shows only two VSCCS at the bridging carbon atom. One VSCC points at the carbonyl oxygen atom, while the other one is broadened and directed towards the Co-Co midpoint (Figure 5-9).

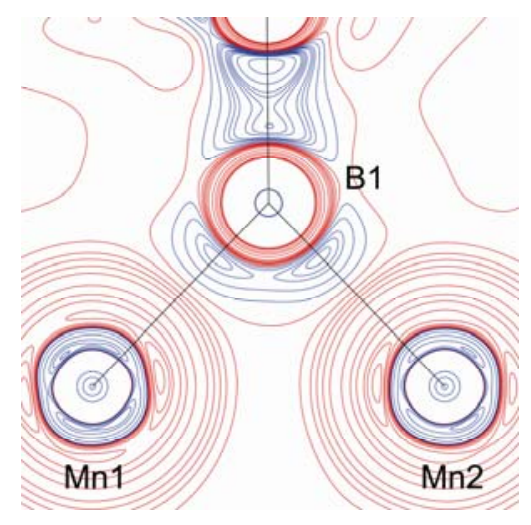

(1)

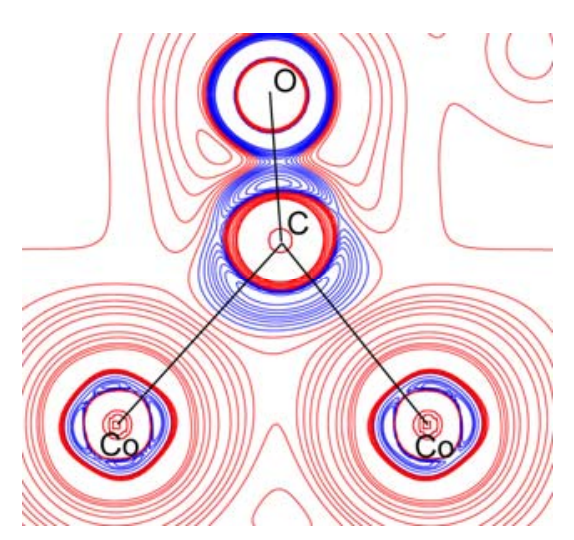

(2)

Figure 5-9: Contour plot of $\nabla^{2} \rho(\mathbf{r})$ in $\left[\left\{\mathrm{Cp}(\mathrm{CO})_{2} \mathrm{Mn}\right\}_{2} \mathrm{~B}\left(\mu-\mathrm{B}^{t} \mathrm{Bu}\right)\right]$ in the $\mathrm{Mn}_{2} \mathrm{~B}$ plane (4, left) and in $\mathrm{Co}_{2}(\mathrm{CO})_{8}$ in the $\mathrm{CO}_{2}(\mathrm{CO})$ plane (right).

\subsubsection{Metal-Metal-Bonding}

The ongoing discussion on metal-metal bonding in bridged and non-bridged organometallic complexes made $\left[\left\{\mathrm{Cp}(\mathrm{CO})_{2} \mathrm{Mn}\right\}_{2}\left(\mu-\mathrm{B}^{t} \mathrm{Bu}\right)\right](\mathbf{4})$ a paradigm model compound. When formulating the LEWIS structure of $\mathbf{4}$, one is tempted to draw a "bond" between the two manganese atoms in order to suit the 18-electron-rule. ${ }^{[118,310]}$ This assumption is further justified by the short distance between the two manganese 
atoms $\left(2.78 \AA\right.$ ) and the acute $M n-B-M n$ angle $\left(87^{\circ}\right)$. In addition, there is no experimental evidence for unpaired electrons in the complex.

Surprisingly, neither in the experiment nor from calculations at the bp/TZVP ${ }^{[177,180]}$ level of theory was a BP (and correspondingly a BCP) found between the two manganese atoms. This finding again supports the close relationship to its carbonylbridged analogues. The absence of BPs in supported transition metal-transition metal bonded complexes is well known and has been subject of several studies. ${ }^{[77]}$ Recently, there has been some discussion, if the absence of a bond path implies the absence of a bond. ${ }^{[229]}$ Only slight variations in the geometry of semi-bridged iron carbonyl complexes cause the abrupt disappearance of the BP while other bond descriptors change in a physically more meaningful way. ${ }^{[105]}$ Apparently, the formation of a BP can also be averted by a general raising of the level of the density in the bonding region in three-membered rings. ${ }^{[75]}$

An examination of the total electron density $\rho(\mathbf{r})$ (Figure 5-10a) already reveals an indentation in the $\mathrm{Mn}-\mathrm{Mn}$ region and the orthogonal gradient-vector trajectories (Figure 5-10b) explain, why the formation of an Mn-Mn BP is prevented: The atomic basin of the boron atom spreads out between the two manganese atom basins and inhibits the formation of a saddle point.
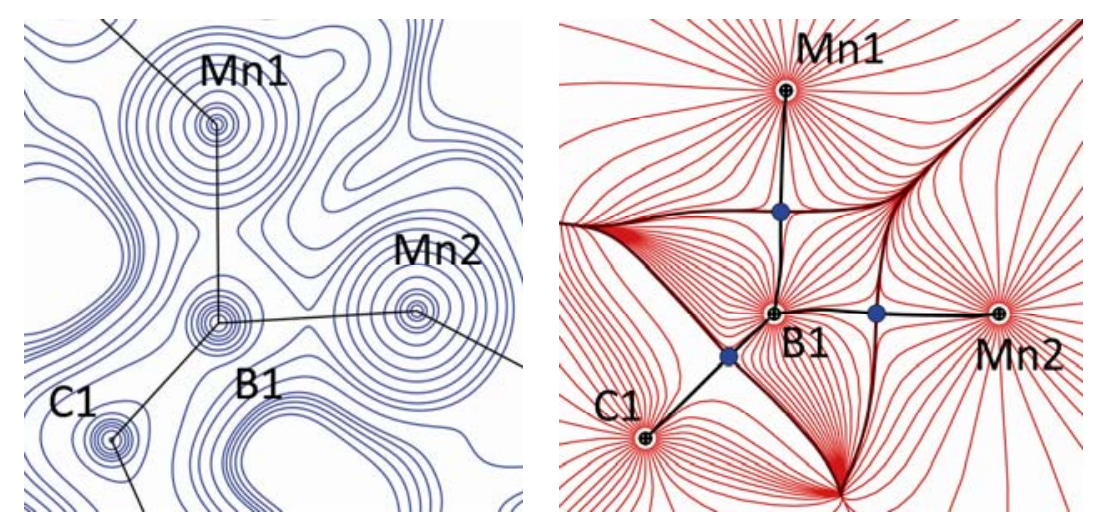

Figure 5-10: Contour plot of the density $\rho(\mathbf{r})$ in the $\mathrm{Mn}_{2} \mathrm{~B}$ plane of 4 (left); gradient vector field in the same plane (right).

Focusing on the metal-metal interaction, the source function (SF) ${ }^{[85]}$ provides a very efficient tool for the analysis of EDDs. It is suitable for determining the contribution of functional groups to the electron density at defined points, e.g. at BCPs and allows the 
quantification of weak interactions like hydrogen bridging ${ }^{[86-88,90]}$ or metal-metal bonds, ${ }^{[89]}$ where the topological indicators are not as decisive as in classical $2 \mathrm{c}-2 \mathrm{e}$ bonds.

Due to the non-existent $\mathrm{BCP}$, the local SF was determined on experimentally as well as theoretically derived charge distributions along the $\mathrm{Mn}-\mathrm{Mn}$ vector (Figure 5-11) with the midpoint $(\mathrm{MP})^{[89]}$ taken as the reference point. The density at the MP was determined to be 0.2 e $\AA^{-3}$. The property profiles derived from theory and experiment show a very good agreement. The LAPLACIAN remains positive in a large interval around the midpoint and consequently the SF is negative in the same range.

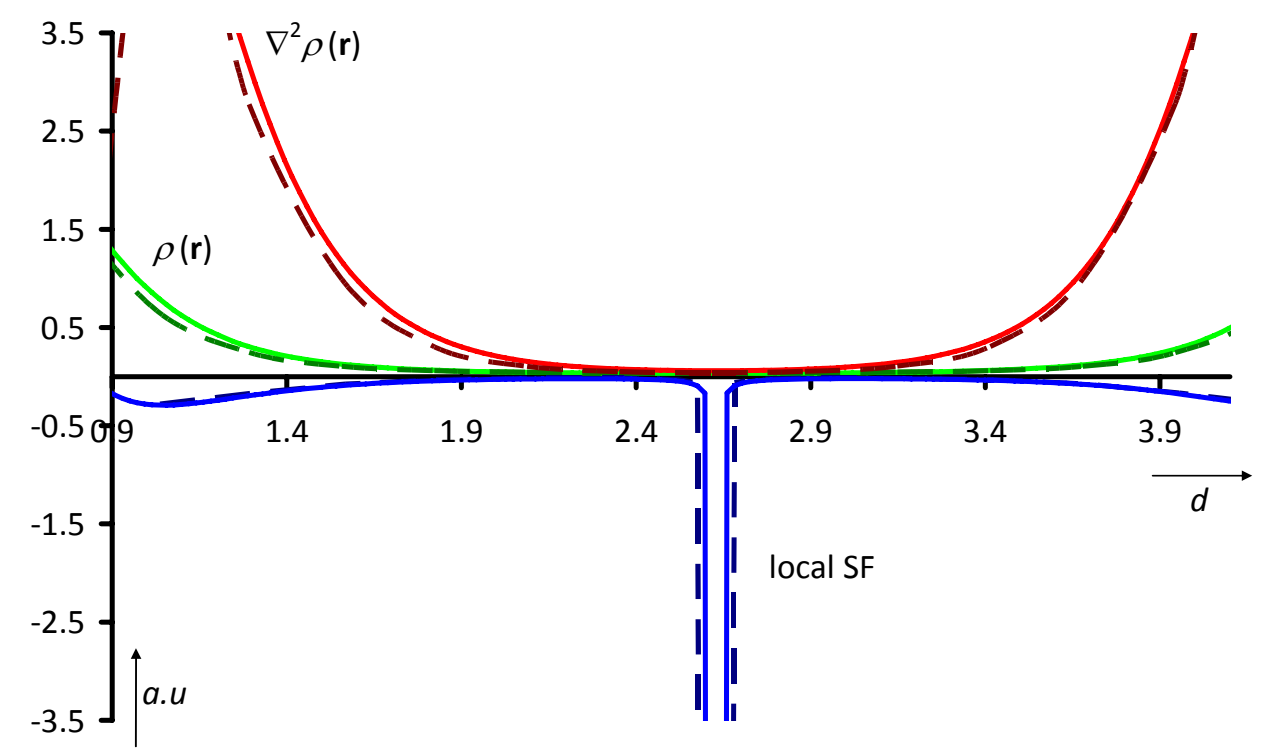

Figure 5-11. Property profiles in a.u. along the metal-metal vector with $\mathrm{d}$ being the distance from $\mathrm{Mn} 1$ (red: $\nabla^{2} \rho(\mathbf{r})$; green: $\rho(\mathbf{r})$; blue: local SF; dashed lines represent theoretical data) in $\mathbf{4}$.

In addition, the integrated SF was examined to determine the density contributions at the MP. More than $50 \%$ of the density at the MP is contributed by the carbonyl groups, while the bridging boron atom is subtracting density from the MP $(S(B)=-11.69 \%))$. Following the arguments of GATTI and LASI, the SF of 4 depicts the $\mathrm{Mn}-\mathrm{Mn}$ bond as strongly non-localized, ${ }^{[111]}$ because the metal atoms serve as sinks $(\mathrm{S}(\mathrm{Mn} 1)=-9.27 \%$ and $\mathrm{S}(\mathrm{Mn} 2)=-7.93 \%)$ rather than being sources of bond density. ${ }^{[89]}$ 
Table 5-3: Experimental and theoretical topological features of 4 and the related key metal carbonyls $\left[\mathrm{Co}_{2}(\mathrm{CO})_{8}\right]^{[312,313]}$ and $\left[\mathrm{Mn}_{2}(\mathrm{CO})_{10}\right]^{[107,108,314]}$ at the $\mathrm{M}-\mathrm{M}$ midpoint or at the $\mathrm{BCP}$, respectively.

\begin{tabular}{|c|c|c|c|c|c|c|c|}
\hline & & $\begin{array}{c}d(M-M) \\
{[\AA]}\end{array}$ & $\begin{array}{c}\rho \rho(r) \\
{\left[e \AA^{-3}\right]}\end{array}$ & $\begin{array}{l}\nabla^{2} \rho(r) \\
{\left[\text { e } \AA^{-5}\right]}\end{array}$ & $\begin{array}{c}\text { G } \\
\text { [a.u.] }\end{array}$ & $\begin{array}{c}|\mathrm{V}| \\
\text { [a.u.] }\end{array}$ & $|V| / G$ \\
\hline \multirow{2}{*}{ a) } & & 2.782 & 0.217 & 1.428 & 0.019 & 0.014 & 0.737 \\
\hline & & 2.807 & 0.263 & 0.952 & 0.020 & 0.024 & 1.200 \\
\hline \multirow{2}{*}{ b) } & & $2.538^{[\mathrm{a}]}$ & - & - & - & - & - \\
\hline & & 2.548 & 0.311 & 2.101 & 0.035 & 0.048 & 1.371 \\
\hline \multirow{2}{*}{ c) } & oc co co co & 2.903 & 0.144 & 0.720 & 0.014 & 0.012 & 0.857 \\
\hline & ${ }^{O C}$ oc Co co & 2.906 & 0.200 & -0.071 & 0.009 & 0.017 & 1.889 \\
\hline
\end{tabular}

[a] For b) no further experimental values are available because the charge density study in ref. 309 did not include a QTAIM analysis.

According to the bond descriptors shown in Table 5-3 the Mn-Mn distance in 4 is shorter and the density at the midpoint accordingly higher compared to $\left[\mathrm{Mn}_{2}(\mathrm{CO})_{10}\right]$, which is commonly believed to feature an $\mathrm{Mn}-\mathrm{Mn}$ bond. However, the ratio $|\mathrm{V}| / \mathrm{G}$, which classifies bonding by energy density considerations, is the smallest in the series $\left[\mathrm{Mn}_{2}(\mathrm{CO})_{10}\right]^{[107,108,314]},\left[\mathrm{Co}_{2}(\mathrm{CO})_{8}\right],{ }^{[89,312,313]}$ and $\left[\left\{\mathrm{Cp}(\mathrm{CO})_{2} \mathrm{Mn}\right\}_{2}\left(\mu-\mathrm{B}^{t} \mathrm{Bu}\right)\right],(4)$.

In the framework of BADER'S QTAIM the interpretation of the experimentally and theoretically derived electron density of $\mathbf{4}$ concordantly excludes the existence of a $\mathrm{Mn}-\mathrm{Mn}$ bond. However, this result cannot unambiguously be deduced from the employed indecisive bond descriptors. Like in other examples the density distribution in the triangular motif might prevent the formation of a bond path. With this complex however, the $\mathrm{Mn}-\mathrm{B}$ bonding shows that electron-pairing is accomplished via the boron atom and hence bonding is delocalized. The bond paths to the boron ligand serve as preferred exchange channels ${ }^{[315]}$ and preclude the postulation of a diradical. Hence the findings are in tune with the experimental diamagnetic nature of the complex. 


\subsubsection{Coordination of $\mu$ - and $\mu^{5}$ - Carbon Ligands}

Additional ligands are present in $\mathbf{4}$. As the bonding situation of transition metal-carbon bonds has already extensively been discussed, only a few words will be spent on this.

Regarding the group charges of the two Cp-rings $(-0.09$ and $+0.24 \mathrm{e})$, a molecular asymmetry is revealed. The positive charges have to be counterbalanced primarily by the four carbonyl groups. Interestingly, the $\mathrm{CO}$ group charges differ from approx. zero (C5-O1 and $\mathrm{C} 7-03)$ to -0.24 and -0.27 e (C6-O2 and C8-04, respectively). This asymmetry is mirrored in the signals for the $\mathrm{Cp}$ and CO ligands in the IR spectrum (calc. $V\left[\mathrm{~cm}^{-1}\right] \mathrm{Cp}_{\text {rot. }} 28.0$ and 54.7; $\mathrm{CO}_{\text {stretch }} 1900.6,1916.0$ (asym.) and 1937.1, 1968.9 (sym.)).

Both negatively charged $\mathrm{CO}$ groups on the same side of the $\mathrm{Mn}-\mathrm{Mn}$ line as the $\mathrm{B}^{\mathrm{t}} \mathrm{Bu}$ unit. In a projection along the $\mathrm{Cp}$-ring center-Mn vector these carbonyl groups are oriented "eclipsed" to two of the four ring carbon atoms which form BPs to the manganese atoms. Only two BPs are made up between each manganese atom and the corresponding $\mathrm{Cp}$-ring. The establishment of a BP is supported by either short $\mathrm{Mn}-\mathrm{C}_{\text {ring }}$ distances $(C(15)$ and $C(25))$ or tagged eclipsed orientation $(C(12)$ and $C(22))$. The dependence of BP formation from metal-ring carbon distances as well as from the rotation angle of the ring is a known feature of these interactions. All four paths are remarkably curved at the carbon atoms $\left(\mathrm{TOA}=10.29^{\circ}\right.$ to $\left.67.60^{\circ}\right)$, which indicates, together with the fact that just two of the five anticipated Mn-C BPs are found, a small contribution of direct $\mathrm{C} \rightarrow \mathrm{M}$ donation.
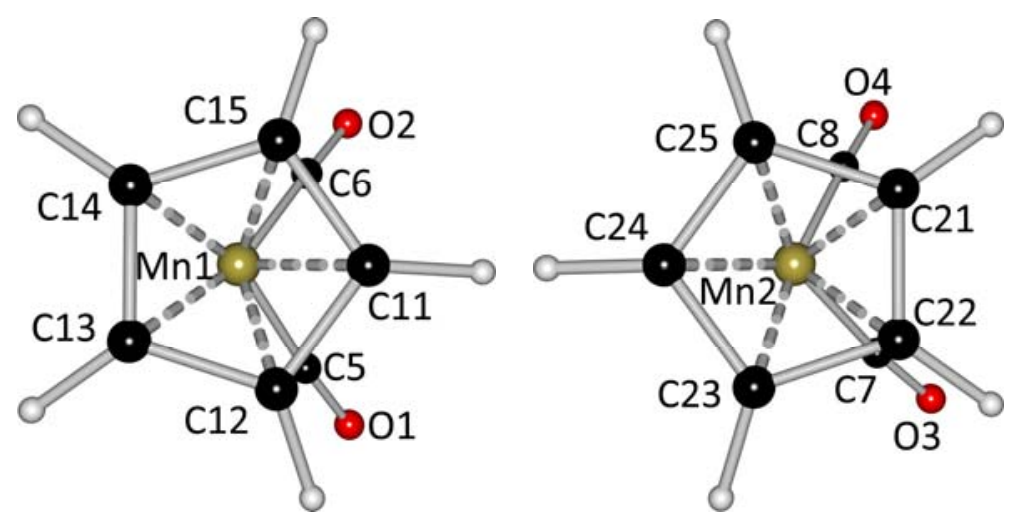

Figure 5-12: Arrangement of the carbonyl groups in relation to the $\mathrm{Cp}$-rings in 4. 
In the vicinity of each manganese atom in $\mathbf{4}$ six charge concentrations (CCs) are detected in a distorted octahedral geometry, one of which faces a VSCC at the boron atom, indicating contributions of shared interactions. Ligand-induced charge concentrations (LICCS) are found trans as well as cis to the bonding charge concentration. $^{[231]}$

The VSCCs of the carbon atoms of the carbonyl groups face charge depletions at the manganese atoms (Figure 5-13).

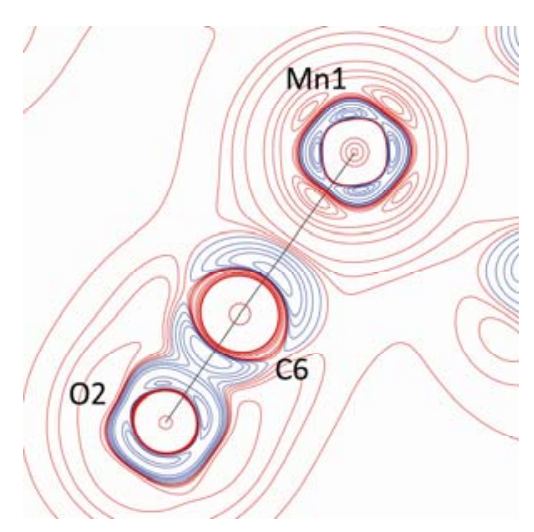

Figure 5-13: Contour of the LAPLACIAN distribution in the Mn1-C6-O2 plane of 4, showing one VSCC of the carbonyl carbon atom facing a charge depletions at the manganese atom and one VSCC being directed towards the oxygen atom.

The $\mathrm{Cp}$-coordination is made up of a CC at the corresponding manganese atom oriented towards the ring center (Figure 5-14), while the VSCCs at the ring carbon atoms are oriented outwards the straight $\mathrm{Mn}-\mathrm{C}$ paths. The outer shell structure of the manganese atoms, showing well resolved charge concentrations and depletions, is indicative of the superb quality of the data.
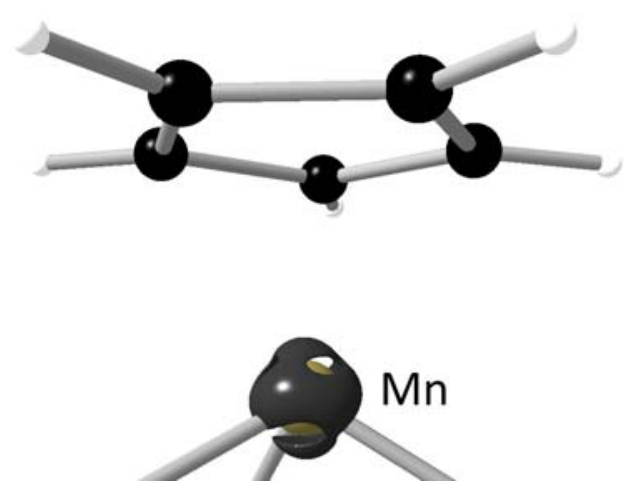

Figure 5-14: Isosurface representation of the LAPLACIAN distribution around the manganese atom in 4. 
The arrangement and related values of the CCs coincide with the calculated $d$-orbital populations from the refined multipole parameters. ${ }^{[147]}$ The orbital population analysis leads to net charges of -0.73 and -0.76 e for the two manganese atoms. The $d_{z^{2}}$-orbitals reveal the highest population, reflecting the predominant contribution of these orbitals to the $\mathrm{Mn}-\mathrm{Cp}$ bonds (Table 5-4). Therefore its shape is mimicked by the static deformation density distribution (Figure 5-15). [309]

Table 5-4: $d$-orbital populations of 4 from the multipole parameters.

\begin{tabular}{|c|c|c|c|c|c|}
\hline & $\mathbf{z}^{\mathbf{2}}$ & $\mathbf{x z}$ & $\mathbf{y z}$ & $\mathbf{x}^{\mathbf{2}}-\mathbf{y}^{\mathbf{2}}$ & $\mathbf{x y}$ \\
\hline $\mathbf{M n}(\mathbf{1})$ & 1.51 & 0.91 & 0.79 & 1.33 & 1.19 \\
\hline $\mathbf{M n}(\mathbf{2})$ & 1.43 & 0.81 & 0.88 & 1.24 & 1.37 \\
\hline
\end{tabular}

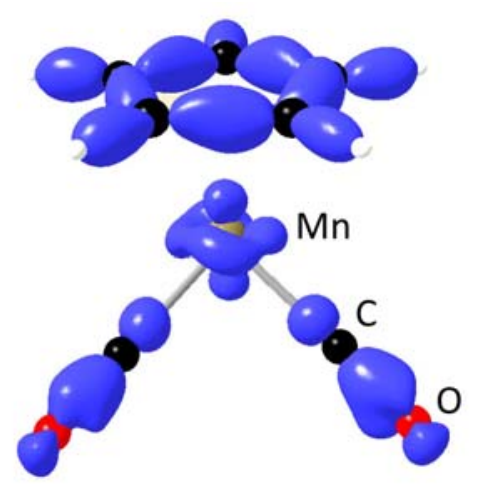

Figure 5-15: Static deformation density of 4

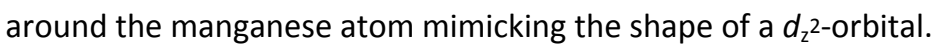

\subsubsection{Conclusion}

In summary, the apparently simple question of bonding between the metal atoms still cannot be answered ultimately by the present bond descriptors. Clearly, further experiments on the complex metal-metal bonding will provide even more sophisticated bond descriptors and point the way to more resilient concepts.

The LAPLACIAN distribution around the boron atom with its three VSCCS clearly shows the difference between the borylene ligand and the carbonyl ligand. Consequently, 4 obviously has to be classified as a dimetallaborane rather than a borylene complex. 


\section{CONCLUSION AND OUTLOOK}

Two major aims have been pursued in the course of this thesis. On the one hand, reasons for the different reactivities of two LEWIS acids based on tris(pentafluorophenyl)borane, namely bis(pentafluorophenyl)( $N$-pyrrolyl)borane (1) and bis(pentafluorophenyl)(N-pyrrolidinyl)borane (2) were to be elucidated. On the other hand, the nature of the bonding between a transition metal and a boron atom in borylene complexes was to be examined for two exemplary compounds, a terminal (3) and a bridging borylene complex (4). In order to answer these questions, experimental electron density studies have been performed on four different compounds. Multipole refinements have been carried out on high-resolution data from the low-temperature X-ray diffraction experiments. The electron density distributions obtained were analyzed topologically in accordance with BADER's quantum theory of atoms in molecules (QTAIM). The chemical interpretation of the resulting descriptors facilitated the elucidation of the question raised above.

\subsection{Experimental Electron Density Studies on LEWIS Acidic Organoboron Complexes}

Electrophilic boranes are amongst other applications used for the generation of electron-deficient early transition metal cations. By the abstraction of an alkyl-group they activate the catalyst precursor, which can then be employed in polymerization reactions. As the cations formed often build ion pairs with the co-catalyst, i.e. the electrophilic borane, the properties of the borane influence the activity of the catalyst.

The electrophilic tris(pentafluorophenyl)borane $\mathrm{B}\left(\mathrm{C}_{6} \mathrm{~F}_{5}\right)_{3}$ is a widely applied reagent for these kind of reactions, as the boron atom shows a high LEWIS acidity due to the electron-withdrawing pentafluorophenyl groups. Owing to this very pronounced electron-withdrawing characteristics, a precise adjustment of the reactivity can only be achieved by a variation of these ligands. The group of Prof. ERKER succeeded in synthesizing borane complexes in which one of the pentafluorophenyl substituents is replaced by a pyrrol or a pyrrolidin ring, respectively. The reactivities of the two compounds are fundamentally different: While the pyrrolyl-substituted derivative, 
$\left[\left(\mathrm{C}_{6} \mathrm{~F}_{5}\right)_{2} \mathrm{~B}\left(\mathrm{NC}_{4} \mathrm{H}_{4}\right)\right]$, still shows a marked LEWIS acidity and thus can be utilized as a co-catalyst, the pyrrolidinyl-substituted derivative, $\left[\left(\mathrm{C}_{6} \mathrm{~F}_{5}\right)_{2} \mathrm{~B}\left(\mathrm{NC}_{4} \mathrm{H}_{8}\right)\right]$, does no longer show this ability. As, in most cases, LEWIS acidity relies upon an electronic depletion, the examination of the electronic structures of the molecules allows inferences on the reasons for the change in reactivity.

In both molecules the electron-withdrawing pentafluorophenyl substituents cause a pronounced electronic depletion at the boron atoms. This is clearly reflected by the positive BADER charges and the positive electrostatic potentials of the boron atoms. However, a difference in magnitude can be observed. While this electronic depletion is partly compensated by the pyrrolidinyl substituent, this can hardly be observed for the pyrrolyl substituent. The compensation of the electronic depletion is achieved via a delocalization of the lone pair from the nitrogen's $\mathrm{p}$-orbital into the $\mathrm{B}-\mathrm{N}$ bond or the coupling of the lone pair in the delocalized system resulting in its expansion over the $\mathrm{B}-\mathrm{N}$ bond. From electron density studies, these $p_{\pi}-p_{\pi}$-interactions can be concluded from an ellipticity along the $\mathrm{B}-\mathrm{N}$ bond differing significantly from zero. However, again gradual differences can be observed. The ellipticity along the $\mathrm{B}-\mathrm{N}$ bond in $\left[\left(\mathrm{C}_{6} \mathrm{~F}_{5}\right)_{2} \mathrm{~B}\left(\mathrm{NC}_{4} \mathrm{H}_{8}\right)\right]$ is higher than in $\left[\left(\mathrm{C}_{6} \mathrm{~F}_{5}\right)_{2} \mathrm{~B}\left(\mathrm{NC}_{4} \mathrm{H}_{4}\right)\right]$. Consequently, the delocalization of the electron density over the $\mathrm{B}-\mathrm{N}$ bond is more pronounced in $\left[\left(\mathrm{C}_{6} \mathrm{~F}_{5}\right)_{2} \mathrm{~B}\left(\mathrm{NC}_{4} \mathrm{H}_{8}\right)\right]$ than in $\left[\left(\mathrm{C}_{6} \mathrm{~F}_{5}\right)_{2} \mathrm{~B}\left(\mathrm{NC}_{4} \mathrm{H}_{4}\right)\right]$.

This can easily be understood, when keeping in mind, that a complete coupling of the nitrogen's electron pair into the $\mathrm{B}-\mathrm{N}$ bond would remove electrons from the aromatic system in $\left[\left(\mathrm{C}_{6} \mathrm{~F}_{5}\right)_{2} \mathrm{~B}\left(\mathrm{NC}_{4} \mathrm{H}_{4}\right)\right]$, and thus disturb the aromaticity. Instead, the aromatic system expands out of the ring system into the $\mathrm{B}-\mathrm{N}$ bond. Compared to that, the $\mathrm{B}-\mathrm{N}$ bonding situation in the molecule with the non-aromatic heterocycle features a lone pair at the nitrogen atom which can totally be used for the $\mathrm{B}-\mathrm{N}$ bond reinforcement. This leads to an increased $\pi$-character of the bond in $\left[\left(\mathrm{C}_{6} \mathrm{~F}_{5}\right)_{2} \mathrm{~B}\left(\mathrm{NC}_{4} \mathrm{H}_{8}\right)\right]$ relative to $\left[\left(\mathrm{C}_{6} \mathrm{~F}_{5}\right)_{2} \mathrm{~B}\left(\mathrm{NC}_{4} \mathrm{H}_{4}\right)\right]$.

The different strength of the bonding of the two nitrogen atoms to their neighboring atoms is also be reflected by the values of the valence shell charge concentrations (VSCCs) at the nitrogen atoms. In the pyrrolyl-substituted derivative, the VSCCs pointing in the direction of the ring carbon atoms show higher values compared to the VSCC directed towards the boron atom. In the pyrrolidinylsubstituted derivative, however, the boron-directed VSCC dominates. 
These gradual differences of the descriptors, which can solely be ascribed to the aromatic or non-aromatic character of the newly introduced substituents and the resulting differences in the nature of the $\mathrm{B}-\mathrm{N}$ bond, are crucial for the reactivity.

A very descriptive interpretation of the differences in the reactivity is given by the reactive surface. Holes in this isosurface of the LAPLACIAN are points for nucleophilic attack, or expressed the other way round, electrophilic parts of the molecule analyzed. While the isosurface around the boron atom in $\left[\left(\mathrm{C}_{6} \mathrm{~F}_{5}\right)_{2} \mathrm{~B}\left(\mathrm{NC}_{4} \mathrm{H}_{4}\right)\right]$ exhibits exposed areas on top and on bottom, the boron atom in $\left[\left(\mathrm{C}_{6} \mathrm{~F}_{5}\right)_{2} \mathrm{~B}\left(\mathrm{NC}_{4} \mathrm{H}_{8}\right)\right]$ is electronically shielded by claws formed by this isosurface.

Thus, with the help of experimental electron density studies, the reasons for the different reactivities of $\left[\left(\mathrm{C}_{6} \mathrm{~F}_{5}\right)_{2} \mathrm{~B}\left(\mathrm{NC}_{4} \mathrm{H}_{4}\right)\right]$ and $\left[\left(\mathrm{C}_{6} \mathrm{~F}_{5}\right)_{2} \mathrm{~B}\left(\mathrm{NC}_{4} \mathrm{H}_{8}\right)\right]$ could be determined. This clearly demonstrates that experimental electron density studies can give definite answers to chemical questions. The examination of these two model compounds with known reactivity provides a relation between the electronic structure and the reactivity of the two compounds. An expansion of these studies on other LEWIS acids of the same structural type could allow for a quantification of these relations. Tris(pentafluorophenyl)borane, for example, could be another "measuring point", at which the gradual reactivity could be linked to the descriptors from electron density studies. The known better reactivity of this compound should be reflected by them. An examination of the reactivity as well as the electron density distribution of tris(pyrrolyl)borane would also be interesting to confirm the results obtained. By means of such systematic studies, it could become possible to predict the reactivity of a compound. This relation between structure and reactivity could noticeably eased the development of enhanced co-catalysts.

\subsection{Experimental Electron Density Studies on Transition Metal-Boron Complexes}

There are numerous compound classes, in which a transition metal atom is bonded to a boron atom. The nature of the bond between these two atoms, which controls the structure and the reactivity of a compound, is manifold and in many cases not unambiguously clarified. While borides, metallaboranes and transition metal 
complexes with boron heterocycles have already been known for quite some time, the class of transition metal complexes of boron constitutes a rather new compound class. This compound class can be subdivided into three groups depending on the coordination number of the boron atom and the number of transition metal-boron bond, namely borane, boryl and borylene complexes.

Due to the structural relation to the isolobal carbonyl group, the borylene ligand attracted special interest. Borylene ligands shows, just as their the carbon analogues, different coordination modes to the transition metal atom. Thereby, the transition metal-boron bond, however, is more stable against cleavage than the corresponding transition metal-carbon bond. This can mainly be assigned to the more advantageous energetic level of the $\sigma$ donor orbitals as the energy of the $\pi^{*}$ orbitals stays roughly the same. The narrow HOMO-LUMO gap induces a positive charge at the boron atom, which is therefore susceptible towards nucleophilic attack. Kinetic stability can be achieved by a steric shielding from bulky ligands at the boron atom. In addition, it could be shown, that selected metal fragments, like for example $\left\{\mathrm{CpMn}(\mathrm{CO})_{2}\right\}_{2}$, result in reducing the kinetic instability to a certain extent by lowering the imbalance between the HOMO and the LUMO.

Numerous theoretical studies on different borylene complexes present unequal answers on the character of the transition metal-boron bond. Therefore, in the work leading to this thesis, electron density studies of a terminal as well as a bridged borylene complex have been performed.

$\left[(\mathrm{CO})_{5} \mathrm{CrBN}\left(\mathrm{SiMe}_{3}\right)_{2}\right]$ was chosen a the terminal borylene complex. Even if the IAM refinement provided promising results, distinct residual density maxima were present after the multipole refinement, from which a rotational disorder has to be inferred. An IAM refinement including the disorder proved to be unstable, but accomplishable, while a multipole refinement based on this IAM refinement failed just like an invariom refinement of the disordered molecule. As the maxima of the residual density distribution after the multipole refinement not considering the disorder clearly showed the features of the disorder, it was assumed, that the multipole model obviously only describes the electron density of the main component. Therefore, an analysis of the electron density distribution obtained was performed. As the reliability of such investigations is not sufficiently known, supporting theoretical calculations are indispensable in this case and are being performed. 
The topological analysis of the experimental electron density showed a surprising bonding situation for the $\mathrm{B}-\mathrm{N}$ bond in $\left[(\mathrm{CO})_{5} \mathrm{CrBN}\left(\mathrm{SiMe}_{3}\right)_{2}\right]$. The low ellipticity along the whole bond path excludes the description of the bond as a double bond as it has been expected. The LAPLACIAN distribution rather leads to the description of the $\mathrm{B}-\mathrm{N}$ bond as being strongly polarized, if not even ionic. The examination of the $\mathrm{Cr}-\mathrm{B}$ bond revealed a discrepancy between the theoretical and the experimental results. This can most probably be assigned to the disorder. The theoretical calculations show one VSCC at the boron atom pointing towards a charge depletion at the chromium atom. In accordance with the other bond descriptors at the bond critical point of the $\mathrm{Cr}-\mathrm{B}$ bond, the bonding situation can be characterized in the same way known for the carbon analogues, the carbonyl complexes.

The examination of the bridged borylene complex was performed on $\left[\left\{\mathrm{Cp}(\mathrm{CO}){ }_{2} \mathrm{Mn}\right\}_{2} \mathrm{~B}\left(\mu-\mathrm{B}^{t} \mathrm{Bu}\right)\right]$. The predicted kinetic instability of the borylene is mitigated in this compound by two factors: On the one hand, the complexation was achieved with the $\left\{\mathrm{CpMn}(\mathrm{CO})_{2}\right\}_{2}$-fragment, which, as already described above, reduces the instability and on the other hand by the borylene ligand being a tert-butyl-borylene, which has a sterically demanding organic group, shielding the boron atom additionally against nucleophilic attack.

The coordination of the borylene ligand to the transition metal shows a significant difference to the bridging carbonyl complexes, which is was assigned to be related to by bonding. Two VSCCs are found at the carbonyl carbon atom, one of which points towards the carbonyl oxygen atom, while the other one is broadened and directed towards the middle of the metal-metal bond. At the borylene boron atom, however, three VSCCS are found each pointing in the direction of one of the bonding partners. The examination of the bond paths between the transition metal atoms and the boron atom show a pronounced curvature, which is indicative of bond delocalization. The inspection of the angles between the bond paths and the direct atom-atom vectors at the boron atom and the two manganese atoms allows for a quantification of this delocalization. The dimension of the angles implies a dominant direct and symmetrical donating interaction from the boron to the manganese atoms and an indirect, less pronounced and unsymmetrical manganese-boron back bond.

Besides the transition metal-boron bond in the bridging molecule another structural motif of constant interest was present. For bridging carbonyl complexes it is 
postulated, that no metal-metal bond is found. This could also be observed with the borylene complexes. The QTAIM analysis of neither the theoretically nor the experimentally derived electron densities showed a bond path between the two manganese atoms. An examination of the source function illustrates, that the manganese atoms rather withdraw density from the bond than donate. This implies the presence of a non-localized bond. As the complex under investigation does not show any sign of paramagnetism, a coupling of the electrons via the boron atom seems feasible, the more so as bond paths, found between the manganese atoms and the boron atom, were described to serve a privileged exchange channels for electron interactions.

Even if no bond critical point was found, an increased electron density - albeit on a very low level - could be found between the two manganese atoms. This could also be interpreted as some kind of interaction. Therefore, for a concluding review either more investigations or the development of more specific descriptors are necessary, to be able to describe bonding situations like metal-metal bonds unambiguously.

The examination of the two borylene complexes as performed in the work leading to this thesis clearly shows that the borylene complexes are promising model systems due to their interesting bonding situation. The examination of a non-disordered terminal borylene complex is still missing. Especially the investigation of a nondisordered crystal of $\left[(\mathrm{CO})_{5} \mathrm{CrBN}\left(\mathrm{SiMe}_{3}\right)_{2}\right]$ would give, next to the information on bonding itself, an insight in the reliability of electron density properties obtained from a disordered structure.

The topic of borylene complexes provides a large playground for questions, as compounds with transition metals are generally still sparsely understood. Thus, the bonding in a bridging alkylborylene complex is now, due to the electron density studies, understood, the aminoborylene analogues however were only investigated theoretically. What is more, numerous theoretical studies have been performed on boryl complexes, but up to now, there is no such electron density investigation. Also borides, which are assigned to have ionic, covalent and metallic bonding contributions, are appealing targets. 


\section{ZUSAMMENFASSUNG UND ZUKÜNFTIGE ZIELE}

Im Rahmen dieser Doktorarbeit wurden hauptsächlich zwei Ziele verfolgt. Zum einen sollten die Gründe für die Reaktivitätsunterschiede der zwei, auf Tris(pentafluorophenyl)boran basierenden, LEWIS-Säuren Bis(pentafluorophenyl)( $N$-pyrrolyl)boran (1) und Bis(pentafluorophenyl)(N-pyrrolidinyl)boran (2) aufgeklärt werden. Zum anderen sollte die Natur der Übergangsmetall-Bor-Bindung in Borylen-Komplexen an zwei Beispielen, einem terminalen (3) und einem verbrückten Borylen-Komplex (4), untersucht werden. Zur Beantwortung dieser Fragen wurden experimentelle Elektronendichteuntersuchungen an vier Verbindungen unternommen. Mithilfe hochaufgelöster Daten aus Tieftemperatur-Röntgenbeugungsexperimenten wurden Multipolverfeinerungen durchgeführt. Die so erhaltenen Elektronendichteverteilungen wurden mithilfe von BADERS Quantentheorie von Atomen in Molekülen (QTAIM) topologisch analysiert. Die chemische Interpretation der resultierenden Deskriptoren erlaubte die Aufklärung obiger Fragestellungen.

\subsection{Experimentelle Elektronendichteuntersuchungen von LEWIS-sauren Organoborverbindungen}

Elektrophile Borane werden unter anderem zur Darstellung von elektronenarmen frühen Übergangsmetallkationen eingesetzt. Durch das Abstrahieren einer AlkylGruppe aktivieren sie die Vorstufe des Katalysators, der dann für Polymerisationsreaktionen eingesetzt werden kann. Da die gebildeten Kationen häufig lonenpaare mit dem Cokatalysator, also dem elektrophilen Boran, bilden, sind die Eigenschaften des Borans mitentscheidend für die Aktivität des Katalysators.

Ein häufig verwendetes Reagenz für diese Reaktionen ist das elektrophile Tris(pentafluorophenyl)boran, $\mathrm{B}\left(\mathrm{C}_{6} \mathrm{~F}_{5}\right)_{3}$, da das Boratom aufgrund der stark elektronenziehenden Pentafluorophenylgruppen eine hohe LEWIS-Acidität aufweist. Aufgrund dieser sehr ausgeprägten elektronenziehenden Eigenschaften kann eine genaue Anpassung der Reaktivität nur durch Variation dieser Liganden erreicht werden. Der Gruppe von Prof. ERKER ist es gelungen, Boran-Komplexe zu synthetisieren, in denen einer der Pentafluorophenyl-Substituenten durch entweder einen Pyrrol- oder einen 
Pyrrolidin-Ring ersetzt wurde. Die Reaktivitäten der beiden erhaltenen Verbindungen sind grundsätzlich verschieden: Während das pyrrolyl-substituierte Derivat, $\left[\left(\mathrm{C}_{6} \mathrm{~F}_{5}\right)_{2} \mathrm{~B}\left(\mathrm{NC}_{4} \mathrm{H}_{4}\right)\right](\mathbf{1})$, weiterhin eine ausgeprägte LEWIS-Acidität zeigt und somit als Cokatalysator eingesetzt werden kann, hat das pyrrolidinyl-substituierte Derivat, $\left[\left(\mathrm{C}_{6} \mathrm{~F}_{5}\right)_{2} \mathrm{~B}\left(\mathrm{NC}_{4} \mathrm{H}_{8}\right)\right](2)$, diese Fähigkeit gänzlich verloren. Da die LEWIS-Acidität häufig auf einer elektronischen Verarmung beruht, erlaubt die Untersuchung der elektronischen Strukturen der Moleküle Rückschlüsse auf die Ursachen dieses Reaktivitätswandels.

In beiden Molekülen sorgen die elektronenziehenden PentafluorophenylSubstituenten für einen ausgeprägten Elektronendichtemangel an den Boratomen. Dies spiegelt sich deutlich in den positiven BADER-Ladungen und den positiven elektrostatischen Potentialen der Boratomen wider. Es zeigt sich jedoch ein Unterschied in der Ausprägung. Während durch den Pyrrolidinyl-Substituenten dieser Elektronenmangel teilweise ausgeglichen wird, ist dies beim Pyrrolyl-Substituenten kaum zu beobachten. Der Ausgleich des Elektronenmangels erfolgt mittels einer Delokalisierung des freien Elektronenpaares aus dem p-Orbital des Stickstoffatoms in die B-N-Bindung bzw. einem Einkoppeln des freien Elektronenpaares in das delokalisierte System und damit dessen Ausweitung auf die B-N Bindung. Diese $p_{\pi}-p_{\pi}$-Wechselwirkung ist in den Elektronendichtestudien erkennbar an den deutlich von Null verschiedenen Elliptizitäten entlang der gesamten B-N-Bindung. Doch auch hier zeigen sich graduelle Unterschiede. Die Elliptizität entlang der B-N-Bindung in $\mathbf{2}$ ist höher in 1. Folglich ist die Delokalisation der Elektronendichte über die B-N-Bindung in $\left[\left(\mathrm{C}_{6} \mathrm{~F}_{5}\right)_{2} \mathrm{~B}\left(\mathrm{NC}_{4} \mathrm{H}_{8}\right)\right](2)$ stärker ausgeprägt als in $\left[\left(\mathrm{C}_{6} \mathrm{~F}_{5}\right)_{2} \mathrm{~B}\left(\mathrm{NC}_{4} \mathrm{H}_{4}\right)\right](\mathbf{1})$.

Dies lässt sich leicht verstehen, wenn man bedenkt, dass ein vollständiges Einkoppeln des Elektronenpaares des Stickstoffatoms in die B-N-Bindung im Falle von $\left[\left(\mathrm{C}_{6} \mathrm{~F}_{5}\right)_{2} \mathrm{~B}\left(\mathrm{NC}_{4} \mathrm{H}_{4}\right)\right](\mathbf{1})$ Elektronendichte aus dem aromatischen System abziehen und somit die Aromatizität stören würde. Stattdessen kommt es zu einer Ausweitung des delokalisierten Systems über den Ring hinaus in die B-N-Bindung. Vergleicht man dagegen die B-N-Bindungssituation für das Molekül mit dem nichtaromatischen Substituenten, so steht das freie Elektronenpaar des Stickstoffatoms vollständig zur B-N-Bindungsstärkung zur Verfügung, was zu einem höheren $\pi$-Bindungsanteil in $\left[\left(\mathrm{C}_{6} \mathrm{~F}_{5}\right)_{2} \mathrm{~B}\left(\mathrm{NC}_{4} \mathrm{H}_{8}\right)\right](2)$ im Vergleich zu $\left[\left(\mathrm{C}_{6} \mathrm{~F}_{5}\right)_{2} \mathrm{~B}\left(\mathrm{NC}_{4} \mathrm{H}_{4}\right)\right](\mathbf{1})$ führt.

Auch die Valenzschalenladungskonzentrationen (VSCCs) der beiden Stickstoffatome spiegeln die unterschiedliche Stärke der Bindungen der Stickstoffatome zu ihren 
Nachbaratomen wieder. Im pyrrolyl-substituierten Derivat (1) weisen die VSCCs, die in Richtung der Ring-Kohlenstoffatome zeigen, höhere Werte auf als das VSCC, das in Richtung des Boratoms zeigt. Im pyrrolidinyl-substituierten Derivat (2) hingegen, dominiert das zum Boratom zeigende VSCC.

Diese graduellen Unterschiede der Deskriptoren, die einzig auf den aromatischen bzw. den nichtaromatischen Charakter der neu eingeführten Substituten und die daraus resultierenden Unterschiede der B-N-Bindungsnatur zurückzuführen sind, sind somit reaktivitätsentscheidend.

Besonders anschaulich lassen sich die Ursachen der Reaktionsunterschiede anhand der reaktiven Oberfläche verdeutlichen. Löcher in dieser Isofläche der LAPLACEVerteilung stellen potentielle Angriffspunkte für nukleophile Reaktanden oder andersherum ausgedrückt elektrophile Stellen des analysierten Moleküls dar. Während die Isofläche um das Boratom in $\left[\left(\mathrm{C}_{6} \mathrm{~F}_{5}\right)_{2} \mathrm{~B}\left(\mathrm{NC}_{4} \mathrm{H}_{4}\right)\right](1)$ auf der Ober- und der Unterseite offene Bereiche aufweist, wird das Boratom in $\left[\left(\mathrm{C}_{6} \mathrm{~F}_{5}\right)_{2} \mathrm{~B}\left(\mathrm{NC}_{4} \mathrm{H}_{8}\right)\right](2)$ durch Ausläufer, die das Boratom umklammern, elektronisch abgeschirmt.

Mithilfe der experimentellen Elektronendichteuntersuchungen konnten somit die Ursachen für die unterschiedlichen Reaktivitäten von $\left[\left(\mathrm{C}_{6} \mathrm{~F}_{5}\right)_{2} \mathrm{~B}\left(\mathrm{NC}_{4} \mathrm{H}_{4}\right)\right]$ und $\left[\left(\mathrm{C}_{6} \mathrm{~F}_{5}\right)_{2} \mathrm{~B}\left(\mathrm{NC}_{4} \mathrm{H}_{8}\right)\right]$ ermittelt werden. Dies zeigt deutlich, dass die Analyse experimentell erhaltener Elektronendichteverteilungen klare Antworten auf chemische Fragestellungen geben kann. Die Untersuchung dieser beiden Modellverbindungen mit bekannter Reaktivität erlaubte es, eine Beziehung zwischen der elektronischen Struktur und der Reaktivität dieser beiden Moleküle herzustellen. Eine Erweiterung dieser Studien auf zusätzliche LEWIS-Säuren vom gleichen Typ könnte eine Quantifizierung dieser Zusammenhänge ermöglichen. Tris(pentafluorophenyl)boran wäre beispielsweise ein weiterer "Messpunkt", an dem die abgestuften Reaktivitäten mit Deskriptoren aus Elektronendichtestudien in Verbindung gebracht werden könnten. Die bekannte bessere Reaktivität dieser Verbindung sollte sich in diesen widerspiegeln. Interessant wäre auch die Untersuchung sowohl der Reaktivität als auch der Elektronendichteverteilung des Tris(pyrrolyl)borans, um die gewonnenen Ergebnisse zu untermauern. Anhand solcher systematischer Studien könnte es somit möglich werden, Vorhersagen über die Reaktivität einer Verbindung zu treffen. Diese Struktur-Reaktivitätsbeziehung könnte es deutlich vereinfachen, verbesserte Cokatalysatoren zu entwickeln. 


\subsection{Experimentelle Elektronendichteuntersuchungen von Übergangsmetall-Bor-Verbindungen}

Es gibt zahlreiche Verbindungsklassen, in denen ein Übergangsmetallatom an ein Boratom gebunden ist. Die strukturell maßgebliche und für die chemische Reaktivität entscheidende Natur der Bindung zwischen dem Übergangsmetall- und dem Boratom ist dabei sehr vielfältig und häufig noch nicht eindeutig aufgeklärt. Während Boride, Metallaborane und Übergangsmetallkomplexe mit Borheterozyklen schon verhältnismäßig lange bekannt sind, stellt die Klasse der Übergangsmetallkomplexe des Bors eine relativ neue Verbindungsklasse dar. Diese lässt sich anhand der Koordinationszahl des Boratoms und der Anzahl der Übergangsmetall-Bor-Bindungen in der jeweiligen Verbindungen wiederum in drei Gruppen unterteilen: Borane, Boryle und Borylene.

Aufgrund der strukturellen Verwandtschaft zur isolobalen Carbonyl-Gruppe hat der Borylen-Ligand besondere Aufmerksamkeit erfahren. Borylen-Liganden weisen, wie auch die Kohlenstoffanaloga, verschiedene Arten der Koordination zum Übergangsmetallatom auf. Die Übergangsmetall-Bor-Bindung ist dabei gegenüber einer Bindungsspaltung stabiler als die korrespondierende ÜbergangsmetallKohlenstoff-Bindung. Dies ist hauptsächlich im energetisch günstigeren Niveau des $\sigma$-Donor-Orbitals begründet, da die Energie des $\pi^{*}$-Orbitals in etwa gleich bleibt. Die schmale HOMO-LUMO-Lücke führt jedoch dazu, dass das Boratom positiv geladen und somit anfällig gegenüber nukleophilen Angriffen ist. Kinetische Stabilität kann durch eine sterische Abschirmung mithilfe von sperrigen Liganden am Boratom erreicht werden. Außerdem konnte gezeigt werden, dass gewisse Metallfragmente, wie z. B. $\left\{\mathrm{CpMn}(\mathrm{CO})_{2}\right\}_{2}$, die kinetische Instabilität zu einem gewissen Grad reduzieren können, da sie das Ungleichgewicht zwischen HOMO und LUMO verringern.

Zahlreiche theoretische Untersuchungen an verschiedenen Borylen-Komplexen lieferten unterschiedliche Antworten über den Charakter der Übergangsmetall-BorBindung. Deshalb wurden im Rahmen dieser Doktorarbeit Elektronendichtestudien an einem terminalen und einem verbrückten Borylen-Komplex durchgeführt.

Als terminaler Borylen-Komplex wurde $\left[(\mathrm{CO})_{5} \mathrm{CrBN}\left(\mathrm{SiMe}_{3}\right)_{2}\right]$ ausgewählt. Obwohl die IAM-Verfeinerung vielversprechende Ergebnisse lieferte, waren nach der MultipolVerfeinerung Restdichtemaxima vorhanden, die auf eine Rotationsfehlordnung 
schließen ließen. Eine IAM-Verfeinerung unter Berücksichtigung der Fehlordnung erwies sich als instabil, aber durchführbar, wohingegen eine auf die IAM-Verfeinerung aufbauende Multipolverfeinerung wie auch eine Invariomverfeinerung des fehlgeordneten Moleküls fehlschlug. Da nach der Multipolverfeinerung ohne Betrachtung der Fehlordnung die Maxima der Restdichteverteilung jedoch so deutlich auf die Fehlordnung hindeuteten, wurde angenommen, dass das Multipolmodell offensichtlich nur die Elektronendichte der Hauptkomponente beschrieben haben musste. Deshalb wurde die Analyse anhand der hierbei erhaltenen Elektronendichteverteilung durchgeführt. Aufgrund der noch nicht ausreichend bekannten Verlässlichkeit solcher Untersuchungen, sind unterstützende theoretische Berechnungen hier unerlässlich und werden derzeit durchgeführt.

Die topologische Analyse der experimentellen Elektronendichte ergab in $\left[(\mathrm{CO})_{5} \mathrm{CrBN}\left(\mathrm{SiMe}_{3}\right)_{2}\right]$ eine überraschende Bindungssituation für die B-N-Bindung. Die niedrige Elliptizität entlang des gesamten Bindungspfades schließt die eigentlich erwartete Doppelbindung aus. Die LAPLACE-Verteilung deutet viel mehr auf eine stark polarisierte, wenn nicht sogar ionische Bindung hin. Bei der Untersuchung der $\mathrm{Cr}-\mathrm{B}$ Bindung zeigte sich eine Diskrepanz zwischen den theoretischen und den experimentellen Ergebnissen. Diese ist höchstwahrscheinlich auf die Fehlordnung zurückzuführen. Die theoretischen Berechnungen lieferten eine Ladungsdichtekonzentration am Boratom, das in Richtung einer Ladungsdichteverarmung des Chromatoms ausgerichtet ist. Zusammen mit den Bindungsdeskriptoren am bindungskritischen Punkt der $\mathrm{Cr}$-B-Bindung ergab sich so das gleiche Bild, wie es von den Kohlenstoffanaloga, den Carbonyl-Übergangskomplexen bekannt ist.

Die Untersuchung eines verbrückten Borylen-Komplexes wurde an $\left[\left\{\mathrm{Cp}(\mathrm{CO})_{2} \mathrm{Mn}\right\}_{2^{-}}\right.$ $\left.\left(\mu-B^{t} \mathrm{Bu}\right)\right]$ durchgeführt. Die vorhergesagte kinetische Instabilität der Borylene ist in dieser Verbindung gleich durch zwei Faktoren abgeschwächt: Zum einen erfolgte die Komplexierung mithilfe des $\left\{\mathrm{CpMn}(\mathrm{CO})_{2}\right\}_{2}$-Fragments, das wie oben schon beschrieben, die Instabilität reduziert, zum anderen handelt es sich beim BorylenLiganden um ein tert-Butyl-Borylen, dessen sterisch anspruchsvolle organische Gruppe zusätzlich das Boratom vor nukleophilen Angriffen abschirmt.

Bei der Koordination des Borylen-Liganden an das Übergangsmetallatom zeigt sich ein deutlicher Unterschied zu den verbrückten Carbonyl-Komplexen, in deren Verwandtschaft die Borylene strukturell eingeordnet wurden. Am Carbonly- 
Kohlenstoffatom werden zwei VSCCs gefunden, von denen eines in Richtung des Sauerstoffatoms der Carbonyl-Gruppe zeigt, während das andere verbreitert ist und auf die Mitte der Metall-Metall-Bindung ausgerichtet ist. Am Borylen-Boratom hingegen finden sich drei VSCCs, die jeweils in Richtung eines der drei Bindungspartner zeigen. Die Untersuchung der Bindungspfade zwischen den Übergangsmetallatomen und dem Boratom zeigt außerdem eine deutliche Krümmung der Bindungspfade, was eine Delokalisierung der Bindungen impliziert. Die Betrachtung der Winkel zwischen den Bindungspfaden und den direkten Mangan-Bor-Verbindungsachsen am Boratom und den beiden Manganatomen ermöglicht eine Quantifizierung dieser Delokalisation. Die Größe dieser Winkel lässt auf eine dominante direkte und symmetrische donierende Wechselwirkung vom Boratom zu den Manganatomen und eine indirekte, weniger ausgeprägte und unsymmetrische Mangan-Bor-Rückbindung schließen.

Neben der Übergangsmetall-Bor-Bindung findet sich im verbrückten Molekül ein weiteres Strukturmotiv von stetigem Interesse. Für verbrückte Carbonyl-Verbindungen wurde postuliert, dass keine chemische Bindung zwischen den Metallatomen vorliegt. Dies konnte auch im Fall des Borylen-Komplexes beobachtet werden. Die QTAIMAnalyse sowohl der theoretischen als auch der experimentellen Elektronendichteverteilung lieferte keinen Bindungspfad zwischen den beiden Manganatomen. Eine Untersuchung der Ursprungsfunktion (source function) ergab, dass die Manganatome eher Dichte aus der Bindung abziehen als donieren. Dies spricht für eine nicht-lokalisierte Bindung. Da der untersuchte Komplex keine paramagnetischen Eigenschaften aufweist, erscheint eine Kopplung über das Boratom plausibel, zumal die gefundenen Bindungspfade zwischen den Manganatomen und dem Boratom als bevorzugte Austauschkanäle für Elektronenwechselwirkungen beschrieben wurden.

Obwohl kein bindungskritischer Punkt gefunden wurde, konnte aber zwischen den Manganatomen eine erhöhte Elektronendichte, wenn auch auf insgesamt niedrigem Niveau, gefunden werden. Dies könnte auch als Resultat einer Wechselwirkung interpretiert werden. Somit sind zur abschließenden Klärung weitere Untersuchungen oder die Entwicklung spezifischerer Deskriptoren nötig, um damit komplexe Bindungssituationen wie etwa von Metall-Metall-Bindungen eindeutig beschreiben zu können. 
Die Untersuchung der beiden Borylene, wie sie in dieser Arbeit vorgenommen wurde, zeigt deutlich, dass diese aufgrund ihrer interessanten Bindungssituationen vielversprechende Modellsysteme darstellen. Die Untersuchung eines nichtfehlgeordneten terminalen Borylens steht jedoch noch aus. Interessant wäre es, hierbei v. a. auch einen nicht-fehlgeordneten Kristall von $\left[(\mathrm{CO})_{5} \mathrm{CrBN}\left(\mathrm{SiMe}_{3}\right)_{2}\right] \mathrm{zu}$ analysieren, um die Verlässlichkeit der erhaltenen Eigenschaften zu überprüfen.

Das Thema der Borylene bietet noch viele interessante für Fragestellungen, da Verbindungen mit Übergangsmetallen generell noch schlecht verstanden sind. So ist nun zwar die Bindung in einem verbrückten Alkylborylen anhand Elektronendichteuntersuchungen analysiert, die Aminoborylen-Analoga wurden bisher jedoch nur vielfach theoretisch betrachtet. Ebenso wurden Boryl-Verbindungen bisher durch zahllose theoretische Berechnungen untersucht, experimentelle Elektronendichtebestimmungen gibt es hingegen noch keine. Auch die Boride, denen kovalente, ionische und metallische Bindungsbeiträge zugeschrieben werden, stellen ansprechende Untersuchungsobjekte dar. 



\section{REFERENCES}

[1] L. Pauling, J. Am. Chem. Soc. 1932, 54, 988.

[2] W. Friedrich, P. Knipping, M. von Laue, Sitzungsberichte der math.-phys. Klasse der k.-b. Akad. der Wissenschaften zu München 1912, 303.

[3] M. von Laue, Sitzungsberichte der math.-phys. Klasse der k.-b. Akad. der Wissenschaften zu München 1912, 363.

[4] W. H. Bragg, W. L. Bragg, Proc. R. Soc. London, A 1913, 88, 428.

[5] W. L. Bragg, Proc. R. Soc. London, A 1914, 89, 248.

[6] W. L. Bragg, R. W. James, C. H. Bosanquet, Philos. Mag. 1921, 41, 1.

[7] W. L. Bragg, R. W. James, C. H. Bosanquet, Philos. Mag. 1921, 41, 309.

[8] W. L. Bragg, R. W. James, C. H. Bosanquet, Philos. Mag. 1922, 44, 433.

[9] W. L. Bragg, W. H. Bragg, Nature 1913, 91, 557.

[10] W. L. Bragg, W. H. Bragg, Proc. R. Soc. London, A 1913, 89, 277.

[11] J. D. Bernal, Proc. R. Soc. London, A 1924, 106, 749.

[12] O. Hassel, H. Mack, Zeitschrift für Physik 1924, 25, 317.

[13] R. G. Dickinson, A. L. Raymond, J. Am. Chem. Soc. 1923, 45, 22.

[14] A. Müller, J. Chem. Soc. Dalton Trans. 1923, 123, 2043.

[15] W. H. Bragg, Nature 1925, 115, 266.

[16] M. De Broglie, J. J. Trillat, C. R. I'Academie. Sci., Ser. II Univers 1925, 180, 1485.

[17] W. B. Saville, G. Shearer, J. Chem. Soc. Dalton Trans. 1925, 127, 591.

[18] J. J. Trillat, Ann. Phys. 1926, 6, 5.

[19] W. A. Caspari, J. Chem. Soc. Dalton Trans. 1928, 3235.

[20] A. Müller, Proc. R. Soc. London, A 1928, 120, 437.

[21] A. Müller, Proc. R. Soc. London, A 1929, 124, 317.

[22] S. H. Piper, J. Chem. Soc., Faraday Trans. 1929, 25, 348.

[23] F. H. Allen, Annual Operational Report for 2007, The Cambridge Crystallographic Data Centre (CCDC), Cambridge (United Kingdom), 2007.

[24] CCDC, CSD Statistics 2009.

[25] H. Hope, Acta Crystallogr., Sect. B: Struct. Sci. 1988, 44, 22.

[26] T. Kottke, D. Stalke, J. Appl. Crystallogr. 1993, 26, 615.

[27] T. Kottke, R. J. Lagow, D. Stalke, J. Appl. Crystallogr. 1996, 29, 465.

[28] D. Stalke, Chem. Soc. Rev. 1998, 27, 171.

[29] T. Kottke, D. Stalke, Angew. Chem. 1993, 105, 619; Angew. Chem. Int. Ed. Engl. 1993, 32, 580.

[30] F. H. Allen, Acta Crystallogr., Sect. B: Struct. Sci. 2002, 58, 380.

[31] W. Massa, Crystal Structure Determination, Springer, Berlin, 2004.

[32] P. Müller, R. Herbst-Irmer, A. L. Spek, T. R. Schneider, M. R. Sawaya in Crystal Structure Refinement - A Crystallographer's Guide to SHELXL in IUCR Texts on Crystallography, Vol. 8 (Ed.: P. Müller), Oxford University Press, Oxford (England), 2006.

[33] D. Leusser, B. Walfort, D. Stalke, Angew. Chem. 2002, 114, 2183; Angew. Chem. Int. Ed. 2002, 41, 2079.

[34] U. Flierler, M. Burzler, D. Leusser, J. Henn, H. Ott, H. Braunschweig, D. Stalke, Angew. Chem. 2008, 120, 4393; Angew. Chem. Int. Ed. 2008, 47, 4321.

[35] P. Debye, Ann. Phys. 1915, 351, 809.

[36] B. Dawson, Acta Crystallogr. 1964, 17, 990.

[37] R. F. Stewart, J. Chem. Phys. 1968, 48, 4882.

[38] R. F. Stewart, J. Chem. Phys. 1969, 51, 4569.

[39] R. F. Stewart, Chem. Phys. Lett. 1973, 19, 462.

[40] R. F. Stewart, J. Chem. Phys. 1973, 58, 1668.

[41] F. L. Hirshfeld, Acta Crystallogr., Sect. B: Struct. Sci. 1971, 27, 769.

[42] M. Harel, F. L. Hirshfeld, Acta Crystallogr., Sect. A: Found. Crystallogr. 1975, 31, 162.

[43] N. K. Hansen, P. Coppens, Acta Crystallogr., Sect. A: Found. Crystallogr. 1978, 34, 909.

[44] N. K. Hansen, MOLLY, a Computer Program for Multipole Charge-Density Refinement, U. H. Poincare, Nancy I (France), 1991. 
[45] T. Koritsanszky, S. Howard, P. R. Mallinson, Z. Su, T. Richter, N. K. Hansen, XD - A Computer Program Package for Multipole Refinement and Analysis of Electron Densities from Diffraction Data, Berlin (Germany), 1996.

[46] R. F. Stewart, M. A. Spackman, C. Flensburg, VALRAY, C.-M. University, Pittsburgh, PA (USA), 2000.

[47] A. Volkov, P. Macchi, L. J. Farrugia, C. Gatti, P. R. Mallinson, T. Richter, T. Koritsanszky, XD2006, A Computer Program Package for Multipole Refinement, Topological Analysis of Charge Densities and Evaluation of Intermolecular Energies from Experimental or Theoretical Structure Factors, 2006.

[48] P. Coppens, Acta Crystallogr., Sect. A: Found. Crystallogr. 1984, 40, 184.

[49] A. Martin, A. A. Pinkerton, Acta Crystallogr., Sect. B: Struct. Sci. 1998, 54, 471.

[50] S. Kuntzinger, S. Dahaoui, N. E. Germani, C. Lecomte, J. A. K. Howard, Acta Crystallogr., Sect. B: Struct. Sci. 1999, 55, 867.

[51] T. Schulz, K. Meindl, D. Leusser, D. Stern, J. Graf, C. Michaelsen, M. Ruf, G. M. Sheldrick, D. Stalke, J. Appl. Crystallogr. 2009, submitted.

[52] C. Jelsch, V. Pichon-Pesme, C. Lecomte, A. Aubry, Acta Crystallogr., Sect. D: Biol. Crystallogr. 1998, 54, 1306.

[53] B. Dittrich, T. Koritsanszky, P. Luger, Angew. Chem. 2004, 116, 2773; Angew. Chem. Int. Ed. 2004, 43, 2718.

[54] V. Pichon-Pesme, C. Lecomte, H. Lachekar, J. Phys. Chem. 1995, 99, 6242.

[55] B. Dittrich, C. B. Hübschle, P. Luger, M. A. Spackman, Acta Crystallogr., Sect. D: Biol. Crystallogr. 2006, 62, 1325.

[56] B. Dittrich, C. B. Huebschle, F. P. A. Fabbiani, J. Appl. Crystallogr. 2009, submitted.

[57] W. Wei, J. Appl. Crystallogr. 1985, 18, 442.

[58] M. Sakata, M. Sato, Acta Crystallogr., Sect. A: Found. Crystallogr. 1990, 46, 263.

[59] R. Y. de Vries, W. Briels, D. Feil, Acta Crystallogr., Sect. A: Found. Crystallogr. 1994, 50, 383.

[60] S. van Smaalen, L. Palatinus, M. Schneider, Acta Crystallogr., Sect. A: Found. Crystallogr. 2003, $59,459$.

[61] M. Eisenstein, Acta Crystallogr., Sect. B: Struct. Sci. 1979, 35, 2614.

[62] F. L. Hirshfeld, H. Hope, Acta Crystallogr., Sect. B: Struct. Sci. 1980, 36, 406.

[63] A. Kirfel, A. Gupta, G. Will, Acta Crystallogr., Sect. B: Struct. Sci. 1980, 36, 1311.

[64] A. Kirfel, G. Will, Acta Crystallogr., Sect. B: Struct. Sci. 1981, 37, 525.

[65] P. Coppens, Coord. Chem. Rev. 1985, 65, 285.

[66] D. Cremer, E. Kraka, Angew. Chem. 1984, 96, 612; Angew. Chem. Int. Ed. Engl. 1984, 23, 627.

[67] P. Coppens, E. D. Stevens, Adv. Quantum Chem. 1977, 10, 1.

[68] P. Coppens, Angew. Chem. 1977, 84, 33; Angew. Chem. Int. Ed. Engl. 1977, 16, 32.

[69] T. Haumann, R. Boese, S. I. Kozhushkov, A. K. Rauch, A. De Meijere, Liebigs Ann. Chem. 1997, 2047.

[70] T. Haumann, J. Benet-Buchholz, F.-G. Klarner, R. Boese, Liebigs Ann. Chem. 1997, 1429.

[71] R. F. W. Bader, Atoms in Molecules - A Quantum Theory, Oxford University Press, New York, 1990.

[72] W. Shu-Guang, W. H. E. Schwarz, Angew. Chem. 2000, 112, 1827; Angew. Chem. Int. Ed. 2000, 39, 1757.

[73] A. Haaland, D. J. Shorokhov, N. V. Tverdova, Chem. Eur. J. 2004, 10, 4416.

[74] J. Henn, PhD thesis, Würzburg (German), 2004.

[75] J. Henn, D. Leusser, D. Stalke, J. Comput. Chem. 2007, 28, 2317.

[76] H. Jacobsen, J. Comput. Chem. 2009, DOI 10.1002/jcc.21135.

[77] P. Macchi, A. Sironi, Coord. Chem. Rev. 2003, 238-239, 383.

[78] N. Kocher, PhD thesis, Würzburg (Germany), 2003.

[79] D. Kost, B. Gostevskii, N. Kocher, D. Stalke, I. Kalikhman, Angew. Chem. 2003, 115, 1053; Angewandte Chemie Int. Ed. 2003, 42, 1023.

[80] N. Kocher, J. Henn, B. Gostevskii, D. Kost, I. Kalikhman, B. Engels, D. Stalke, J. Am. Chem. Soc. 2004, 136, 5563.

[81] N. Kocher, D. Leusser, A. Murso, D. Stalke, Chem. Eur. J. 2004, 10, 3622.

[82] N. Kocher, C. Selinka, D. Leusser, D. Kost, I. Kahlikhman, D. Stalke, Z. Anorg. Allg. Chem. 2004, 630, 1777. 
[83] Y. A. Abramov, Acta Crystallogr., Sect. A: Found. Crystallogr. 1997, 53, 264.

[84] A. Stash, V. Tsirelson, J. Appl. Crystallogr. 2002, 35, 371.

[85] R. F. W. Bader, C. Gatti, Chem. Phys. Lett. 1998, 287, 233.

[86] J. Overgaard, B. Schiøtt, F. K. Larsen, B. B. Iversen, Chem. Eur. J. 2001, 7, 3756.

[87] C. Gatti, F. Cargnoni, L. Bertini, J. Comput. Chem. 2003, 24, 422.

[88] C. Gatti, L. Bertini, Acta Crystallogr., Sect. A: Found. Crystallogr. 2004, 60, 438.

[89] C. Gatti, D. Lasi, Faraday Discuss. 2007, 135, 55.

[90] J. Sørensen, H. F. Clausen, R. D. Poulsen, J. Overgaard, B. Schiøtt, J. Phys. Chem. A 2007, 111, 345.

[91] C. D. Kim, S. Pillet, G. Wu, W. K. Fullagar, P. Coppens, Acta Crystallogr., Sect. A: Found. Crystallogr. 2002, 58, 133.

[92] H. B. Bürgi, Faraday Discuss. 2003, 122, 41.

[93] L. X. Chen, Faraday Discuss. 2003, 122, 315.

[94] J. M. Cole, P. R. R. Raithby, M. Wulff, F. Schotte, A. Plech, S. J. Teat, G. Bushnell-Wye, Faraday Discuss. 2003, 122, 119.

[95] E. Collet, M.-H. Lemée-Cailleau, M. Buron-Le Cointe, H. Cailleau, M.-. Wulff, T. Luty, S.-Y. Koshihara, M. Meyer, L. Toupet, P. Rabiller, S. Techert, Science 2003, 300.

[96] P. Coppens, I. V. Novozhilova, Faraday Discuss. 2003, 122, 1.

[97] A. E. Whitten, D. Jayatilaka, M. A. Spackman, J. Phys. Chem. 2006, 125, 174505.

[98] P. Coppens, Angew. Chem. 2005, 117, 6970; Angew. Chem. Int. Ed. 2005, 44, 6810.

[99] D. Stalke, H. Ott, Nachrichten aus der Chemie 2008, 56, 131.

[100] E. J. Yearley, E. A. Zhurova, V. V. Zhurov, A. A. Pinkerton, J. Am. Chem. Soc. 2007, 129, 15013.

[101] E. J. Yearley, E. A. Zhurova, V. V. Zhurov, A. A. Pinkerton, J. Mol. Struct. 2008, 890, 240.

[102] B. Dittrich, T. Koritsanszky, A. Volkov, S. Mebs, P. Luger, Angew. Chem. 2007; Angew. Chem. Int. Ed. 2007, 46, 2935.

[103] B. Rohrmoser, G. Eickerling, M. Presnitz, W. Scherer, V. Eyert, R.-D. Hoffmann, U. C. Rodewald, C. Vogt, R. Poettgen, J. Am. Chem. Soc. 2007, 129, 9356.

[104] M. Yashima, Y. Ando, Y. Tabira, J. Phys. Chem. B 2007, 111, 3609.

[105] P. Macchi, L. Garlaschelli, A. Sironi, J. Am. Chem. Soc. 2002, 124, 14173.

[106] L. J. Farrugia, C. Evans, D. Lentz, M. Roemer, J. Am. Chem. Soc. 2009, 131, 1251.

[107] R. Bianchi, G. Gervasio, D. Marabello, Chem. Commun. 1998, 1535.

[108] R. Bianchi, G. Gervasio, D. Marabello, Inorg. Chem. 2000, 39, 2360.

[109] J. Overgaard, H. F. Clausen, J. A. Platts, B. B. Iversen, J. Am. Chem. Soc. 2008, 130, 3834.

[110] J. F. van der Maelen, E. Gutierrez-Puebla, A. Monge, S. Garcia-Granda, I. Resa, E. Carmona, M. T. Fernandez-Diaz, G. J. Mclntyre, P. Pattison, H.-P. Weber, Acta Crystallogr., Sect. B: Struct. Sci. 2007, 63, 862.

[111] D. Leusser, PhD thesis, Würzburg (Germany), 2002.

[112] D. Leusser, J. Henn, N. Kocher, B. Engels, D. Stalke, J. Am. Chem. Soc. 2004, 126, 1781.

[113] S. Deuerlein, PhD-Thesis, Göttingen (Germany), 2007.

[114] S. Deuerlein, D. Leusser, U. Flierler, H. Ott, D. Stalke, Organometallics 2008, 27, 2306.

[115] T. Stey, D. Stalke in Lead structures in lithium organic chemistry in The chemistry of organolithium compounds (Eds.: Z. Rappoport, I. Marek), John Wiley \& Sons, Chichester, 2004, pp. 47.

[116] H. Ott, PhD thesis, Göttingen (Germany), 2009.

[117] M. Granitzka, private communication, Göttingen, 2008.

[118] N. V. Sidgwick, Electronic Theory of Valency, Oxford University Press, Oxford, 1927.

[119] V. Bachler, N. Metzler-Nolte, Eur. J. Inorg. Chem. 1998, 733.

[120] A. W. Ehlers, E. J. Baerends, F. M. Bickelhaupt, U. Radius, Chem. Eur. J. 1998, 4, 210.

[121] H. Braunschweig, M. Colling, Coord. Chem. Rev. 2001, 223, 1.

[122] H. Braunschweig, M. Colling, Eur. J. Inorg. Chem. 2003, 393.

[123] B. Blank, M. Colling-Hendelkens, C. Kollann, K. Radacki, D. Rais, K. Uttinger, G. R. Whittell, H. Braunschweig, Chem. Eur. J. 2007, 13, 4770.

[124] D. Förster, PhD thesis, Berlin (Germany), 2008.

[125] D. Förster, C. B. Hübschle, P. Luger, T. Hugle, D. Lentz, Inorg. Chem. 2008, 47, 1874.

[126] K. Götz, M. Kaupp, H. Braunschweig, D. Stalke, Chem. Eur. J. 2009, 15, 623. 
[127] U. Flierler, D. Leusser, H. Ott, G. Kehr, G. Erker, S. Grimme, D. Stalke, Chem. Eur. J. 2009, DOI 10.1002/chem.200802344.

[128] M. Born, Zeitschrift für Physik 1926, A38, 803.

[129] P. Coppens, X-Ray Charge Densities and Chemical Bonding, Oxford University Press, Oxford, 1997.

[130] C. A. Coulson, M. W. Thomas, Acta Crystallogr., Sect. B: Struct. Sci. 1971, 27, 1354.

[131] R. F. Stewart, D. Feil, Acta Crystallogr., Sect. A: Found. Crystallogr. 1980, 36, 503.

[132] International Tables for X-Ray Crystallography, Vol. 4 (Eds.: C. K. Johnson, H. A. Levy), Kynoch Press, Birmingham, 1974.

[133] P. Coppens in Neutron Diffraction in Topics in Current Physics, Vol. 6 (Ed.: H. Dachs), Springer, Berlin, 1978.

[134] F. H. Allen, Acta Crystallogr., Sect. B: Struct. Sci. 1986, 42, 515.

[135] G. A. Jeffrey, D. W. J. Cruickshank, Quarterly Reviews of the Chemical Society of London 1953, 7, 335.

[136] P. Coppens, M. S. Lehmann, Acta Crystallogr., Sect. B: Struct. Sci. 1976, 32, 1777.

[137] M. S. Lehmann, P. Coppens, Acta Chem. Scand. 1977, A31, 530.

[138] A. Volkov, Y. A. Abramov, P. Coppens, C. Gatti, Acta Crystallogr., Sect. A: Found. Crystallogr. 2000, 56, 332.

[139] E. Clementi, D. L. Raimondi, J. Chem. Phys. 1963, 38, 2686.

[140] E. Clementi, C. Roetti, Atomic Data and Nuclear Data Tables 1974, 14, 177.

[141] D. Stern, D. Kratzert, T. Schulz, H. Ott, U. Flierler, T. Tatic, D. Stalke, AK Stalke in the Framework of the SPP 1178, Berichtskolloquium, Banz (Germany), 2009.

[142] F. L. Hirshfeld, Acta Crystallogr., Sect. A: Found. Crystallogr. 1976, 32, 239.

[143] V. Schoemaker, K. N. Trueblood, Acta Crystallogr., Sect. B: Struct. Sci. 1968, 24, 64.

[144] J. M. Savariault, M. S. Lehmann, J. Am. Chem. Soc. 1980, 102, 1298.

[145] J. D. Dunitz, W. B. Schweizer, P. Seiler, J. Am. Chem. Soc. 1983, 105, 7056.

[146] Z. Su, P. Coppens, Acta Crystallogr., Sect. A: Found. Crystallogr. 1998, 54, 646.

[147] A. Holladay, P. Leung, P. Coppens, Acta Crystallogr., Sect. A: Found. Crystallogr. 1983, $39,377$.

[148] K. B. Wiberg, C. M. Breneman, J. Am. Chem. Soc. 1990, 112, 8765.

[149] M. Messerschmidt, A. Wagner, M. W. Wong, P. Luger, J. Am. Chem. Soc. 2002, 124, 732.

[150] R. F. W. Bader, J. Phys. Chem. A 1998, 102, 7314.

[151] H. Hopf, Math. Ann. 1927, 96, 209.

[152] K. Collard, G. G. Hall, Int. J. Quantum Chem. 1977, 12, 623.

[153] T.-H. Tang, R. F. W. Bader, P. J. MacDougall, Inorg. Chem. 1985, 24, 2047.

[154] R. J. Gillespie, Molecular Geometry, Reinhold Van Nostrand, London, 1972.

[155] R. J. Gillespie, I. Hargittai in The VSEPR Model of Molecular Geometry in The VSEPR Model of Molecular Geometry, Allyn and Bacon, Boston, 1991.

[156] I. Bytheway, R. J. Gillespie, T.-H. Tang, R. F. W. Bader, Inorg. Chem. 1995, 34, 2407.

[157] R. J. Gillespie, E. A. Robinson, Angew. Chem. 1996, 108, 539; Angew. Chem. Int. Ed. Engl. 1996, 35, 477.

[158] P. J. MacDougall, M. B. Hall, R. F. W. Bader, J. R. Cheeseman, Can. J. Chem. 1989, 67, 1842.

[159] R. F. W. Bader, R. J. Gillespie, P. J. MacDougall, Molecular Structure and Energetics 1989, 11, 1.

[160] R. F. W. Bader, S. Johnson, T.-H. Tang, P. L. A. Popelier, J. Phys. Chem. 1996, 100, 15398.

[161] Chemical Bonding and Molecular Geometry in Chemical Bonding and Molecular Geometry (Eds.: R. J. Gillespie, P. L. A. Popelier), Oxford University Press, New York, 2001.

[162] J. R. Cheeseman, M. T. Carroll, R. F. W. Bader, Chem. Phys. Lett. 1988, 143, 451.

[163] D. A. Kirzhnits, Sov. Phs. - JEPT 1957, 32, 115.

[164] Bruker APEX v2.1-0, Bruker AXS Inst. Inc., Madison (WI, USA), 2007.

[165] SAINT v7.23A, Bruker AXS Inst. Inc., Madison (WI, USA), 2005.

[166] W. Kabsch, J. Appl. Crystallogr. 1988, 21, 916.

[167] G. M. Sheldrick, SADABS 2006/4, Göttingen, 2006.

[168] G. M. Sheldrick, XPREP in SHELXTL v6.12, Bruker AXS Inst. Inc., Madison (WI, USA), 2000.

[169] G. M. Sheldrick, SHELXS in SHELXTL v6.12, Bruker AXS Inst. Inc., Madison (WI, USA), 2000.

[170] G. M. Sheldrick, Acta Crystallogr., Sect. A: Found. Crystallogr. 2008, 64, 112.

[171] P. Macchi, P. Coppens, Acta Crystallogr., Sect. A: Found. Crystallogr. 2001, 57, 656. 
[172] A. Volkov, Y. A. Abramov, P. Coppens, Acta Crystallogr., Sect. A: Found. Crystallogr. 2001, 57, 272.

[173] G. R. Moss, M. Souhassou, R. H. Blessing, Acta Crystallogr., Sect. B: Struct. Sci. 1995, 51, 650.

[174] E. Espinosa, E. Molins, C. Lecomte, Phys. Rev. B: Condens. Matter 1997, 56, 1820.

[175] P. M. Dominiak, P. Coppens, Acta Crystallogr., Sect. A: Found. Crystallogr. 2006, 62, 224.

[176] R. Ahlrichs, M. Bär, M. Häser, H. Horn, C. Kölmel, Chem. Phys. Lett. 1989, 162, 165.

[177] A. Schäfer, C. Huber, R. Ahlrichs, J. Chem. Phys. 1994, 100, 5829.

[178] J. P. Perdew, K. Burke, M. Ernzerhof, Phys. Rev. Lett. 1996, 77, 3865.

[179] C. Adamo, V. Barone, J. Chem. Phys. 1998, 108, 664.

[180] J. P. Perdew, Phys. Rev. B: Condens. Matter Mater. Phys. 1986, 33, 8822.

[181] A. D. Becke, Phys. Rev. A: At., Mol., Opt. Phys. 1988, 38, 3098.

[182] F. Biegler-König, J. Schönbohm, D. Bayles, J. Comput. Chem. 2001, 22, 545.

[183] T. Laue, A. Plagens, Namen- und Schlagwortreaktionen der organischen Chemie, Teubner Verlag, Wiesbaden, 2006.

[184] R. G. Pearson, J. Am. Chem. Soc. 1963, 85, 3533.

[185] R. G. Parr, R. G. Pearson, J. Am. Chem. Soc. 1983, 105, 7512.

[186] R. G. Pearson, J. Am. Chem. Soc. 1985, 107, 6801.

[187] W. E. Piers, T. Chivers, Chem. Soc. Rev. 1997, 26, 345.

[188] R. D. Chambers, T. Chivers, Organomet. Chem. Rev. 1966, 1, 279.

[189] S. C. Cohen, A. G. Massey, Adv. Fluorine Chem. 1970, 6, 149.

[190] H. Jacobsen, H. Berke, S. Döring, G. Kehr, G. Erker, R. Fröhlich, O. Meyer, Organometallics 1999, 18, 1724.

[191] K. Ishihara, N. Hanaki, M. Funahashi, M. Miyata, H. Yamamoto, Bull. Chem. Soc. Jpn. 1995, 68, 1721.

[192] D. J. Parks, W. E. Piers, J. Am. Chem. Soc. 1996, 118, 9440.

[193] X. Yang, C. L. Stern, T. J. Marks, J. Am. Chem. Soc. 1991, 113, 3623.

[194] X. Yang, C. L. Stern, T. J. M. Marks, J. Am. Chem. Soc. 1994, 116, 10015.

[195] M. Bochmann, S. J. Lancaster, M. B. Hursthouse, K. M. A. Malik, Organometallics 1994, 13, 2235.

[196] B. Temme, G. Erker, R. Fröhlich, M. Grehl, Angew. Chem. 1994, 106, 1570 Angew. Chem. Int. Ed. Engl. 1994, 33, 1480.

[197] B. Temme, J. Karl, G. Erker, Chem. Eur. J. 1996, 2, 919.

[198] Y. Sun, R. E. v. H. Spence, W. E. Piers, M. Parvez, G. P. A. Yap, J. Am. Chem. Soc. 1997, 119, 5132.

[199] G. S. Hill, L. M. Rendina, R. J. Puddephatt, J. Chem. Soc. Dalton Trans. 1996, 1809.

[200] M. L. H. Green, J. Haggitt, C. P. Mehnert, J. Chem. Soc. Chem. Commun. 1995, 1853.

[201] M. Bochmann, D. M. Dawson, Angew. Chem. 1996, 108, 2371 Angew. Chem. Int. Ed. Engl. 1996, 35, 2226.

[202] G. Kehr, R. Fröhlich, B. Wibbeling, G. Erker, Chem. Eur. J. 2000, 6, 258.

[203] M. Bochmann, Angew. Chem. 1992, 104, 1206; Angew. Chem. Int. Ed. Engl. 1992, 31, 1181.

[204] Y.-X. Chen, M. V. Metz, L. Li, C. L. Stern, T. J. Marks, J. Am. Chem. Soc. 1998, 120, 6287.

[205] P. A. Deck, C. L. Beswick, T. J. Marks, J. Am. Chem. Soc. 1998, 120, 1772.

[206] M. Bochmann, S. J. Lancaster, O. B. Robinson, J. Chem. Soc. Chem. Commun. 1995, 2081.

[207] X. Song, M. Bochmann, J. Organomet. Chem. 1997, 545-546, 597.

[208] Y. Sun, W. E. Piers, G. P. A. Yap, Organometallics 1997, 15, 2509.

[209] W. E. Piers, Chem. Eur. J. 1998, 4, 13.

[210] H. van Heijden, B. Hessen, A. G. Orpen, J. Am. Chem. Soc. 1998, 120, 1112.

[211] R. F. Jordan, Adv. Organomet. Chem. 1991, 32, 325.

[212] M. Bochmann, A. J. Jaggar, J. C. Nicholls, Angew. Chem. 1990, 102, 830; Angew. Chem. Int. Ed. Engl. 1990, 29, 780.

[213] J. C. W. Chien, W. M. Tsai, R. D., J. Am. Chem. Soc. 1991, 113, 8570.

[214] H. Sinn, W. Kaminsky, H.-J. Vollmer, W. Rüdiger, Angew. Chem. 1980, 92, 396; Angew. Chem. Int. Ed. Engl. 1980, 19, 390.

[215] A. G. Massey, A. J. Park, F. G. A. Stone, Proceedings of the Chemical Society 1963, 212.

[216] A. G. Massey, A. J. Park, J. Organomet. Chem. 1964, 2, 245.

[217] R. F. Childs, D. L. Mulholland, A. Nixon, Can. J. Chem. 1982, 60, 809.

[218] R. F. Childs, D. L. Mulholland, A. Nixon, Can. J. Chem. 1982, 60, 801. 
[219] A. G. Massey, A. J. Park in Organometallic Synthesis, Vol. 3 (Eds.: R. B. King, J. J. Eisch), Elsevier, New York, 1986, pp. 461.

[220] P. Lazlo, M. Teston, J. Am. Chem. Soc. 1990, 112, 8750.

[221] S. Döring, G. Erker, R. Fröhlich, O. Meyer, K. Bergander, Organometallics 1998, 17, 2183.

[222] T. Koritsanszky, P. Coppens, Chem. Rev. 2001, 101, 1583.

[223] C. Lecomte, M. Souhassou, S. Pillet, J. Mol. Struct. 2003, 647, 53.

[224] C. Gatti, Z. Kristallogr. 2005, 220, 399.

[225] R. F. W. Bader, H. Essén, J. Chem. Phys. 1984, 80, 1943.

[226] R. Flaig, T. Koritsanszky, B. Dittrich, A. Wagner, P. Luger, J. Am. Chem. Soc. 2002, 124, 3407.

[227] D. E. Hibbs, J. Overgaard, J. A. Platts, M. P. Waller, M. B. Hursthouse, J. Am. Chem. Soc. 2004, 108, 3663.

[228] T. Koritsanszky, A. Volkov, Chem. Phys. Lett. 2004, 385, 431.

[229] L. J. Farrugia, C. Evans, M. Tegel, J. Phys. Chem. A 2006, 110, 7952.

[230] W. Scherer, P. Sirsch, D. Shorokhov, G. S. McGrady, S. A. Mason, M. G. Gardiner, Chem. Eur. J. 2002, 8, 2324.

[231] W. Scherer, P. Sirsch, D. Shorokhov, M. Tafipolsky, G. S. McGrady, E. Gullo, Chem. Eur. J. 2003, 9, 6057.

[232] H. Braunschweig, Angew. Chem. 1998, 110, 1882; Angew. Chem. Int. Ed. 1998, 37, 1786.

[233] H. Braunschweig, C. Kollann, D. Rais, Angew. Chem. 2006, 118, 5380; Angew. Chem. Int. Ed. 2006, 45, 5254.

[234] B. Post in Rare Earth Research II (Ed.: K. S. Korres), Gordon and Breach, New York, 1964, pp. 107.

[235] R. Thompson in Progress in Boron Chemistry (Eds.: R. J. Brotherton, H. Steinberg), Pergamon, Oxford, 1970, pp. 173.

[236] T. Lundström in Encyclopedia of Inorganic Chemistry, Vol. 1 (Ed.: R. B. King), Wiley, New York, 1994, pp. 328.

[237] C. E. Housecroft, T. P. Fehlner in Adv. Organomet. Chem., Vol. 21 (Eds.: F. G. A. Stone, R. West), Academic Press, New York, 1981, pp. 57.

[238] C. E. Housecroft, Boranes and Metalloboranes, Wiley, New York 1990.

[239] T. P. Fehlner in Electron Deficient Boron and Carbon Clusters (Eds.: G. A. Olah, K. Wade, R. E. Williams), Wiley, New York, 1991, pp. 287.

[240] M. F. Hawthorne, J. Organomet. Chem. 1975, 100, 97.

[241] R. N. Grimes, Chem. Rev. 1992, 92, 251.

[242] C. E. Housecroft in Encyclopedia of Inorganic Chemistry (Ed.: R. B. King), Wiley, New York, 1994, pp. 375.

[243] G. E. Herberich in Comprehensive Organometallic Chemistry, Vol. 1 (Eds.: G. Wilkinson, F. G. A. Stone, E. W. Abel), Pergamon, Oxford, 1982, pp. 381.

[244] G. E. Herberich, B. Buller, B. Hessner, W. Oschmann, J. Organomet. Chem. 1980, 195, 253.

[245] G. E. Herberich, B. Hessner, R. Saive, J. Organomet. Chem. 1987, 319, 9.

[246] W. Siebert, Angew. Chem. 1985, 97, 924; Angew. Chem. Int. Ed. Engl. 1985, $24,943$.

[247] A. J. Ashe III, E. Meyers, P. Shu, T. von Lehmann, J. Bastide, J. Am. Chem. Soc. 1975, 97, 6865.

[248] G. E. Herberich, C. Engelke, W. PahImann, Chem. Ber. 1979, 112, 607.

[249] H. Werner, R. Prinz, E. Deckelmann, Chem. Ber. 1969, 102, 95.

[250] G. Huttner, B. Krieg, Angew. Chem. 1971, 83, 541; Angew. Chem. Int. Ed. Engl. 1971, 10, 512.

[251] K. Delpy, D. Schmitz, P. Paetzold, Chem. Ber. 1983, 116, 2994.

[252] G. Schmid, Angew. Chem. 1970, 82, 920; Angew. Chem. Int. Ed. Engl. 1970, 9, 819.

[253] R. T. Baker, D. W. Ovenall, J. C. Calabrese, S. A. Westcott, N. J. Taylor, I. D. Williams, T. B. Marder, J. Am. Chem. Soc. 1990, 112, 9399.

[254] J. R. Knorr, J. S. Merola, Organometallics 1990, 9, 3008.

[255] K. Wade, Adv. Inorg. Chem. Radiochem. 1976, 18, 1.

[256] K. Wade in Electron Deficient Boron and Carbon Clusters (Eds.: G. A. Olah, K. Wade, R. E. Williams), New York, 1991, pp. 95.

[257] W. Mowat, A. Shortland, N. J. Yagupsky, M. Hill, G. Wilkinson, J. Chem. Soc. Dalton Trans. 1972, 533.

[258] P. J. Davidson, M. F. Lappert, R. Pearce, Acc. Chem. Res. 1974, 7, 209.

[259] E. O. Fischer, Adv. Organomet. Chem. 1976, 14, 1. 
[260] R. R. Schrock, Acc. Chem. Res. 1979, 12, 98.

[261] T. D. Tilley, Chemistry of Organic Silicon Compounds, Wiley, New York, 1989.

[262] U. Schubert, Transition Met. Chem. 1991, 16, 136.

[263] P. D. Lickiss, Chem. Soc. Rev. 1992, 21, 271.

[264] C. Zybill, H. Handwerker, H. Friedrich, Advances in Organometallic Chemistry, Academic Press, New York, 1994.

[265] G. J. Irvine, M. J. G. Lesley, T. B. Marder, N. C. Norman, C. R. Rice, E. G. Robins, W. R. Roper, G. R. Whittell, L. J. Wright, Chem. Rev. 1998, 98, 2585.

[266] M. R. Smith III, Progress in Inorganic Chemistry, Wiley, New York, 1999.

[267] R. A. Fischer, J. Weiss, Angew. Chem. 1999, 111, 3002; Angew. Chem. Int. Ed. 1999, 38, 2830.

[268] D. Männig, H. Nöth, Angew. Chem. 1985, 97, 854; Angew. Chem. Int. Ed. Engl. 1985, $24,878$.

[269] K. Burgess, M. J. Ohlmeyer, Chem. Rev. 1991, 91, 1179.

[270] I. Beletskaya, A. Pelter, Tetrahedron 1997, 53, 4957.

[271] H. Wadepohl, Angew. Chem. 1997, 109, 2547; Angew. Chem. Int. Ed. 1997, 36, 2441.

[272] T. B. Marder, N. C. Norman, Top. Catal. 1998, 5, 63.

[273] T. Ishiyama, N. Miyaura, J. Synth. Org. Chem. Jpn. 1999, 57, 503.

[274] T. Ishiyama, N. Miyaura, J. Organomet. Chem. 2000, 611, 392.

[275] C. M. Crudden, D. Edwards, Eur. J. Org. Chem. 2003, 4695.

[276] H. Chen, S. Schlecht, T. C. Semple, J. F. Hartwig, Science 2000, 287, 1995.

[277] J. Y. Cho, M. K. Tse, D. Holmes, R. E. Maleczka, M. R. Smith III jr., Science 2002, 295, 305.

[278] T. Ishiyama, N. Miyaura, J. Organomet. Chem. 2003, 680, 3.

[279] T. Ishiyama, Y. Nobuta, J. F. Hartwig, N. Miyaura, Chem. Commun. 2003, 2924.

[280] G. A. Chotana, M. A. Rak, M. R. S. III, J. Am. Chem. Soc. 2005, 127, 10539.

[281] D. N. Coventry, A. S. Batsanov, A. E. Goeta, J. A. K. Howard, T. B. Marder, R. N. Perutz, Chem. Commun. 2005, 2172.

[282] J. F. Hartwig, K. S. Cook, M. Hapke, C. D. Incarvito, Y. Fan, C. E.Webster, M. B. Hall, J. Am. Chem. Soc. 2005, 127, 2538.

[283] I. A. I. Mkhalid, D. N. Coventry, D. Albesa-Jove, A. S.Batsanov, J. A. K. Howard, R. N. Perutz, T. B. Marder, Angew. Chem. 2006, 118, 503; Angew. Chem. Int. Ed. 2006, 45, 489-491.

[284] C. D. Entwistle, T. B. Marder, Angew. Chem. 2002, 114, 3051; Angew. Chem. Int. Ed. Engl. 2002, 41, 2927.

[285] C. D. Entwistle, T. B. Marder, Chem. Mater. 2004, 16, 4574.

[286] H. Braunschweig, D. Rais, Angew. Chem. 2005, 117, 8036; Angew. Chem. Int. Ed. 2005, $44,7826$.

[287] C. Boehme, J. Uddin, G. Frenking, Coord. Chem. Rev. 2000, 197, 249.

[288] H. Braunschweig, R. D. Dewhurst, T. Herbst, K. Radacki, Angew. Chem. 2008, 120, 6067; Angew. Chem. Int. Ed. 2008.

[289] G. J. Irvine, C. E. F. Rickard, W. R. Roper, A. Williamson, L. J. Wright, Angew. Chem. 2000, 112, 978; Angew. Chem. Int. Ed. 2000, 39, 948.

[290] S. G. Feng, P. S. White, J. L. Templeton, J. Am. Chem. Soc. 1990, 112, 8192.

[291] S. G. Feng, P. S. White, J. L. Templeton, J. Am. Chem. Soc. 1992, 114, 2951.

[292] P. R. Rablen, S. P. Nolan, J. F. Hartwig, J. Am. Chem. Soc. 1994, 116, 4121.

[293] D. G. Musaev, K. Morokuma, J. Phys. Chem. 1996, 100, 6509.

[294] S. Sakaki, T. Kikuno, Inorg. Chem. 1997, 36, 226.

[295] G. Frenking, N. Fröhlich, Chem. Rev. 2000, 100, 717.

[296] H. Braunschweig, C. Kollann, U. Englert, Angew. Chem. 1998, 110, 3355; Angew. Chem. Int. Ed. 1998, 37, 3179.

[297] B. Wrackmeyer, Angew. Chem. 1999, 111, 817; Angew. Chem. Int. Ed. 1999, 38, 771.

[298] H. Braunschweig, M. Colling, J. Organomet. Chem. 2000, 614, 18.

[299] S. Aldridge, D. L. Coombs, Coord. Chem. Rev. 2004, 248, 535.

[300] H. Braunschweig, Adv. Organomet. Chem. 2004, 51, 163.

[301] U. Radius, F. M. Bickelhaupt, A. W. Ehlers, N. Goldberg, R.-D. Hoffmann, Inorg. Chem. 1998, 47, 1080.

[302] C. L. B. Macdonald, A. H. Cowley, J. Am. Chem. Soc. 1999, 121, 12113.

[303] J. Uddin, C. Boehme, G. Frenking, Organometallics 2000, 19, 571.

[304] Y. Chen, G. Frenking, J. Chem. Soc. Dalton Trans. 2001, 434.

[305] J. Uddin, G. Frenking, J. Am. Chem. Soc. 2001, 123, 1683. 
[306] H. Braunschweig, C. Burschka, M. Burzler, S. Metz, K. Radacki, Angew. Chem. 2006, 118, 4458; Angew. Chem. Int. Ed. 2006, 45, 4352.

[307] H. Braunschweig, T. Wagner, Angew. Chem. 1995, 107, 904; Angewandte Chemie Int. Ed. Engl 1995, 34, 825.

[308] R. Littger, H. Nöth, M. Suter, Eur. J. Inorg. Chem. 2000, 1571.

[309] W. Scherer, G. Eickerling, D. Shorokhov, E. Gullo, G. S. McGrady, P. Sirsch, New J. Chem. 2006, $30,309$.

[310] C. Elschenbroich, A. Salzer, Organometallics - A Concise Introduction, 2, VCH, Weinheim, 1992.

[311] J. D. Dunitz, A. Gavezzotti, Angew. Chem. 2005, 44, 1766; Angew. Chem. Int. Ed. 2005, 117, 1796.

[312] G. Gardner Sumner, H. P. Klug, L. E. Alexander, Acta Crystallogr. 1963, 17, 732.

[313] P. C. Leung, P. Coppens, Acta Crystallogr., Sect. B: Struct. Sci. 1983, 39, 535.

[314] L. J. Farrugia, P. R. Mallinson, B. Stewart, Acta Crystallogr., Sect. B: Struct. Sci. 2003, $59,234$.

[315] A. M. Pendás, E. Francisco, M. A. Blanco, C. Gatti, Chem. Eur. J. 2007, 13, 9362. 


\section{Persönliche Daten}

$\begin{array}{ll}\text { Name } & \text { Ulrike Flierler } \\ \text { Adresse } & \text { Hermann-Rein-Straße 8B, 37075 Göttingen } \\ \text { Telefon } & \text { (0551) } 2503827 \\ \text { E-Mail } & \text { ulrike.flierler@web.de } \\ \text { Geburtsdatum, -ort } & \text { 01. August 1980, Eichstätt } \\ \text { Staatsangehörigkeit } & \text { deutsch } \\ \text { Familienstand } & \text { ledig, keine Kinder }\end{array}$

\section{Schulische Ausbildung}

09/1987 - 08/1991 Grundschule Am Graben in Eichstätt

09/1991 - 06/2000 Willibald-Gymnasium in Eichstätt

$06 / 2000$

Abschluss der Gymnasiallaufbahn mit dem Abitur (Note 1,6) Abiturfächer: Biologie, Englisch, Chemie und Geschichte Thema der Facharbeit: "Krebs - Wesen, Entstehung und Ursachen"

\section{Universitäre Ausbildung}

10/2000 - 12/2006 Studium der Fächer Chemie und Biologie (Lehramt an Gymnasien) an der Julius-Maximilians-Universität in Würzburg

10/2002 Akademische Zwischenprüfung im Fach Chemie

03/2003 Akademische Zwischenprüfung im Fach Biologie

06/2004 Erste Staatsprüfung für das Lehramt an Gymnasien (Erziehungswissenschaften)

02/2005 Abgabe der schriftlichen Hausarbeit mit dem Thema: Konzeption und Ausarbeitung des praktikumsbegleitenden Seminars zum "Anorganisch-Chemischen Praktikum I für Lehramtskandidaten"

12/2005 Erste Staatsprüfung für das Lehramt an Gymnasien (Chemie und Biologie)

seit $02 / 2006$

Promotion im Arbeitskreis von Prof. Dr. Dietmar Stalke an der GeorgAugust-Universität in Göttingen im Bereich der experimentellen Elektronendichteuntersuchungen an Röntgenbeugungsdaten; angestrebter Abschluss: Dr. rer. nat. 


\title{
Universitäre Tötigkeiten
}

\author{
seit 10/2002 Betreuung diverser Praktika für Studierende des Lehramts \\ (Gymnasium sowie Grund-, Haupt- und Realschule) in Würzburg und \\ Göttingen \\ 10/2007-04/2008 Leitung und Organisation des Seminars zur Experimentalchemie- \\ vorlesung "Allgemeine und Anorganische Chemie" für die \\ Studierenden des Lehramts und der Nebenfächer \\ im Verlauf der \\ Messung an Großforschungseinrichtungen (Synchrotron \\ Promotion \\ DESY/HASYLAB, Hamburg und Neutronenreaktor RESI/FRMII, \\ Garching)
}

im Verlauf der Gestaltung von Postern und Präsentationen zu Präsentationszwecken Promotion für die Universität und den Arbeitskreis

\section{Fremdsprachenkenntnisse}

$\begin{array}{ll}\text { Englisch } & \text { fließend in Wort und Schrift } \\ \text { Französisch } & \text { Grundkenntnisse }\end{array}$

\section{Veröffentlichungen}

Ulrike Flierler, Michael Burzler, Dirk Leusser, Julian Henn, Holger Ott, Holger Braunschweig, Dietmar Stalke (Angew. Chem. 2008, 120, 4393-4397.)

"Elektronendichteuntersuchung der Metall-Metall-Bindung im zweikernigen „Borylen“Komplex $\left[\left\{C p(C O)_{2} M n\right\}_{2}\left(\mu-B^{t} B u\right)\right]^{\prime \prime}$

Stephan Deuerlein, Dirk Leusser, Ulrike Flierler, Holger Ott, Dietmar Stalke (Organometallics 2008, 27, 2306-2315.)

"[(thf $\left.) L i_{2}\left\{\mathrm{H}_{2} \mathrm{CS}\left(\mathrm{N}^{t} \mathrm{Bu}\right)_{2}\right\}\right]_{2}$ : Synthesis, Polymorphism, and Experimental Charge Density to Elucidate the Bonding Properties of a Lithium Sulfur Ylide"

Ulrike Flierler, Dirk Leusser, Holger Ott, Gerald Kehr, Gerhard Erker, Stefan Grimme, Dietmar Stalke (Chem. Eur. J. 2009, DOI 10.1002/chem.200802344.)

"Catalytic abilities of $\left[\left(\mathrm{C}_{6} \mathrm{~F}_{5}\right)_{2} \mathrm{BR}\right], \mathrm{R}=\mathrm{NC}_{4} \mathrm{H}_{4}$ and $\mathrm{NC}_{4} \mathrm{H}_{8}$, deduced from experimental and theoretical charge density investigations"

Holger Ott, Ursula Pieper, Dirk Leusser, Ulrike Flierler, Julian Henn und Dietmar Stalke (Angew. Chem. 2009, DOI 10.1002/ange.200806221.)

"Carbanion oder Amid? Elektronendichteuntersuchung am 2-Picolyllithium-Stammsystem" 

"Gäbe es die letzte Minute nicht, so würde niemals etwas fertig." 